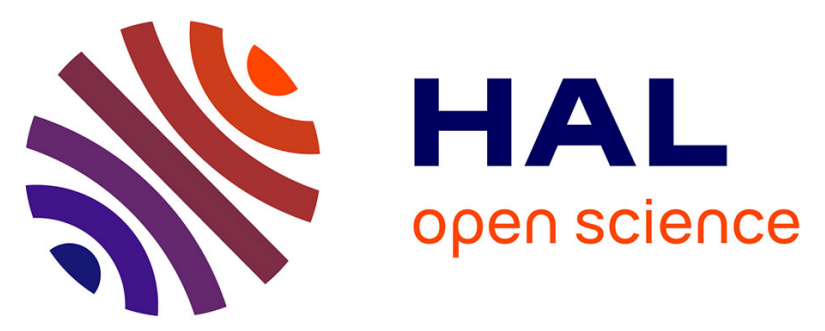

\title{
Partial characterization of the pigments produced by the marine-derived fungus Talaromyces albobiverticillius 30548. Towards a new fungal red colorant for the food industry
}

Mekala Venkatachalam, Miroslava Zelena, Francesco Cacciola, Lenka Ceslova, Emmanuelle Girard-Valenciennes, Patricia Clerc, Paola Dugo, Luigi Mondello, Mireille Fouillaud, Archimede Rotondo, et al.

\section{- To cite this version:}

Mekala Venkatachalam, Miroslava Zelena, Francesco Cacciola, Lenka Ceslova, Emmanuelle GirardValenciennes, et al.. Partial characterization of the pigments produced by the marine-derived fungus Talaromyces albobiverticillius 30548. Towards a new fungal red colorant for the food industry. Journal of Food Composition and Analysis, 2018, 67, pp.38-47. 10.1016/j.jfca.2017.12.036 . hal-01695109

\section{HAL Id: hal-01695109 \\ https://hal.univ-reunion.fr/hal-01695109}

Submitted on 5 Feb 2018

HAL is a multi-disciplinary open access archive for the deposit and dissemination of scientific research documents, whether they are published or not. The documents may come from teaching and research institutions in France or abroad, or from public or private research centers.
L'archive ouverte pluridisciplinaire HAL, est destinée au dépôt et à la diffusion de documents scientifiques de niveau recherche, publiés ou non, émanant des établissements d'enseignement et de recherche français ou étrangers, des laboratoires publics ou privés. 


\section{Partial characterization of the pigments produced by the marine-derived fungus Talaromyces albobiverticillius 30548. Towards a new fungal red colorant for the food industry}

Mekala Venkatachalam $^{\mathrm{a}}$, Miroslava Zelena ${ }^{\mathrm{b}}$, Francesco Cacciola ${ }^{\mathrm{c}}$, Lenka Ceslova ${ }^{\mathrm{b}}$, Emmanuelle GirardValenciennes $^{\mathrm{a}}$, Patricia Clerc ${ }^{\mathrm{a}}$, Paola Dugo ${ }^{\mathrm{d}, \mathrm{e}}$, Luigi Mondello ${ }^{\mathrm{d}, \mathrm{e}}$, Mireille Fouillaud ${ }^{\mathrm{a}}$, Archimede Rotondo ${ }^{c}$, Daniele Giuffrida ${ }^{c}$, Laurent Dufossé ${ }^{\mathrm{a}, *}$

${ }^{\mathrm{a}}$ Laboratoire de Chimie des Substances Naturelles et des Sciences des Aliments_LCSNSA EA 2212 \& ESIROI Agroalimentaire, Université de la Réunion, 15 Avenue René Cassin, CS 92003, F-97744, Saint-Denis Cedex 9, Ile de la Réunion, France

${ }^{\mathrm{b}}$ Department of Analytical Chemistry, Faculty of Chemical Technology, University of Pardubice, Pardubice, Czech Republic

${ }^{\mathrm{c}}$ Dipartimento di Scienze biomediche, odontoiatriche e delle immagini morfologiche e funzionali, University of Messina, via Consolare Valeria, 98125 , Messina, Italy $\mathrm{d}$ Dipartimento di Scienze Dipartimento di Scienze biomediche, odontoiatriche e delle immagini morfologiche e funzionali, University of Mess
chimiche, biologiche, farmaceutiche ed ambientali, University of Messina, Viale Annunziata, 98168, Messina, Italy

${ }^{\text {e } C h r o m a l e o n t ~ S . r . L ., ~ V i a l e ~ B o c c e t t a, ~ 70, ~ 98100, ~ M e s s i n a, ~ I t a l y ~}$

A B S T R A C T.

The interest about red color in the food industry has been growing because of its wide application in variety of foods and beverages and also due to the carcinogenic and teratogenic effects of some synthetic colorants. Many ascomycetous fungi naturally synthesize and secrete pigments and thus provide readily available additional and/or alternative sources of natural colorants that are independent of agro-climatic conditions. Some species of Talaromyces produce large amounts of Monascus-like azaphilone red pigments without any toxins. In this study, Talaromyces albobiverticillius 30548 was isolated from the outer slope of the coral reef of the Reunion Island, Indian Ocean. The biosynthesized intracellular and extracellular pigments were extracted by successive cold extractions or by single solvent extraction methods The pigments were then analyzed by HPLC-PDA-ESI/MS system in positive and negative ionization modes. Twelve different compounds were detected and four were tentatively identified as Monascus-type pigments, based on the results obtained and the available literature. In particular, N-threonine-monascorubramine, N-glutarylrubropunctamine and PP-O were tentatively identified; further, this work reports for the first time on the PDA, MS and NMR characterization of the here named as N-GABA-PP-V (6-[(Z)-2-Carboxyvinyl]-N-GABA-PP-V) pigment bearing a cis configuration at the C10-C11 double bond, in Talaromyces albobiverticillius 30548.

\section{Introduction}

There is a growing interest for the use of natural colors mainly from the consumers due to the harmful concerns associated with synthetic dyes and pigments. Natural pigments are derived from various sources, mainly from plants and microalgae and have applications in many foods and beverages. However, they have several drawbacks like instability, seasonal availability and high cost when considering the industrial application (Dufossé et al., 2005; Gunasekaran and Poorniammal, 2008; Jiang et al., 2005). Aside from these sources, microorganisms provide an alternative to synthetic pigments as they are able to grow in different culture systems (Campoy et al., 2003; Yan et al., 2005), are independent of climatic conditions and supply of agricultural raw materials (Mapari et al., 2006). Also, some of the pigments produced by microbes possess a high stability towards light, heat and $\mathrm{pH}$. (Joshi et al., 2003; Malik et al., 2012). With these advantages, special attention has been focused on filamentous fungi which are the potential producers of numerous shades of pigments ranging from yellow, red, reddish brown, bronze and maroon (Caro et al., 2012). In fungi, these pigments have been thought to serve different ecological functions, for example, melanins protect them against environmental stress, carotenoids against lethal photo-oxidations, and flavins act as cofactors in enzyme catalysis (Firn and Jones, 2003; Spiteller, 2015).

Fungal colorants can be chemically classified as carotenoids, melanins, polyketides, etc. in which the polyketides constitute the most representative class of pigments. Current industrial fungal productions

\footnotetext{
* Corresponding author.

E-mail address: laurent.dufosse@univ-reunion.fr (L. Dufossé)
} 
Table 1

Overall compounds detected by HPLC-PDA-ESI/MS in IC and EC extracts ${ }^{\mathrm{a}}$ of Talaromyces albobiverticillius 30548 , with reference to the chromatogram shown in Fig. 2.

\begin{tabular}{|c|c|c|c|c|}
\hline Compound N. & R.t. & $\operatorname{PDA} \lambda \mathrm{nm}$ & MS/ESI & Tentative identification \\
\hline 1 & 4.89 & 207,362 & $255[\mathrm{M}+\mathrm{H}]^{+}$ & n.i. \\
\hline 2 & 7.35 & 223,390 & $269[\mathrm{M}+\mathrm{H}]^{+} 267[\mathrm{M}-\mathrm{H}]^{-}$ & n.i. \\
\hline 3 & 10.04 & $222,273,422,511$ & $484[\mathrm{M}+\mathrm{H}]^{+} 482[\mathrm{M}-\mathrm{H}]^{-}$ & $\mathrm{N}$-threonine-monascorubramine \\
\hline 4 & 10.32 & $221,273,425,522$ & $496[\mathrm{M}+\mathrm{H}]^{+} ; 456[\mathrm{M}+\mathrm{H}-42]^{+} 498[\mathrm{M}-\mathrm{H}]^{-} ; 454[\mathrm{M}-\mathrm{H}-42]^{-}$ & N-GABA-PP-V (see NMR) \\
\hline 5 & 10.92 & $223,430,499$ & $484[\mathrm{M}+\mathrm{H}]^{+} 482[\mathrm{M}-\mathrm{H}]^{-}$ & N-glutaryl-rubropunctamine \\
\hline 6 & 11.57 & 225,409 & $375[\mathrm{M}+\mathrm{H}]^{+}$ & n.i \\
\hline 7 & 12.6 & $222,280,461$ & $413[\mathrm{M}+\mathrm{H}]^{+} 411[\mathrm{M}-\mathrm{H}]^{-}$ & n.i. \\
\hline 8 & 12.8 & $223,286,458,470$ & $413[\mathrm{M}+\mathrm{H}]^{+} 411[\mathrm{M}-\mathrm{H}]^{-}$ & PP-O \\
\hline 9 & 13.4 & $224,287,458$ & $459[\mathrm{M}+\mathrm{H}]^{+} 457[\mathrm{M}-\mathrm{H}]^{-}$ & n.i. \\
\hline 10 & 14.4 & 225,421 & $503[\mathrm{M}+\mathrm{H}]^{+} 501[\mathrm{M}-\mathrm{H}]^{-}$ & n.i. \\
\hline 11 & 15.2 & 224,446 & $445[\mathrm{M}+\mathrm{H}]^{+} 443[\mathrm{M}-\mathrm{H}]^{-}$ & n.i. \\
\hline 12 & 15.6 & 225,458 & $459[\mathrm{M}+\mathrm{H}]^{+}$ & n.i. \\
\hline
\end{tabular}

n.i. $=$ not identified

${ }^{a}$ the analysed samples were extracted with different solvent systems. In Table 1 are reported the compounds detected in all the different samples and, in particular, the EtOAc extract was the most representative as shown in Fig. 3. Only compounds 1, 2 and 6 were detected mainly in the $\mathrm{CHCl}_{3}$ extract.

are running at multi metric tons level with yellow-orange-red foodcolorants $\beta$-carotene and lycopene, biosynthesized by Blakeslea trispora (Finkelstein et al., 1995; López-Nieto et al., 2004; Xu et al., 2007). Polyketide based pigments are structurally complex and involve pathways catalyzed by the enzymes polyketide synthases. The main classes of polyketide pigments include anthraquinones, hydroxyanthraquinones, naphthoquinones, and azaphilone structures, each of which exhibits an array of color hues (Mapari et al., 2010). Since ancient times, azaphilone pigments produced by Monascus sp have widely been used in the oriental countries (particularly Japan and China) to color rice wine, koji, soyabean, cheese and meat. However, the use of Monascus pigments as food colorants is still forbidden in European countries owing to the time-to-time production of the mycotoxin citrinin (Liu et al., 2005) and also the production of the unwanted cholesterol-lowering drug mevinolin when added to foods (Patakova, 2013). Some species of Aspergillus sp (A. glaucus, A. cristatus, and $A$. repens) produce hydroxyanthraquinoid (HAQN) pigments like emodin (yellow), physcion (yellow), questin (yellow to orange-brown), erythroglaucin (red), catenarin (red), and rubrocristin (red) along with several mycotoxins such as secalonic acid, oxaline, citrinin, tanzawaic acid A, cyclochlorotine, islanditoxin, luteoskyrin, erythroskyrin, rugulosin or aspergiolide A. Many of these mycotoxins are pigmented and show substitution on both aromatic rings which arise biosynthetically by the polyketide pathway (Caro et al., 2012; Goyal et al., 2016).

In the search to identify potential non-toxic pigment producers for industrial application, several species of fungi have been evaluated and identified belonging to the genus Paecilomyces, Cordyceps, Penicillium, Aspergillus, Epicoccum, Fusarium (Cho et al., 2002; Pradeep et al., 2013; Suhr et al., 2002; Unagul et al., 2005). On the other side, several nonpathogenic to humans Talaromyces sp producing azaphilone series of yellow and red pigments without the production of mycotoxin seem to be an alternative to Monascus red pigments (Frisvad et al., 2013). Azaphilones are interesting set of fungal secondary metabolites namely pigments with pyrone - quinone structures containing a highly oxygenated bicyclic core and a chiral quaternary center (Osmanova et al., 2010). Studies have shown that some Talaromyces sp such as Talaromyces aculeatus, T. pinophilus, T. purpurogenus, T. funiculosus, T. amestolkiae, T. ruber and T. stolii naturally produce polyketide azaphilone Monascus red pigments and their amino acid derivatives (Mapari et al., 2008; Mapari et al., 2009). But, the later three species do not diffuse pigments into the culture medium and also T. purpurogenus produces mycotoxins such as rubratoxins $\mathrm{A}$ and $\mathrm{B}$, rugulovasins and luteoskyrin which limits the biotechnological production of pigments by using this species (Yilmaz et al., 2012). Such compounds, for example, rubratoxin was produced in a high concentration in a rhubarb-wine contaminated with $T$. purpurogenus and induced an immediate liver transplant when consumed by a teenager (Richer et al., 1997; Sigler et al., 1996).
Some other species, specifically T. atroroseus, T. albobiverticillius, T. minioluteus, and T. marneffei produce diffusing strong red pigments and some yellow pigments. One potential pigment producer among them, namely T. albobiverticillius collected from different sources produces several purple-red-orange azaphilone pigments such as monascorubramine (red), monascorubrin (orange), rubropunctatin (orange), PP-R (purple-red) (Mapari et al., 2005; Ogihara et al., 2001; Ogihara et al., 2000) and a series of yellow-orange pigments such as monascin (yellow), mitorubrin (orange-yellow), mitorubrinic acid (yellow) or mitorubrinol (yellow) (Frisvad et al., 2013). (see structures in Table 3)

The current study describes the pigment production from the marine derived fungus Talaromyces albobiverticillius strain 30548 isolated from the outer slope of the Réunion island coral reef (Indian Ocean) and the characterization of those pigments by high-performance liquid chromatography-diode array detection-electrospray ionization mass spectrometry (HPLC-PDA-ESI/MS), followed by the isolation of major compound(s) and the structure elucidation of a novel red azaphilone using NMR analysis.

\section{Material and methods}

\subsection{Isolation of fungal strain and identification}

The fungus used in this study was sampled from the outer slope of the Réunion island coral-reef (Indian Ocean). After sampling, $5 \mathrm{~g}$ of sediment was crushed and cultured on Potato Dextrose Agar (PDA) using serial dilution method. During the period of incubation, several isolates producing colored metabolites were observed visually. The red pigment producing strain was isolated, purified by monospore culture technique and stored at $-80^{\circ} \mathrm{C}$ for long term preservation. To study its pigment production ability, the fungus was grown on PDA (Samson et al., 2010) (Fig. 1).

The fungal strain was genetically identified as Talaromyces albobiverticillius using gene sequencing at molecular level (30548 indicates the Université de La Réunion collection reference number of the newly isolated strain) (Domsch, 1980; Foster et al., 2011).

\subsection{Submerged fermentation of fungal strain}

For submerged fermentation, Potato Dextrose Broth (PDB) was used as a culture medium and prepared using sterile distilled water. The $\mathrm{pH}$ of the culture medium was adjusted to $5.5 \pm 0.2$ using $0.1 \mathrm{M} \mathrm{HCl}$ prior to sterilization at $121{ }^{\circ} \mathrm{C}$ for $15 \mathrm{~min}$. Pre culture was prepared by taking a loop of fungus from 7-day old culture grown on PDA Petri plates and transferred into $60 \mathrm{~mL}$ sterilized culture medium. The flasks were incubated at $24^{\circ} \mathrm{C}$ for $72 \mathrm{~h}$. Cultivations were then carried out in $250 \mathrm{~mL}$ Erlenmeyer flasks containing volume of $100 \mathrm{~mL}$ sterilized culture 
Table 2

${ }^{1} \mathrm{H}$ and ${ }^{13} \mathrm{C}$ NMR spectroscopic data in $\mathrm{CD}_{3} \mathrm{OD}$ for compound n. 4 reported in Fig. 4.

\begin{tabular}{|c|c|c|c|c|c|c|c|}
\hline Position & $\delta_{\mathrm{C}}(\mathrm{ppm})^{\mathrm{a}}$ & type & $\delta_{\mathrm{H}}(\mathrm{ppm})^{\mathrm{b}}$ & H Mult. $^{\mathrm{cm}}(\mathrm{J}(\mathrm{Hz}))$ & $\cos ^{\mathrm{d}}$ & ROESY & $\mathrm{HMBC}^{\mathrm{f}}$ \\
\hline $\mathrm{C} 2$ & 173.8 & $\mathrm{C}$ & & & & & \\
\hline C3 & 102.7 & $\mathrm{C}$ & & & & & \\
\hline C3a & 174.2 & $\mathrm{C}$ & & & & & H-Me9a \\
\hline $\mathrm{C} 4$ & 99.0 & $\mathrm{CH}$ & 6.66 & s & & H5 & H5 \\
\hline $\mathrm{C} 4 \mathrm{a}$ & 153.2 & $\mathrm{C}$ & & & & & $\mathrm{H} 4, \mathrm{H} 8$ \\
\hline C5 & 121.4 & $\mathrm{CH}$ & 6.94 & s & & $\mathrm{H} 4$ & $\mathrm{H} 4, \mathrm{H} 10$ \\
\hline C6 & 151.2 & $\mathrm{C}$ & & & & & $\mathrm{H} 1^{\prime}, \mathrm{H} 5, \mathrm{H} 8$ \\
\hline C8 & 143.5 & $\mathrm{CH}$ & 8.32 & s & & $\mathrm{H} 1^{\prime}$ & $\mathrm{H} 1^{\prime}$ \\
\hline C8a & 120.0 & $\mathrm{C}$ & & & & & $\mathrm{H} 4, \mathrm{H} 5$ \\
\hline C9 & 196.2 & $\mathrm{C}$ & & & & & $\mathrm{HMeC} 9 \mathrm{a}, \mathrm{H} 8$ \\
\hline C9a & 87.1 & $\mathrm{C}$ & & & & & $\mathrm{HMeC9a}, \mathrm{H} 4$ \\
\hline C-Me9a & 30.5 & $\mathrm{CH}_{3}$ & 1.66 & $\mathrm{~s}$ & & & \\
\hline C10 & 126.7 & $\mathrm{CH}$ & 6.71 & $\mathrm{~d}(11.7)$ & $\mathrm{H} 11$ & $\mathrm{H} 1^{\prime}, \mathrm{H} 11$ & H5 \\
\hline C11 & 137.3 & $\mathrm{CH}$ & 6.47 & br d (11.7) & $\mathrm{H} 10$ & H10 & \\
\hline $\mathrm{C} 12$ & 171.1 & $\mathrm{C}$ & & & & & H11 \\
\hline $\mathrm{C} 13$ & 198.7 & $\mathrm{C}$ & & & & & $\mathrm{H} 14$ \\
\hline C14 & 41.3 & $\mathrm{CH}_{2}$ & 2.80 & br t (6.6) & H15 & H15 & \\
\hline C15 & 26.4 & $\mathrm{CH}_{2}$ & 1.58 & $\mathrm{~m}(6.1)$ & H16, H14 & $\mathrm{H} 14$ & H14 \\
\hline C16 & 30.3 & $\mathrm{CH}_{2}$ & 1.32 & om & $\mathrm{H} 14$ & & \\
\hline $\mathrm{C} 17$ & 30.6 & $\mathrm{CH}_{2}$ & 1.28 & om & & & H15, H14 \\
\hline C18 & 33.0 & $\mathrm{CH}_{2}$ & 1.28 & om & & & $\mathrm{H} 20, \mathrm{H} 16$ \\
\hline C19 & 23.8 & $\mathrm{CH}_{2}$ & 1.30 & om & $\mathrm{H} 20$ & & $\mathrm{H} 20$ \\
\hline $\mathrm{C} 20$ & 14.5 & $\mathrm{CH}_{3}$ & 0.89 & br t (7.1) & H19 & & \\
\hline $\mathrm{C} 1^{\prime}$ & 56.0 & $\mathrm{CH}_{2}$ & 4.14 & $t(6.5)$ & $\mathrm{H} 2^{\prime}$ & $\mathrm{H} 2^{\prime}, \mathrm{H}^{\prime}, \mathrm{H} 10, \mathrm{H} 8$ & $\mathrm{H}^{\prime}, \mathrm{H} 8$ \\
\hline $\mathrm{C} 2^{\prime}$ & 26.5 & $\mathrm{CH}_{2}$ & 2.08 & $\mathrm{p}(6.8)$ & $\mathrm{H} 3^{\prime}, \mathrm{H} 1^{\prime}$ & $\mathrm{H}^{\prime}$ & $\mathrm{H}^{\prime}$ \\
\hline $\mathrm{C}^{\prime}$ & 31.4 & $\mathrm{CH}_{2}$ & 2.40 & br t (6.6) & $\mathrm{H} 3^{\prime}, \mathrm{H} 1^{\prime}$ & $\mathrm{H} 1^{\prime}$ & \\
\hline $\mathrm{C}^{\prime}$ & 176.4 & $\mathrm{C}$ & & & & & $\mathrm{H} 3^{\prime}$ \\
\hline
\end{tabular}

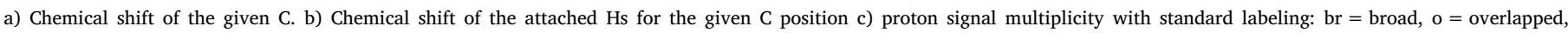

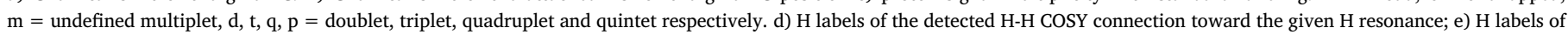
the detected $\mathrm{H}-\mathrm{H}$ ROESY connection toward the given $\mathrm{H}$ resonance; f) $\mathrm{H}$ labels for the detected $\mathrm{C}-\mathrm{H}$ long-range connections respect to the given $\mathrm{C}$ resonance.

medium. The flasks were inoculated with $1 \%(\mathrm{w} / \mathrm{v}) 72$-h-old pre culture and incubated at $24^{\circ} \mathrm{C}$ for 8 days with the agitation of $150 \mathrm{rpm}$ using rotary agitator (Infors Multitron HT).

\subsection{Separation and extraction of fungal pigments}

After 8 days of fermentation, the culture broth and fungal biomass were separated by centrifugation at $8000 \mathrm{rpm}$ for $6 \mathrm{~min}$ (Centrifuge Sigma $3 \mathrm{~K} 3 \mathrm{OH}$ and 19776-H rotor). Both samples were immediately frozen $\left(-80^{\circ} \mathrm{C}\right)$ and then lyophilized into a fine powder (Cryotec cosmos, France). The pigments from both the biomass and the culture filtrate were extracted at room temperature successively with solvents of increasing polarity: $n$ - hexane, chloroform, ethyl acetate and ethanol. The crude extracts were dried using rotary evaporator (Büchi, Germany) at $30{ }^{\circ} \mathrm{C}$ under reduced pressure yielding red colored dried residues. The residues were then dissolved in $1 \mathrm{~mL}$ of methanol $(1: 1 \mathrm{v} /$ v), filtered through Minisart syringe filter of $0.20 \mu \mathrm{m}$ pore size housing with PTFE membrane (Sartorius). The crude filtrates were stored at $4{ }^{\circ} \mathrm{C}$ in an amber vial prior to HPLC analysis.

\subsection{HPLC-DAD-ESI-MS analysis}

The analyses were carried out on a Shimadzu Prominence LC-20A system (Shimadzu, Milan, Italy) equipped with a CBM-20A controller, two LC-20AD pumps, a DGU-20A ${ }_{3}$ degaser, a SIL-20AC autosampler and a SPD-M20A photo diode array detector. The data were processed with the software Shimadzu Labsolution ver. 5.53. For MS analyses a mass spectrometer was used (LCMS-2020, Shimadzu), equipped with an ESI interface, both in positive and negative ionization modes. HPLC separations were performed on a C18 Kinetex (Phenomenex) column $(100 \times 2.1 \mathrm{~mm}-1.7 \mu \mathrm{m}$ particle size $)$; the mobile phases consisted of water $(0.1 \%$ formic acid; eluent $\mathrm{A})$ and acetonitrile, $(0.1 \%$ formic acid; eluent B), using a gradient program as follows: $0 \mathrm{~min}, 5 \% \mathrm{~B} ; 15 \mathrm{~min}$, $95 \% \mathrm{~B} ; 17 \mathrm{~min}, 95 \% \mathrm{~B} ; 18 \mathrm{~min}, 5 \% \mathrm{~B}$. The flow rate was $0.2 \mathrm{~mL} / \mathrm{min}$ and the injection volume was $1 \mu \mathrm{L}$. The column oven temperature was $30^{\circ} \mathrm{C}$. The UV-vis spectra were acquired in the range of $200-600 \mathrm{~nm}$, while the chromatograms were extracted at $470 \mathrm{~nm}$ and $360 \mathrm{~nm}$ (sampling frequency: 1,5625 Hz; time constant: $0.64 \mathrm{~s}$ ). The MS was set as follows: Scan, both ESI positive $(+)$ and negative $(-)$; nebulizing gas flow $\left(\mathrm{N}_{2}\right): 1.5 \mathrm{~L} / \mathrm{min}$; Event Time: $0.3 \mathrm{~s}$; Detector Voltage: $4.5 \mathrm{kV} ; \mathrm{m} / \mathrm{z}$ range: $60-600$; Interface Voltage: $\pm 3.5 \mathrm{kV}$; Interface Temperature: $350{ }^{\circ} \mathrm{C}$; DL Temperature: $250{ }^{\circ} \mathrm{C}$; Heat Block: $400{ }^{\circ} \mathrm{C}$.

\subsection{Nuclear magnetic resonance (NMR) spectroscopy}

Compound n. 4 in Fig. 2, was collected after LC separation in an almost pure form. The eluent was evaporated and the red residue (around $0.6 \mathrm{mg}$ ) was dissolved in $500 \mu \mathrm{L}$ of $\mathrm{CD}_{3} \mathrm{OD}$ and analysed by NMR; afterward the solution was freeze dried and dissolved again in $500 \mu \mathrm{L}$ of $\mathrm{CD}_{3} \mathrm{COCD}_{3}$. This strategy was applied in order to rule out possible solvent effects and/or artefacts. ${ }^{1} \mathrm{H}$ and ${ }^{13} \mathrm{C}\left\{{ }^{1} \mathrm{H}\right\}$ NMR spectra of compound n. 4 were recorded on an Agilent Propulse $500 \mathrm{MHz}$ spectrometer equipped with a OneNMR probe and operating at 499.74 and $125.73 \mathrm{MHz}$ respectively. The sample in a $5 \mathrm{~mm}$ test-tube was analysed after locking on the deuterated lock signal, search for a good field homogeneity (shimming) and frequency modulation (tuning). The saturation $90^{\circ}$ pulse was calculated to be 8 us at $59 \mathrm{~dB}$ of power level and the protonic spectrum was obtained with $2 \mathrm{~s}$ of acquisition time, $2 \mathrm{~s}$ of scan delay and 16 scans; all the other techniques were designed starting from this simple experiment. The complete and unambiguous assignment (Table 2 with the numbering scheme in Fig. 4), was confirmed by homo nuclear 2D-COSY, TOCSY and ROESY (Derome, 2013), and heteronuclear (Willker et al., 1993) ${ }^{13} \mathrm{C}\left\{{ }^{1} \mathrm{H}\right\}$-HSQC and ${ }^{13} \mathrm{C}-\mathrm{HMBC}$ experiments. Calibration was attained using as internal standard residual proton signal of the solvent $\left(\mathrm{CD}_{2} \mathrm{HOD}\right.$ quintet: $\delta=3.31 \mathrm{ppm}$; $\mathrm{CD}_{3} \mathrm{COCD}_{2} \mathrm{H}$ quintet $\delta=2.05 \mathrm{ppm}$ and the ${ }^{13} \mathrm{C}$ solvent septuplets at $\delta=49.0 \mathrm{ppm}$ and $\delta=29.84$ respectively) (Gottlieb et al., 1997) and data were processed by vNMRj software and by the PC software package ACD/Lab, which was also exploited to validate the goodness of the structure elucidation. 
Table 3

Reported structures of pigmented extrolites produced by different collection strains of Talaromyces albobiverticillius, mentioned in (Frisvad et al., 2013) and in this study.

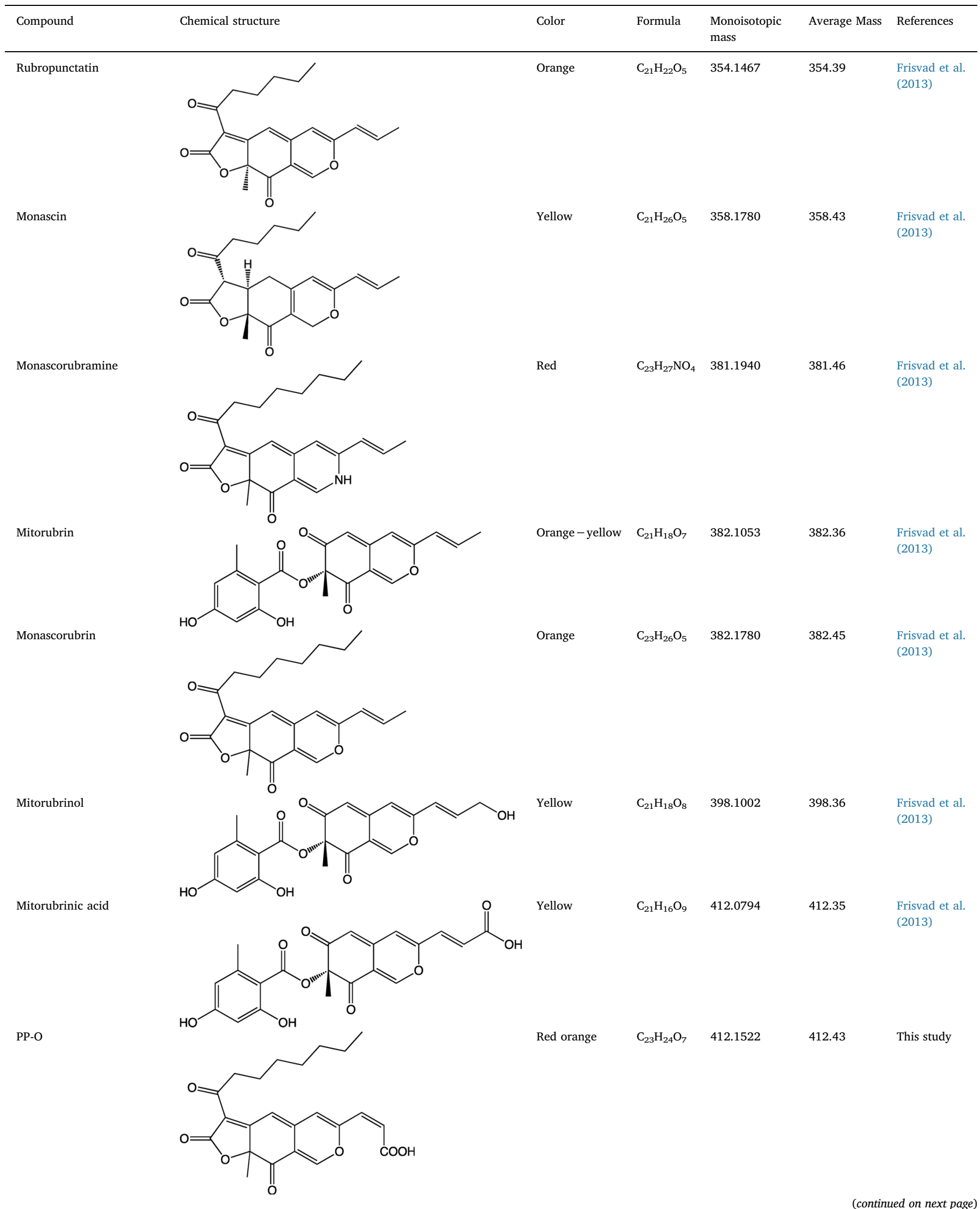




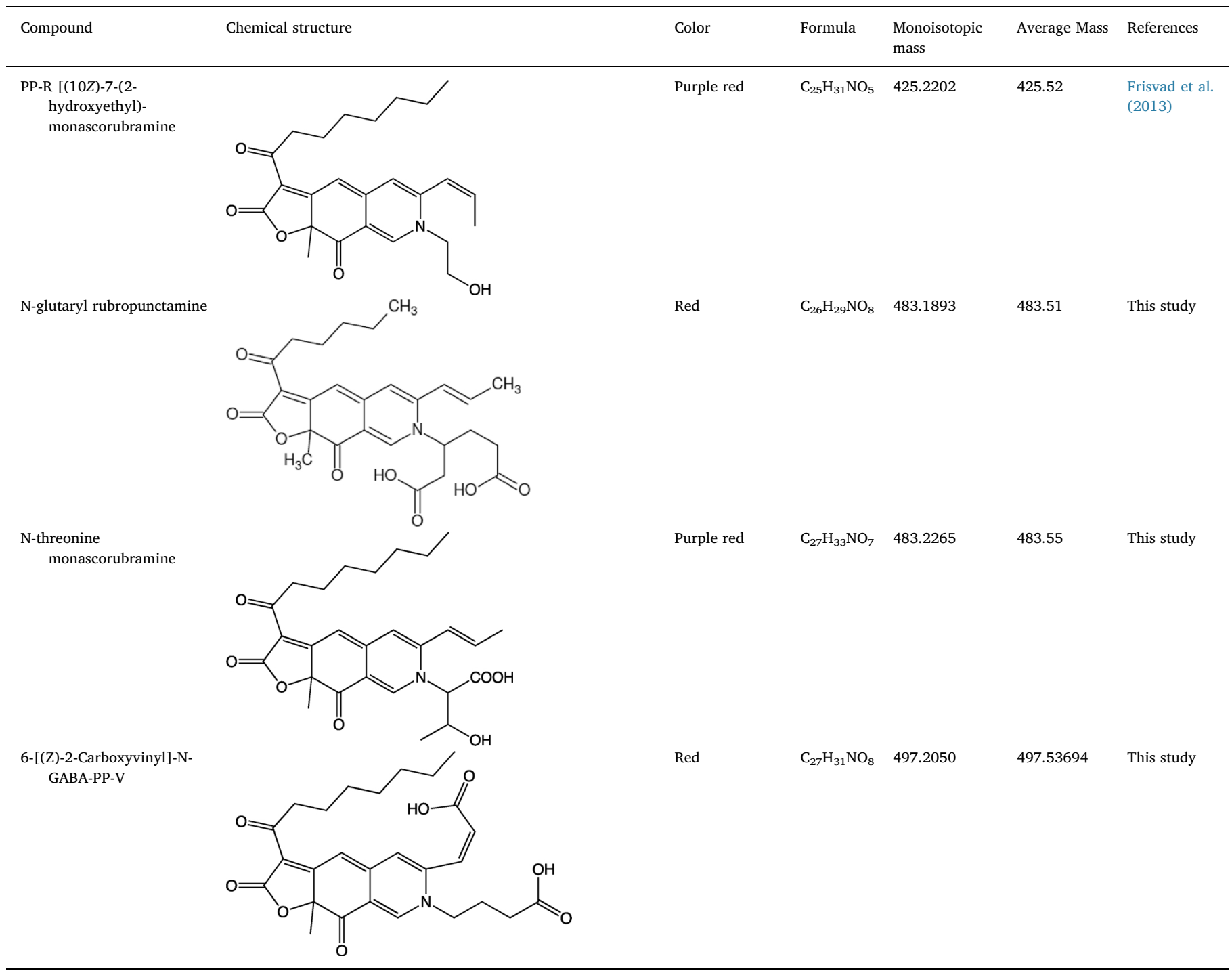

\section{Results}

\subsection{Behavior of fungal pigments during extraction(s)}

An ideal solvent for fungal pigment extraction must have low toxicity, and must be able to solubilize a range of target pigment molecules (Robinson et al., 2014). Initial extraction trials were conducted with the commonly used solvents from low to high polarity such as $n$ hexane, chloroform, ethyl acetate and ethanol successively which yielded differences in amounts of extracted pigments for both biomass and culture filtrate. Simultaneously, extraction was carried out using ethyl acetate and ethanol as single solvent extraction. On the basis of liquid chromatography-diode array detector (LC-DAD) chromatogram, among the used solvents, ethyl acetate as single solvent was found to be the best solvent for extraction of major pigmented compounds followed by ethanol. Indeed, Monascus-like polyketide pigments are hydrophilic in nature, slightly polar and so they are easily handled with polar solvents (Padmavathi and Prabhudessai, 2013). In non-polar solvents like $n$ - hexane and chloroform, the extraction and recovery of pigments was very low and chloroform yielded two compounds (peaks 1 and 2) which were unpigmented. The yield from these solvents was very poor compared to ethyl acetate which yielded 12 different compounds and among them 10 compounds were pigmented (Fig. 2).

\subsection{Characterization of fungal pigments using HPLC-DAD-ESI-MS}

Fig. 2 shows a typical representative chromatogram of the detected pigments (compounds n.s 3-12) in Talaromyces albobiverticillius 30548 obtained from the EtOAc pigment extract and detected at the wavelength of $470 \mathrm{~nm}$; in the same Fig. 2, it is also shown an insert representing the better detection for compound $\mathrm{n} .1$ and $\mathrm{n} .2$ obtained from the $\mathrm{CHCl}_{3}$ extract and recorded at the wavelength of $360 \mathrm{~nm}$. Table 1 presents all of the detected compounds, their corresponding retention times, PDA and MS data, with a relative tentative identification based on the obtained spectroscopic data and the comparison with literature data. Together with PDA, an on line MS detector operating in both ESI positive and ESI negative ionization mode was used in order to have a double confirmation of the mass values.

Twelve different compounds were detected and four were tentatively identified as Monascus-type pigments (Table 1). The identified compounds 3, 5 and 8 are similar to the already known N-threoninemonascorubramine, N-glutaryl-rubropunctamine and PP-O respectively. Further, one compound was also characterized by NMR analysis and a new structure for this molecule, here named as 6-[(Z)-2-Carboxyvinyl]-N-GABA-PP-V, (or as N-GABA-PP-V), is provided for the first time based on PDA, MS and NMR data (see Sections 2.5 and 3.3 of this paper).

Compound 3: Under the assumption that the $\alpha$-amino acid 


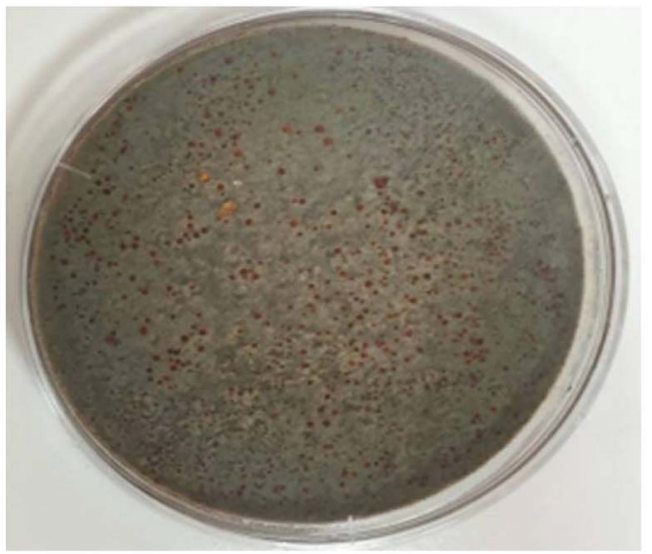

(a)

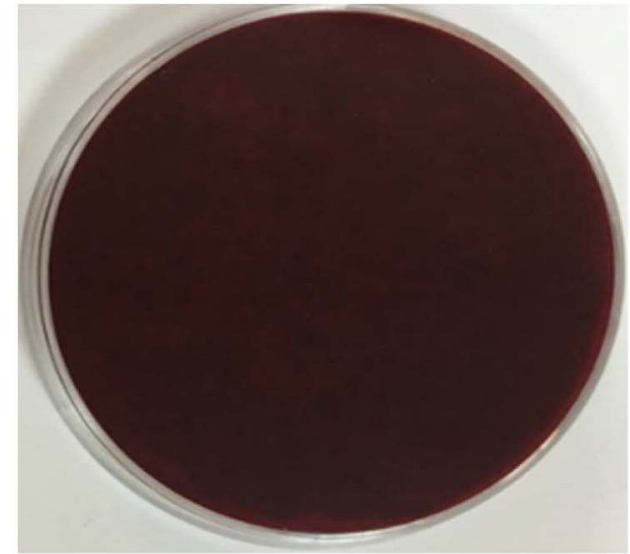

(b)

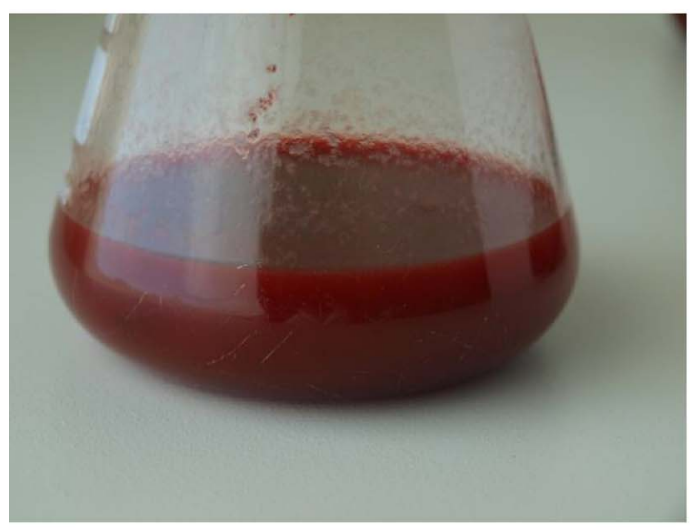

(c)

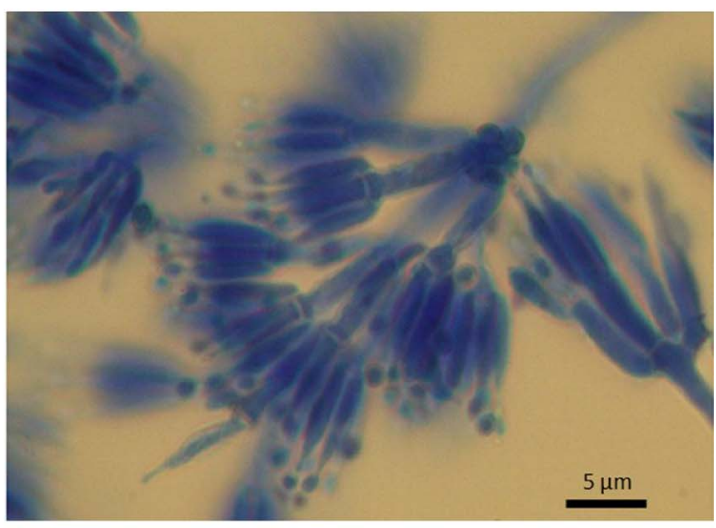

(d)

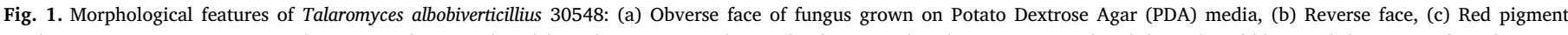

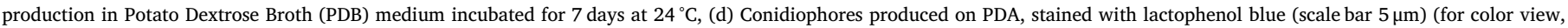
please refer to the online article).

threonine was incorporated into pigment, compound n. 3 was tentatively identified as $\mathrm{N}$-threonine-monascorubramine; the corresponding $[\mathrm{M}+\mathrm{H}]^{+} m / z 484$, and $[\mathrm{M}-\mathrm{H}]^{-} m / z$ 482, pseudomolecular ions mass values were consistent with the values reported by Jung et al., 2003 (Jung et al., 2003) and the corresponding PDA data were also consistent with the reported values for Monascus type pigments (Mapari et al., 2008).

Compound 4: Interestingly compound n.4 was here identified as a never previously reported compound. Under the assumption that the $\gamma$ amino acid, $\gamma$-aminobutyric acid was incorporated into pigment, the name of 6-[(Z)-2-Carboxyvinyl]-N-GABA-PP-V or simply as N - GABA$\mathrm{PP}-\mathrm{V}$ was proposed for compound n.4; the structure was determined on the basis of the obtained PDA and MS data and of a detailed NMR investigation (see Sections 2.5 and 3.3 of this paper). The PDA data are in agreement with the reported values for Monascus type pigments (Mapari et al., 2008) and the compound showed corresponding $[\mathrm{M}+\mathrm{H}]^{+} m / z 498$, and $[\mathrm{M}-\mathrm{H}]^{-} m / z 496$, pseudomolecular ions (see Fig. 3) which are consistent with the proposed structure (Fig. 4) for a compound having a molecular formula of $\mathrm{C}_{27} \mathrm{H}_{31} \mathrm{NO}_{8}$, with a mass value of $497 \mathrm{amu}$.

The PubChem database (PubChem CID: 44715338) reports the existence of a compound named as 4-\{6-[(E)-2-Carboxyvinyl]-9a-methyl-3octanoyl-2,9-dioxo-9,9a-dihydrofuro[3,2-g]isoquinolin-7(2H)-yl\}butanoic acid with a trans configuration at the C10-C11 double bond, but no information was available/reported on the source or in any literatures for this compound. Therefore, this work reports for the first time on the

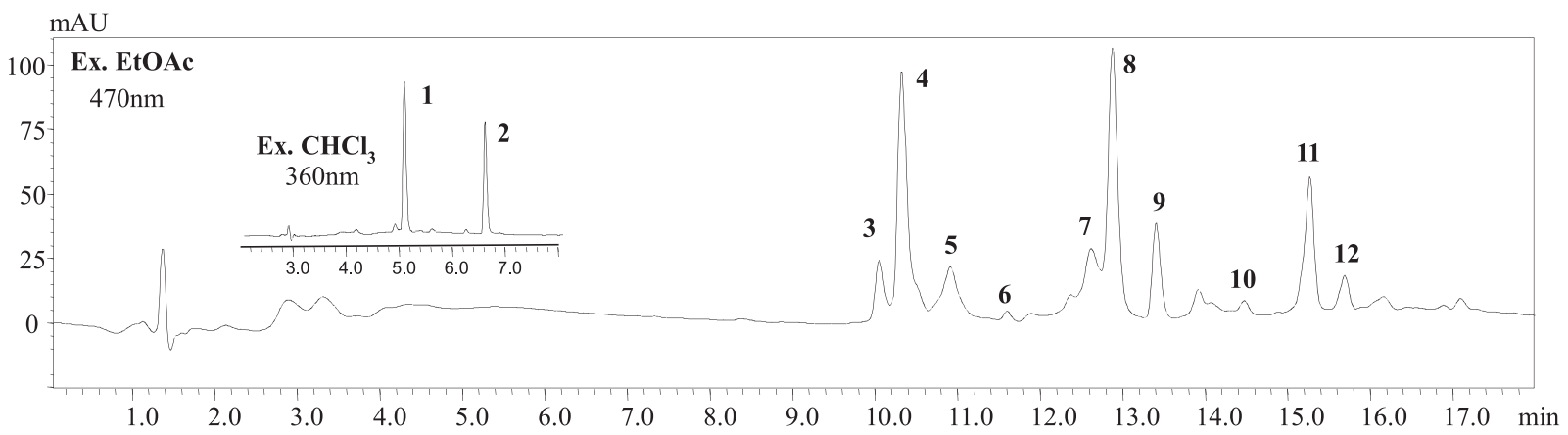

Fig. 2. Chromatogram showing the overall compounds detected by HPLC-PDA- ESI/MS in intracellular (IC) and extracellular (EC) extracts of Talaromyces albobiverticillius. 

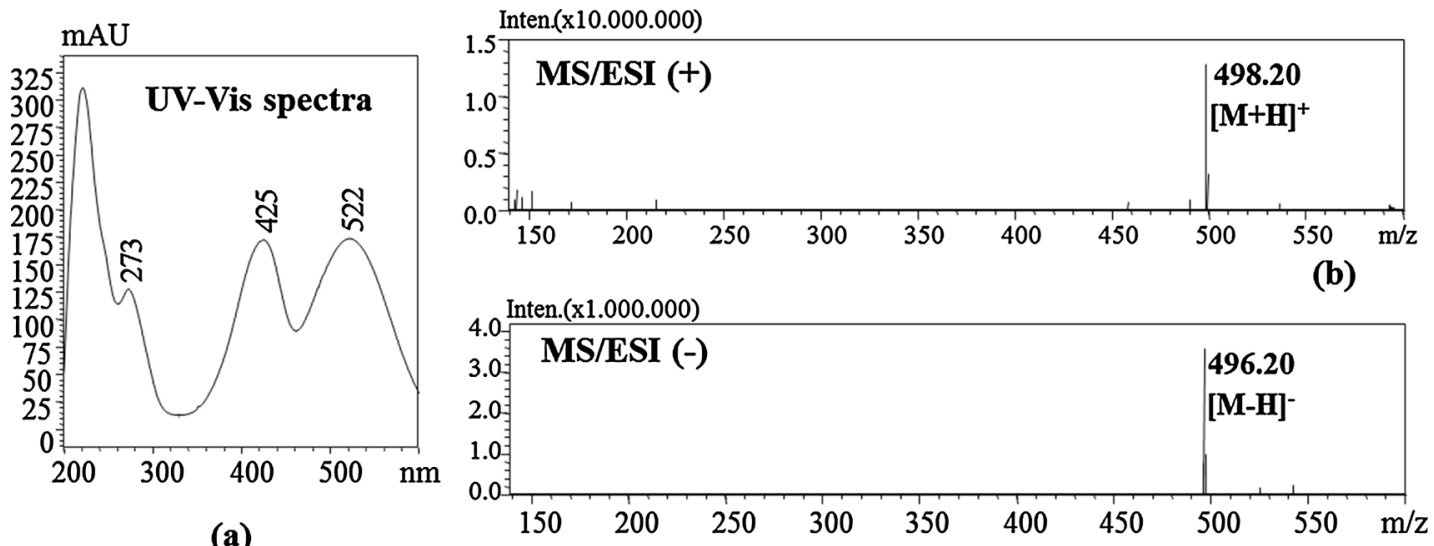

(a)

(c)

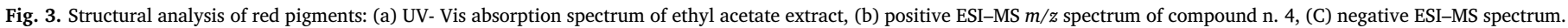<smiles>CCC[PH2+]CCCC(=O)C1=C2C=C3C=C(C=CC(=O)O)N(C)C=C3C(=O)[C@@]2(C)OC1=O</smiles>

Formula Weight: $\quad 497.53694$

Fig. 4. Molecular structure and carbon atom numbering of compound n. 4. Proposed Name: N-GABA-PP-V, 4-\{6-[(E)-2-Carboxyvinyl]-9a-methyl-3-octanoyl-2,9-dioxo-9,9adihydrofuro[3,2-g]isoquinolin-7(2H)-yl\}butanoic acid.

characterization of the pigment N-GABA-PP-V derivative bearing a cis configuration at the C10-C11 double bond, in the investigated Talaromyces albobiverticillius species.

Compound 5: Compound n.5 was tentatively identified as N-glutaryl-rubropunctamine; it showed the $[\mathrm{M}+\mathrm{H}]^{+} \mathrm{m} / \mathrm{z} 484$ and $[\mathrm{M}-$ $\mathrm{H}]^{-} m / z 482$ pseudomolecular ions, and UV-vis absorbance values in agreement with the literature reported values (Mapari et al., 2009).

Compound 8: Compound n.8 was tentatively identified as PP-O; it showed the corresponding $[\mathrm{M}+\mathrm{H}]^{+} m / z 413$ and $[\mathrm{M}-\mathrm{H}]^{-} \mathrm{m} / z 411$ pseudomolecular ions, and UV-vis absorbance values in agreement with the literature reported values (Mapari et al., 2008; Ogihara and Oishi, 2002).

\subsection{Characterization of fungal pigments using NMR}

As explained in the experimental part, HOMO and HETERO nuclear 2D techniques allows chemical shift $(\delta)$ assignments of the ${ }^{1} \mathrm{H}$ and ${ }^{13} \mathrm{C}$ resonances leading to the structure elucidation (Rotondo et al., 2014; Rotondo et al., 2015). Specifically, HSQC-DEPT experiment defines the direct connection of ${ }^{1} \mathrm{H}$ resonances to their ${ }^{13} \mathrm{C}$ parent atom resonances. HMBC spectrum is showing ${ }^{2} \mathrm{~J},{ }^{3} \mathrm{~J}$ and few ${ }^{4} \mathrm{~J}{ }^{1} \mathrm{H}-{ }^{13} \mathrm{C}$ scalar couplings (Table 2), basically consistent with the reported molecular structure and allowed a reasonable assignment of all of the quaternary ${ }^{13} \mathrm{C}$ resonances (Table 2; Fig. 5).

Homo nuclear 2D-TOCSY, which is grouping resonances belonging to the same spin-system (chemical group closely connected through the bonds), clearly distinguished the nature of the azaphilone body and the following side chains: a) the propionyl moiety on the N7 endocyclic

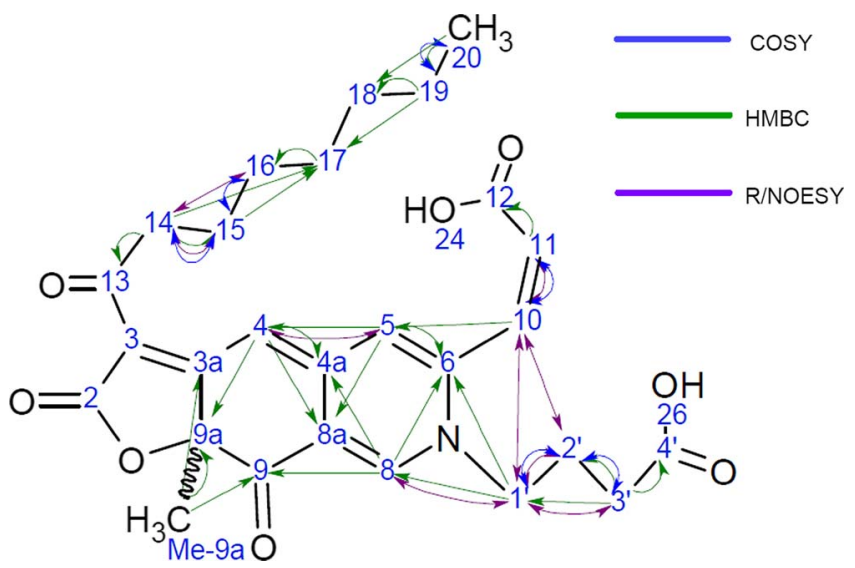

Fig. 5. Selected COSY (doubled headed blue arrows), ROESY (doubled headed red arrows) and HMBC (green arrows) for compound n. 4 reported in Fig. 4 (for color view, please refer to the online article). (For interpretation of the references to colour in this figure legend, the reader is referred to the web version of this article.)

atom; b) the acyl seven-membered chain bound to the C3; c) two connected unsaturated $\mathrm{CH}$ whose $\mathrm{HMBC}$ connection $(\mathrm{C} 10-\mathrm{H} 5)$ fixes on the C6endocyclic carbon atom. Terminal $\mathrm{CH}_{2}-3$ and $\mathrm{CH}-11$ over the $\mathrm{N} 7$ and $\mathrm{C6}$ side chains respectively, were connected to carboxylic acid groups because the HMBC spectrum showed correlations between their proton resonances and those of quaternary carbon atoms at $176.4 \mathrm{ppm}$ (C4') and $171.4 \mathrm{ppm}(\mathrm{C} 12)$ respectively. Chemical nature of these termini was also confirmed by the mass molecular peak of a compound having a molecular formula of $\mathrm{C}_{27} \mathrm{H}_{13} \mathrm{NO}_{8}$ (see Sections 2.4 and 3.2 of this paper). As the aromatic molecular system is very sensitive to the charge density, some calculated ${ }^{13} \mathrm{C}$ chemical shifts (ACD/Lab calculator) deviate significantly from the experimental value; specifically this is the case of C10, C11 and C4. On the other hand, we are confident about the correct assignment in Table 2 because the well detected HMBC spots reasonably supported by the "through the space" (ROESY) connections (Fig. 5).

These same ROESY connections, joined to the ${ }^{3} \mathrm{~J}_{\mathrm{H} 10-\mathrm{H} 11}$ coupling constant (around $11.7 \mathrm{~Hz}$ ), allowed to definitely assess the $\mathrm{Z}$ configuration at the unsaturated $\mathrm{C} 10-\mathrm{C} 11$ bond. After all some other similar molecules, called monascorubramines, were thoroughly analysed (Ogihara and Oishi, 2002), and specifically the compound called PP-R with the same $\mathrm{Z}$ configuration and framework has shown compatible NMR constants (Ogihara et al., 2001) thus providing a very sound support to our overall discussion.

Monascorubamine (4): ${ }^{1} \mathrm{H}$ NMR $\left(\mathrm{CD}_{3} \mathrm{OD}, 499.7 \mathrm{MHz}\right) \delta 8.32(1 \mathrm{H}$, s, H-8), $6.94(1 \mathrm{H}, \mathrm{s}, \mathrm{H}-6), 6.71(1 \mathrm{H}, \mathrm{d}, J=11.7 \mathrm{~Hz}, \mathrm{H}-10), 6.66(1 \mathrm{H}, \mathrm{s}$, H-4), 6.47 (1H, br d, $J=11.7 \mathrm{~Hz}, \mathrm{H}-11), 4.14\left(2 \mathrm{H}, \mathrm{t}, J=6.5 \mathrm{~Hz}, \mathrm{H}-1^{\prime}\right)$, 
$2.80(2 \mathrm{H}, \mathrm{m}, J=6.6 \mathrm{~Hz}, \mathrm{H}-14), 2.40(2 \mathrm{H}, \mathrm{br} \mathrm{t}, J=6.6 \mathrm{~Hz}, 2 \mathrm{H}), 2.08$ $\left(2 \mathrm{H}, \mathrm{p}, J=6.8 \mathrm{~Hz} \mathrm{H}-2^{\prime}\right), 1.66$ (3H, s, H-Me-9a), $1.58(2 \mathrm{H}, \mathrm{m}$, $J=6.1 \mathrm{~Hz}, \mathrm{H}-15), 1.25-1.30$ (8H, m, H-16, H-17, H-18, H-19), 0.89 (3H, br t, $J=7.08 \mathrm{~Hz}, \mathrm{H} 20$ )

${ }^{13} \mathrm{C}$ NMR $\left(\mathrm{CD}_{3} \mathrm{OD}, 125.7 \mathrm{MHz}\right) \delta 198.7$ (C, COOH-12), 196.2 (C, > C = O 9), 176.4 (C, C-4'), 174.2 (C, C-3a), 173.8 (C, C-2), 171.1 (C, C-12), 153.2 (C, C-4a), 151.2 (C, C-6), 143.5 (CH, C-8), 137.3 (CH, C-11), 126.7 (CH, C-10), 121.4 (CH, C-5), 120.0 (C, C-8a), 102.7 (C, C3), 99.0 ( $\mathrm{CH}, \mathrm{C}-4), 87.1$ (C, C-9a), 56.0 (CH2, C-1'), 41.3 (CH2, C-14), 33.0 (CH2, C-18), 31.4 (CH2, C-3'), 30.6 (CH2, C-17), $30.5\left(\mathrm{CH} 3, \mathrm{CH}_{3^{-}}\right.$ C-9a), 30.3 (CH2, C-16), 26.5 (CH2, C-2'), 26.4 (CH2, C-15), 23.8 (CH2, C-19) 14.5 (CH3, C-20);

EIMS $m / z 498[\mathrm{M}]+308$ (28)....fragmentations?.........; HREIMS $\mathrm{m} / \mathrm{z} 497$ (calcd for C27H31NO8).

\section{Discussion}

Talaromyces species, the teleomorph (sexual reproductive) stages of the well-known Penicillium fungi, have a long common history with foods and beverages consumed by human beings. As examples, in Europe, Penicillium camemberti or Penicillium roqueforti are used in cheese production, and many other Talaromyces/Penicillium strains are of great importance in Asia, for soy products.

From a more global point of view, ingredients derived from microbial fermentation are steadily gaining ground in the food industries. Thickening or gelling agents (e.g. polysaccharides such as xanthan, curdlan, gellan), flavour enhancers (yeast hydrolysate, monosodium glutamate), polyunsaturated fatty acids (PUFAs), flavour compounds (gamma-decalactone, diacetyl, methyl-ketones), vitamins, essential amino acids, and acidulants (lactic acid, citric acid) are illustrating this trend. Efforts have been made and continue to be done in order to reduce the production costs of pigments produced by microbial fermentation, since synthetic pigments or those extracted from natural plant sources can often be produced more economically (Dufossé, 2008). The successful marketing of natural pigments such as $\beta$-carotene, lutein, and astaxanthin derived from algae (i.e. non-conventional sources; Salvo et al., 2017) or extracted from plants (conventional sources), both as food colorants and nutritional supplements, reflects the presence and importance of niche markets in which consumers are willing to pay a premium for 'natural healthy ingredients'. Among other non-conventional sources, filamentous fungi are known to produce an extraordinary range of pigments that include several chemical classes such as carotenoids, melanins, azaphilones, anthraquinones, flavins, phenazines, quinones, and more specifically, violacein and indigo (Caro et al., 2016; Dufossé, 2008; Fouillaud et al., 2016). The success of any class of pigment produced by fermentation depends on its acceptance by the consumers, regulatory approval, and the capital investment required in bringing the product onto the market. Twenty years ago, influential representatives from food industry expressed doubts about the successful commercialization of algae-derived and fermented food grade pigments due to the high investment required for open ponds, photobioreactors and fermentation facilities, and the extensive and lengthy toxicity studies required by the regulatory authorities. Poor public perception of fungal-derived products for food use had also to be taken into account. Nowadays, some fungal food grade pigments obtained by fermentation already exist on the market worldwide. Among them, fungal Monascus pigments, Arpink red ${ }^{\mathrm{TM}}$ (now Natural Red $^{\mathrm{TM}}$ ) produced by Penicillium oxalicum, riboflavin from the mold fungus Ashbya gossypii, lycopene and $\beta$-carotene from the tropical mold Blakeslea trispora. As an example, the production yield of $\beta$-carotene may be as high as $17 \mathrm{~g} / \mathrm{L}$ of the Blakeslea trispora culture medium (Dufossé, 2016).

In the Western World (the Occident), pioneering work about large scale production of fungal colorants was done on carotenoids. Academics knew for a long time that fungi belonging to the order Mucorales are able to produce $\beta$-carotene. First papers dealing with Blakeslea trispora carotenoid production were published in the late fifties (Ciegler et al., 1959). It took four decades to move to industrial production, waiting for consumer interest about natural colorants, developing biotechnological techniques, and gaining regulatory approval. For this last aspect, Vitatene, a Spanish company, filled a novel foods and novel food ingredients application in 2003, to place lycopene from Blakeslea trispora on the European market (under Regulation EC $\mathrm{N}^{\circ} 258$ / 97). The positive answer was published on 23 October 2006 (European Commission decision $\left.\mathrm{N}^{\circ} 721 / 2006\right)$.

Red azaphilone pigments are similarly known for a long-time by scientists from Asia and, as explained in the introduction, researchers are trying to find new strains, non-mycotoxigenic, to use as an alternative to the citrinin-producing Monascus.

Pioneering work started at Denmark Technical University (DTU) during the PhD thesis of Sameer Mapari, with co-workers such as Ulf Thrane, Anne S. Meyer, Jens C. Frisvad and co-funding from the worldleading natural colors Chr. Hansen A/S company, represented by Annette Salskov-Iversen. Many papers were published between 2005 and 2009 (Mapari et al., 2005; Mapari et al., 2006; Mapari et al., 2008, Mapari et al., 2009), setting a general framework in the development of fungal reds. International patents were issued such as EP2262862 (=WO2009026923, priority date August 28, 2007) or EP2011/064152 (=WO2012022765, priority date August 19, 2010). Despite the very nice results obtained in these works, no industrial application of red azaphilone (polyketide) Monascus-like pigments appears on the market up to now. A few years later, in 2013, Jens C. Frisvad and co-workers from DTU, the CBS-KNAW Fungal Biodiversity Centre (Utrecht, The Netherlands) and the Department of Biology, Utrecht University (Utrecht, The Netherlands), described a new strain of Talaromyces, they named Talaromyces atroroseus sp. nov., and recommended as an effective producer of the azaphilone biosynthetic families mitorubrins and Monascus-like-pigments without any production of mycotoxins.

In our work, we isolated in the tropical marine environment of Réunion island, Indian Ocean, a different red pigment producing strain belonging to Talaromyces albobiverticillius and this paper brings new information about the pigments produced. The literature (Frisvad et al., 2013) lists ten extrolites (excreted metabolites) in seven collection strains (Table 3): mitorubrin $\mathrm{C}_{21} \mathrm{H}_{18} \mathrm{O}_{7}$ formula weight 382.36 (6 occurrences among 7 strains, i.e. 6/7), mitorubrinic acid $\mathrm{C}_{21} \mathrm{H}_{16} \mathrm{O}_{9}$ formula weight $412.35(6 / 7)$, monascorubramine $\mathrm{C}_{23} \mathrm{H}_{27} \mathrm{NO}_{4}$ formula weight 381.46 (5/7), rubropunctatin $\mathrm{C}_{21} \mathrm{H}_{22} \mathrm{O}_{5}$ formula weight 354.39 (4/7), monascorubrin $\mathrm{C}_{23} \mathrm{H}_{26} \mathrm{O}_{5}$ formula weight 382.45 (2/7), a purpactin (2/7), vermicellin (2/7), PP-R $=$ [(10Z)-7-(2-hydroxyethyl)monascorubramine $\mathrm{C}_{25} \mathrm{H}_{31} \mathrm{NO}_{5}$ formula weight 425.52 (1/7), mitorubrinol $\mathrm{C}_{21} \mathrm{H}_{18} \mathrm{O}_{8}$ formula weight $398.36(1 / 7)$ and monascin $\mathrm{C}_{21} \mathrm{H}_{26} \mathrm{O}_{5}$ formula weight $358.43(1 / 7)$.

During the research presented here four out of twelve compounds were identified in the investigated pigmented extract from Talaromyces albobiverticillius 30548 using HPLC-PDA-ESI/MS and NMR: N-threonine monascorubramine $\left(\mathrm{C}_{27} \mathrm{H}_{33} \mathrm{NO}_{7}\right.$ formula weight 483.55), N-glutaryl rubropunctamine $\left(\mathrm{C}_{26} \mathrm{H}_{29} \mathrm{NO}_{8}\right.$ formula weight 483.51$)$, PP-O = ((10Z)12-carboxylmonascorubrin) $\left(\mathrm{C}_{23} \mathrm{H}_{24} \mathrm{O}_{7}\right.$ formula weight 412.43$)$ and a new compound, a N-GABA-PP-V (6-[(Z)-2-Carboxyvinyl]-N-GABA-PPV) $\left(\mathrm{C}_{27} \mathrm{H}_{31} \mathrm{NO}_{8}\right.$ formula weight 497.53), pigment bearing a cis configuration at the $\mathrm{C} 10-\mathrm{C} 11$ double bond.

This new compound will enlarge the list of 63 Monascus and Monascus-like pigments (24 O-containing compounds and $39 \mathrm{~N}$-containing compounds) recently summarized by (Gao et al., 2013). Azaphilones are a large group of pyrano-quinones structures with a high electron acceptor tension determining sensitivity of oxygen in the primary ring. This yields $\gamma$ - pyridones, exhibiting chromophore properties in which colors depend on their chemical structure. Their name comes from their ability to react with ammonia. Thus in the media, they readily interact with compounds containing amino groups such as proteins, amino acids, or nucleic acids resulting in water soluble colored products. In microorganisms such as fungi, L-glutamate is the main precursor of 4- amino-butyrate (GABA). The production of GABA 
is considered as a shunt of the tricarboxylic acid (TCA) cycle which can lead to the production of succinic semi-aldehyde (GABA bypass)(Kumar and Punekar, 1997). The reaction of GABA with O-containing rubropunctatin precursor is mentioned here in Talaromyces albobiverticillius, in Talaromyces genus, in fungi, for the first time. The specific role of this product in the fungal metabolism has to be clarified. Indeed, the azaphilone skeleton is essential for certain biological activities of these metabolites. The differences observed in their activities can however be ascribed to differences in their reactivity with amines.

The work will continue with large scale cultivation of Talaromyces albobiverticillius 30548 in fermenter, analysis of pigmented extracts with liquid chromatography-mass spectrometry ion trap time-of-flight (LCMS-IT-TOF) mass spectrometer (MS) through an atmospheric-pressure chemical ionization (APCI) source, operating in both positive and negative mode, and finally isolation of still unknown compounds for additional NMR.

\section{Conclusion}

Research efforts on fungal reds will continue in the next years or decades. It is now proven that some Talaromyces/Penicillium species are able to produce pigments with no associated mycotoxin(s) (e.g. Talaromyces atroroseus; T. albobiverticillius - up to now we were unable to detect any mycotoxin(s) in all our extracts, prepared with various solvents, from biomasses produced in many different media). Feeding rats in order to test toxicity on living animals is one of the next steps, as it was done previously with other pigmented extracts or molecules (Jonker et al., 2003; Sanjay et al., 2007).

These Talaromyces atroroseus, T. albobiverticillius fungal reds will also be challenged by new generations of Monascus pigments, biosynthesized by new strains unable to produce the mycotoxin citrinin. The very popular and rapid-evolving technique CRISPR/Cas9 allowing fine targeted genome editing sure opens a new era in molecular biology applied to fungal pigments. More data are soon expected about deletion (s) of polyketide synthase(s) involved in mycotoxin(s) biosynthesis, deletion(s) that should maintain pigment(s) production, such providing safe fungi for the production of food colorants.

\section{Acknowledgements}

This publication was made possible by the following grants: i) DIRED/20131527 from Conseil Régional de la Réunion, France and FEDER action of the European Union, for funding the PhD student Mekala Venkatachalam, ii) DIRED/20140704 COLORMAR project from Conseil Régional de la Réunion, France and FEDER action of the European Union, for funding the work on microbial pigments as new source of food colorants, at Réunion island University. The authors wish to thank the "University of Messina" for support through the "Research and Mobility" Project. Laurent Dufossé would also like to thanks the group from Denmark Technical University (Jens Frisvad, Kristian Fog Nielsen, and co-workers) for their pioneering work about fungal reds and for welcoming him in their labs in December 2014.

\section{Appendix A. Supplementary data}

Supplementary data associated with this article can be found, in the online version, at https://doi.org/10.1016/j.jfca.2017.12.036.

\section{References}

Campoy, S., Perez, F., Martín, J.F., Gutierrez, S., Liras, P., 2003. Stable transformants of the azaphilone pigment-producing Monascus purpureus obtained by protoplast transformation and Agrobacterium-mediated DNA transfer. Curr. Genet. 43 (6), 447-452.

Caro, Y., Anamale, L., Fouillaud, M., Laurent, P., Petit, T., Dufosse, L., 2012. Natural hydroxyanthraquinoid pigments as potent food grade colorants: an overview. Nat. Prod. Bioprospect. 2 (5), 174-193.
Caro, Y., Venkatachalam, M., Lebeau, J., Fouillaud, M., Dufossé, L., 2016. Pigments and colorants from filamentous fungi. In: Mérillon, J.-M., Ramawat, K.G. (Eds.), Fungal Metabolites. Springer, Switzerland. http://dx.doi.org/10.1007/978-3-319-19456-1_ 26-1. Chapter 26, 1-70.

Cho, Y., Park, J., Hwang, H., Kim, S., Choi, J., Yun, J., 2002. Production of red pigment by submerged culture of Paecilomyces sinclairii. Lett. Appl. Microbiol. 35 (3), 195-202.

Ciegler, A., Arnold, M., Anderson, R., 1959. Microbiological production of carotenoids: IV. effect of various grains on production of beta-Carotene by mated strains of blakeslea trispora1. Appl. Microbiol. 7 (2), 94.

Derome, A.E., 2013. Modern NMR Techniques for Chemistry Research. Elsevier.

Domsch, K.H., 1980. Compendium of Soil Fungi by K H Domsch W Gams and TrauteHeidi Anderson. Academic Press.

Dufossé, L., Galaup, P., Yaron, A., Arad, S.M., Blanc, P., Chidambara Murthy, K.N., Ravishankar, G.A., 2005. Microorganisms and microalgae as sources of pigments for food use: a scientific oddity or an industrial reality? Trends Food Sci. Technol. 16 (9), 389-406.

Dufossé, L., 2008. Pigments from microalgae and microorganisms: sources of food colorants. In: Socaciu, C. (Ed.), Food Colorants: Chemical and Functional Properties. CRC Press, Boca Raton, pp. 399-426. http://dx.doi.org/10.1201/9781420009286. sec5c.

Dufossé, L., 2016. Current and potential natural pigments from microorganisms (Bacteria, yeasts, fungi, microalgae). In: Carle, R., Schweiggert, R. (Eds.), Handbook on Natural Pigments in Food and Beverages. Industrial Applications for Improving Food Colour. 1st ed. Woodhead Publishing (Elsevier group), Sawston, Cambridge, UK, pp. 540. http://dx.doi.org/10.1016/B978-0-08-100371-8.00016-6.

Finkelstein M., Huang C.-C., Byng G.S., Tsau B.-R., Leach J., (1995), Blakeslea trispora mated culture capable of increased beta-carotene production, US Patent 5422247.

Firn, R.D., Jones, C.G., 2003. Natural products?a simple model to explain chemical diversity. Nat. Prod. Rep. 20 (4), 382-391.

Foster, M.S., Bills, G.F., Mueller, G.M., 2011. Biodiversity of Fungi: Inventory and Monitoring Methods. Elsevier Science.

Fouillaud, M., Venkatachalam, M., Girard-Valenciennes, E., Caro, Y., Dufossé, L., 2016. Anthraquinones and derivatives from marine-derived fungi: structural diversity and selected biological activities. Mar. Drugs 14 (4), 64.

Frisvad, J.C., Yilmaz, N., Thrane, U., Rasmussen, K.B., Houbraken, J., Samson, R.A., 2013. Talaromyces atroroseus, a new species efficiently producing industrially relevant red pigments. PLoS One 8 (12), e84102.

Gao, J.-M., Yang, S.-X., Qin, J.-C., 2013. Azaphilones: chemistry and biology. Chem. Rev. 113 (7), 4755-4811.

Gottlieb, H.E., Kotlyar, V., Nudelman, A., 1997. NMR chemical shifts of common laboratory solvents as trace impurities. J. Org. Chem. 62 (21), 7512-7515.

Goyal, S., Ramawat, G.K., Mérillon, M.J., 2016. Different shades of fungal metabolites: an overview. In: Merillon, J.-M., Ramawat, G.K., Mérillon, J.-M., Ramawat, K.G. (Eds.), Fungal Metabolites. Springer, Switzerland, pp. 1-29.

Gunasekaran, S., Poorniammal, R., 2008. Optimization of fermentation conditions for red pigment production from Penicillium sp. under submerged cultivation. Afr. J. Biotechnol. 7 (12), 1894-1898.

Jiang, Y., Li, H., Chen, F., Hyde, K., 2005. Production potential of water-soluble Monascus red pigment by a newly isolated Penicillium sp. J. Agric. Technol. 1 (1), 113-126.

Jonker, D., Kuper, C., Fraile, N., Estrella, A., Otero, C.R., 2003. Ninety-day oral toxicity study of lycopene from Blakeslea trispora in rats. Regul. Toxicol. Pharm. 37 (3), $396-406$.

Joshi, V., Attri, D., Bala, A., Bhushan, S., 2003. Microbial pigments. Indian J. Biotechnol. 2 (3), 362-369.

Jung, H., Kim, C., Kim, K., Shin, C.S., 2003. Color characteristics of Monascus pigments derived by fermentation with various amino acids. J. Agric. Food Chem. 51 (5), 1302-1306.

Kumar, S., Punekar, N.S., 1997. The metabolism of 4-aminobutyrate (GABA) in fungi. Mycol. Res. 101 (04), 403-409.

López-Nieto, M., Costa, J., Peiro, E., Méndez, E., Rodríguez-Sáiz, M., De la Fuente, J., Cabri, W., Barredo, J., 2004. Biotechnological lycopene production by mated fermentation of Blakeslea trispora. Appl. Microbiol. Biotechnol. 66 (2), 153-159.

Liu, B.-H., Wu, T.-S., Su, M.-C., Chung, C.P., Yu, F.-Y., 2005. Evaluation of citrinin occurrence and cytotoxicity in Monascus fermentation products. J. Agric. Food Chem. 53 (1), 170-175.

Malik, K., Tokkas, J., Goyal, S., 2012. Microbial pigments: a review. Int. J. Microbial. Res. Technol. 1 (4), 361-365.

Mapari, S.A., Nielsen, K.F., Larsen, T.O., Frisvad, J.C., Meyer, A.S., Thrane, U., 2005. Exploring fungal biodiversity for the production of water-soluble pigments as potential natural food colorants. Curr. Opin. Biotechnol. 16 (2), 231-238.

Mapari, S.A., Meyer, A.S., Thrane, U., 2006. Colorimetric characterization for comparative analysis of fungal pigments and natural food colorants. J. Agric. Food Chem. 54 (19), 7027-7035.

Mapari, S.A., Hansen, M.E., Meyer, A.S., Thrane, U., 2008. Computerized screening for novel producers of Monascus-like food pigments in Penicillium species. J. Agric. Food Chem. 56 (21), 9981-9989.

Mapari, S.A., Meyer, A.S., Thrane, U., Frisvad, J.C., 2009. Identification of potentially safe promising fungal cell factories for the production of polyketide natural food colorants using chemotaxonomic rationale. Microb. Cell Fact. 8 (1), 15. http://dx.doi.org/10. 1186/1475-2859-8-24.

Mapari, S.A., Thrane, U., Meyer, A.S., 2010. Fungal polyketide azaphilone pigments as future natural food colorants? Trends Biotechnol. 28 (6), 300-307.

Ogihara, J., Oishi, K., 2002. Effect of ammonium nitrate on the production of PP-V and monascorubrin homologues by Penicillium sp. AZ. J. Biosci. Bioeng. 93 (1), 54-59.

Ogihara, J., Kato, J., Oishi, K., Fujimoto, Y., Eguchi, T., 2000. Production and structural analysis of PP-V, a homologue of monascorubramine, produced by a new isolate of 
Penicillium sp. J. Biosci. Bioeng. 90 (5), 549-554.

Ogihara, J., Kato, J., Oishi, K., Fujimoto, Y., 2001. PP-R, 7-(2-hydroxyethyl)-monascorubramine, a red pigment produced in the mycelia of Penicillium sp. AZ. J. Biosci. Bioeng. 91 (1), 44-47.

Osmanova, N., Schultze, W., Ayoub, N., 2010. Azaphilones: a class of fungal metabolites with diverse biological activities. Phytochem. Rev. 9 (2), 315-342.

Padmavathi, T., Prabhudessai, T., 2013. A solid liquid state culture method to stimulate Monascus pigments by intervention of different substrates. Int. Res. J. Biol. Sci 2 (10), 22-29.

Patakova, P., 2013. Monascus secondary metabolites: production and biological activity. J. Ind. Microbiol. Biotechnol. 40 (2), 169-181.

Pradeep, F., Begam, M., Palaniswamy, M., Pradeep, B., 2013. Influence of culture media on growth and pigment production by Fusarium moniliforme KUMBF1201 isolated from paddy field soil. World Appl. Sci. J. 22 (1), 70-77.

Richer, L., Sigalet, D., Kneteman, N., Shapiro, J., Jones, A., Scott, R., Ashbourne, R.,

Figler, L., Frisvad, J., Smith, L., 1997. Fulminant hepatic failure following ingestion of moldy homemade rhubarb wine. Gastroenterology 112, A1366.

Robinson, S.C., Hinsch, E., Weber, G., Freitas, S., 2014. Method of extraction and resolubilisation of pigments from Chlorociboria aeruginosa and Scytalidium cuboideum, two prolific spalting fungi. Color. Technol. 130 (3), 221-225.

Rotondo, A., Ettari, R., Zappalà, M., De Micheli, C., Rotondo, E., 2014. NMR characterization and conformational analysis of a potent papain-family cathepsin L-like cysteine protease inhibitor with different behaviour in polar and apolar media. J. Mol. Struct. 1076, 337-343.

Rotondo, A., Ettari, R., Grasso, S., Zappalà, M., 2015. NMR conformational analysis in solution of a potent class of cysteine proteases inhibitors. Struct. Chem. 26 (4), 943-950.

Salvo, A., Giuffrida, D., Rotondo, A., De Pasquale, P., La Torre, G.L., Dugo, G., 2017.
Determination and quantification of carotenoids in sea sponges Raspaciona aculeata and Dictyonella marsilii present in the Ganzirri Lake (Messina), Italy. Nat. Prod. Res. 31 (20), 2397-2404. http://dx.doi.org/10.1080/14786419.2017.1309537.

Samson, R., Houbraken, J., Thrane, U., Frisvad, J., Andersen, B., 2010. Food and Indoor Fungi. CBS Laboratory Manual Series 2. CBS-Fungal Biodiversity Centre, Utrecht.

Sanjay, K., Kumaresan, N., Naidu, K.A., Viswanatha, S., Narasimhamurthy, K., Kumar, S.U., Vijayalakshmi, G., 2007. Safety evaluation of pigment containing Aspergillus carbonarius biomass in albino rats. Food Chem. Toxicol. 45 (3), 431-439.

Sigler, L., Abbott, S., Frisvad, J., (1996). Rubratoxin mycotoxicosis by Penicillium crateriforme following ingestion of homemade rhubarb wine, Abstracts, 96th ASM, New Orleans.F -22 , p. 77.

Spiteller, P., 2015. Chemical ecology of fungi. Nat. Prod. Rep. 32 (7), 971-993.

Suhr, K.I., Haasum, I., Steenstrup, L., Larsen, T.O., 2002. Factors affecting growth and pigmentation of Penicillium caseifulvum. J. Dairy Sci. 85 (11), 2786-2794.

Unagul, P., Wongsa, P., Kittakoop, P., Intamas, S., Srikitikulchai, P., Tanticharoen, M., 2005. Production of red pigments by the insect pathogenic fungus Cordyceps unilateralis BCC 1869. J. Ind. Microbiol. Biotechnol. 32 (4), 135-140.

Willker, W., Leibfritz, D., Kerssebaum, R., Bermel, W., 1993. Gradient selection in inverse heteronuclear correlation spectroscopy. Magn. Reson. Chem. 31 (3), 287-292.

Xu, F., Yuan, Q.-P., Zhu, Y., 2007. Improved production of lycopene and $\beta$-carotene by Blakeslea trispora with oxygen-vectors. Process Biochem. 42 (2), 289-293.

Yan, Y., Chemler, J., Huang, L., Martens, S., Koffas, M.A., 2005. Metabolic engineering of anthocyanin biosynthesis in Escherichia coli. Appl. Environ. Microbiol. 71 (7), 3617-3623.

Yilmaz, N., Houbraken, J., Hoekstra, E., Frisvad, J.C., Visagie, C., Samson, R., 2012. Delimitation and characterisation of Talaromyces purpurogenus and related species. Persoonia-Molecular Phylogeny and Evolution of Fungi 29 (1), 39-54. 
Figure S1. PDA and ESI-MS spectra of azaphilones from Talaromyces albobiverticillius 


\section{HPLC-PDA-ESI/MS}

\section{Sample: EtoAc Single Solvent IC/EC}

- Column C18 Phenomenex, Kinetex (100x2.1 mm; $1.7 \mu \mathrm{m})$.

- Solvent A: Water (0.1\% Formic acid).

- Solvent B: Acetonitrile (0.1\% Formic acid).

- PDA: 200-600 nm.

- MS: ESI positive and ESI negative $60-600 \mathrm{~m} / \mathrm{z}$.

- Gradient: 0 min, 5\% B; 15 min, 95\% B; 17 min, 95\% B; $18 \mathrm{~min}, 5 \% \mathrm{~B}$.

Flow rate: $0.2 \mathrm{ml} / \mathrm{min}$. 
PDA Data and ESI (+) /MS Data for Compound N. 1
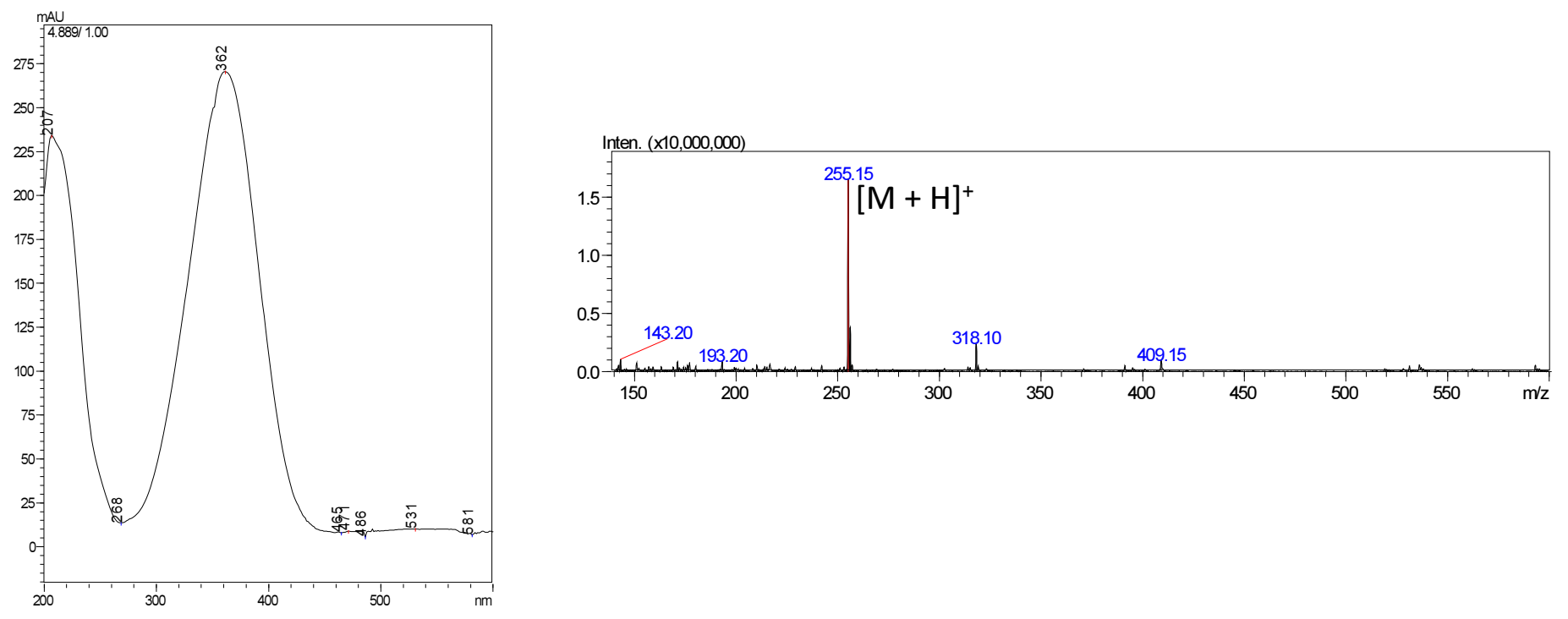
PDA Data and ESI (+) and (-) MS Data for Compound N. 2
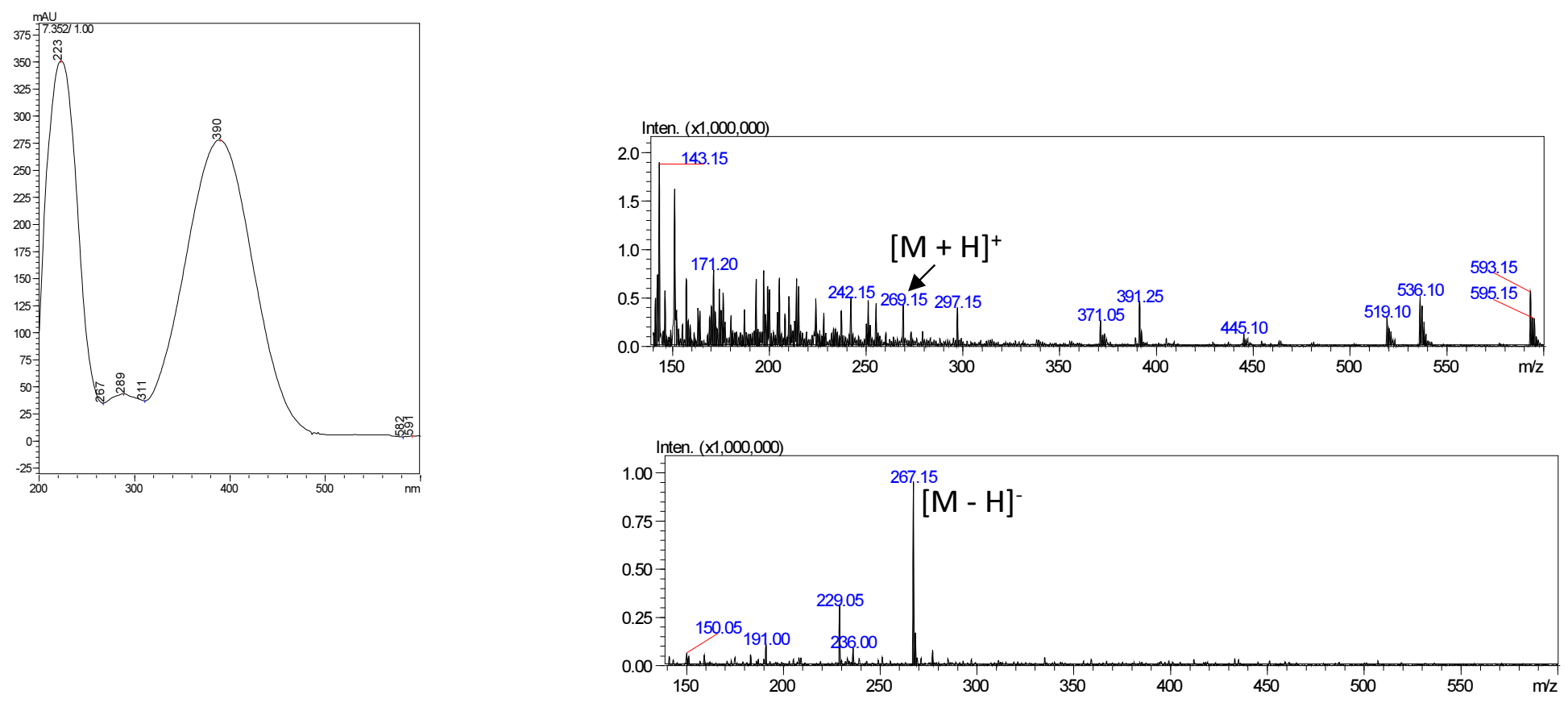
PDA Data and ESI (+) and (-) MS Data for Compound N. 3
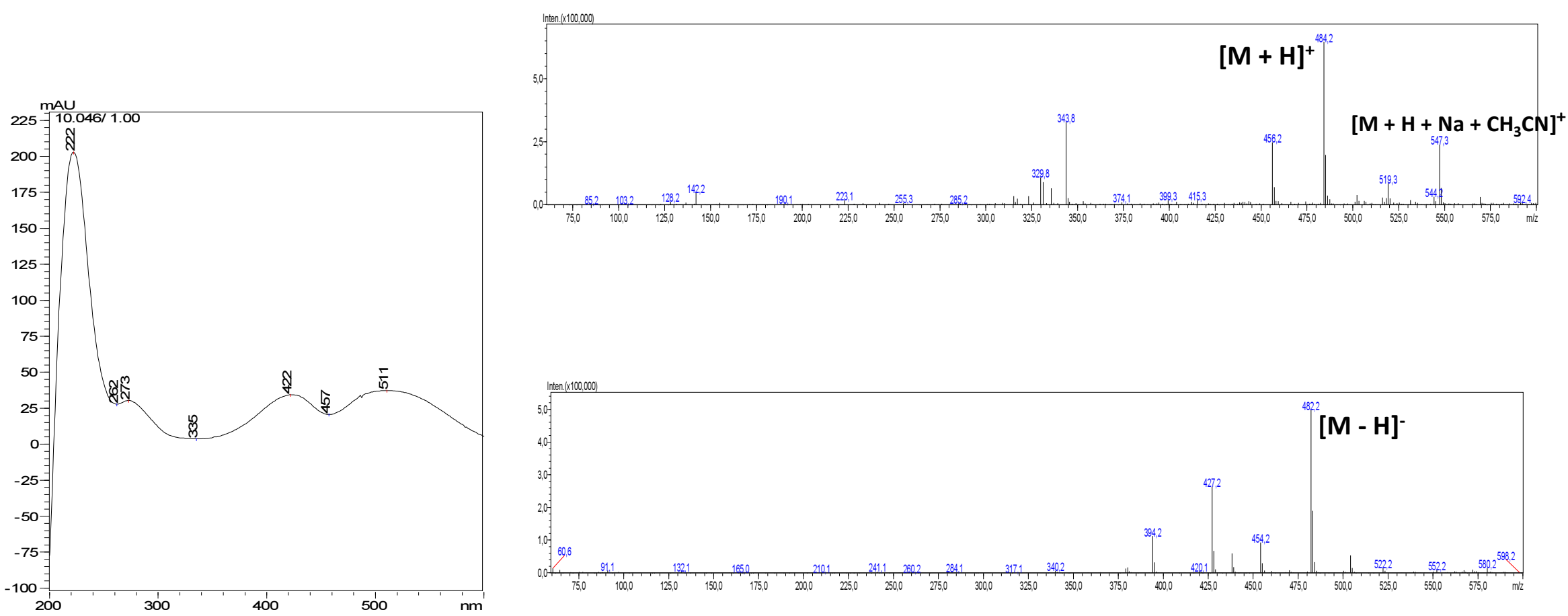
PDA Data and ESI (+) and (-) MS Data for Compound N. 4
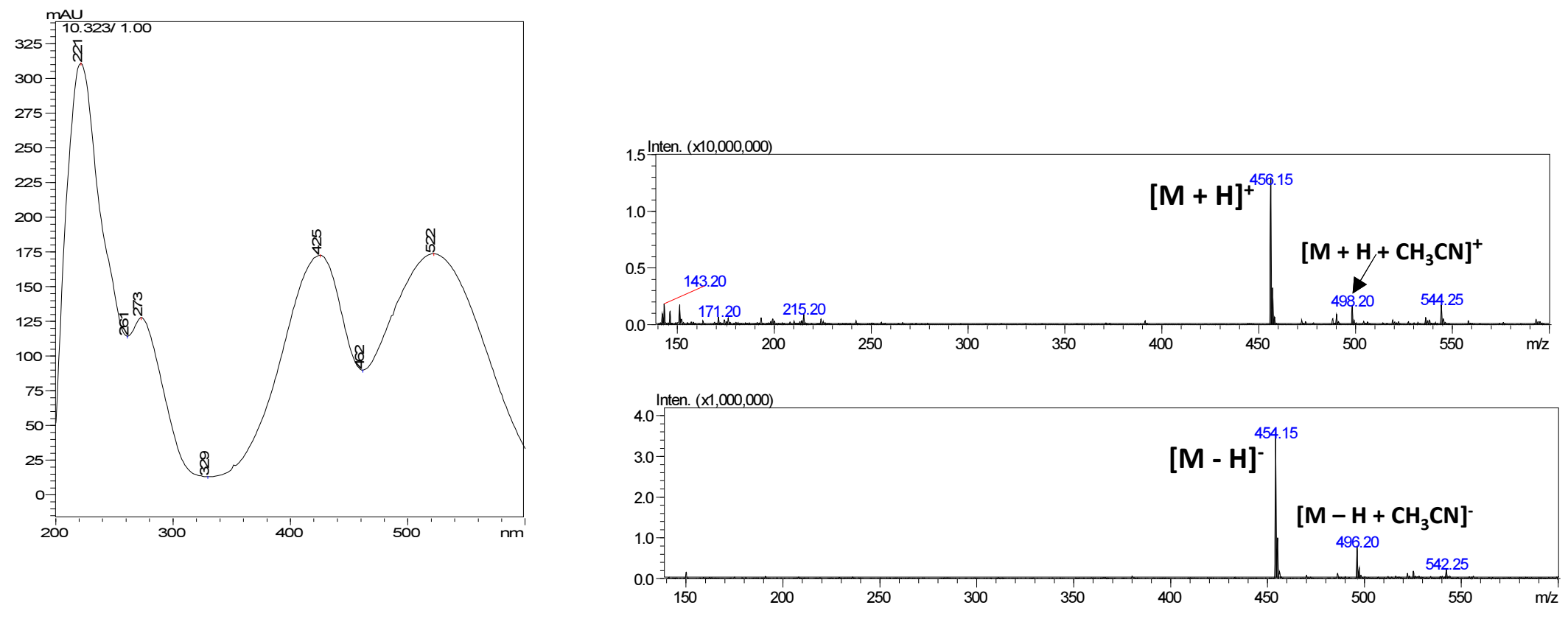
PDA Data and ESI (+) and (-) MS Data for Compound N. 5
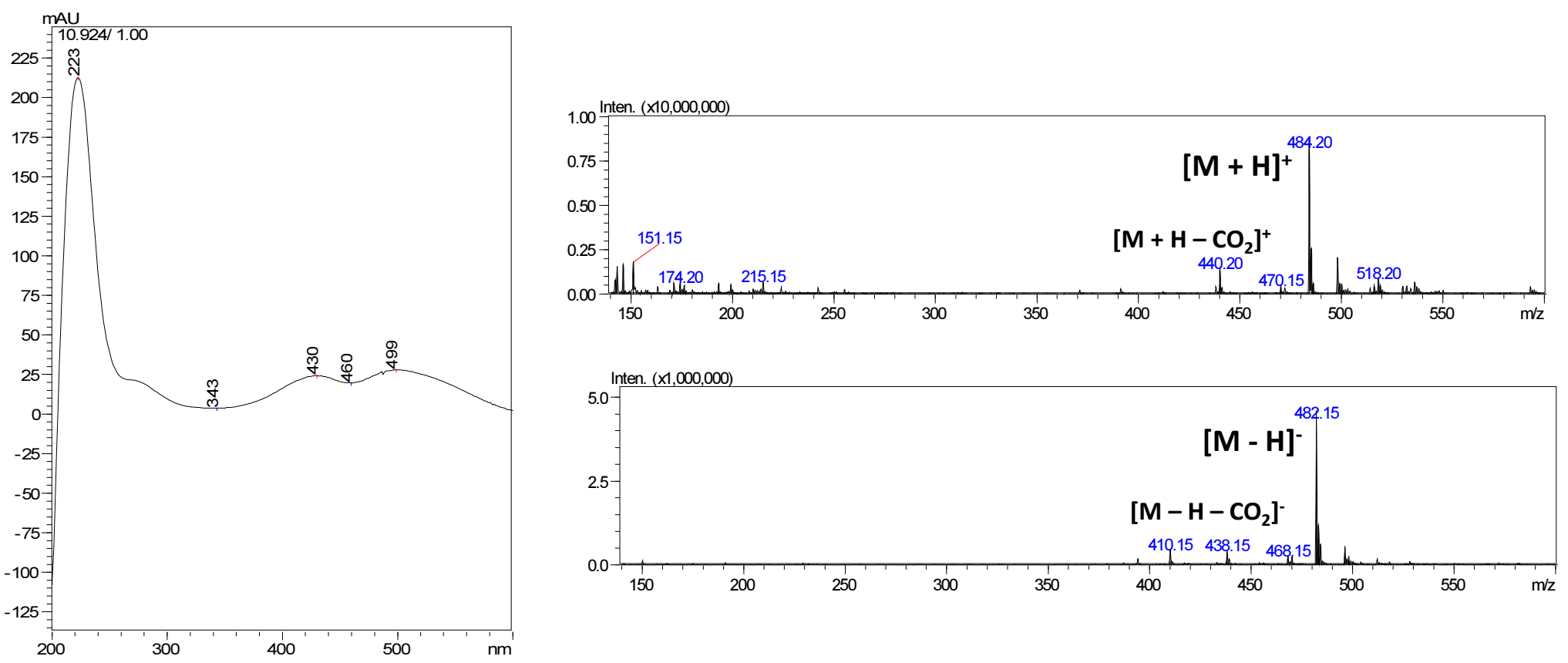
PDA Data and ESI (+) and (-) MS Data for Compound N. 6
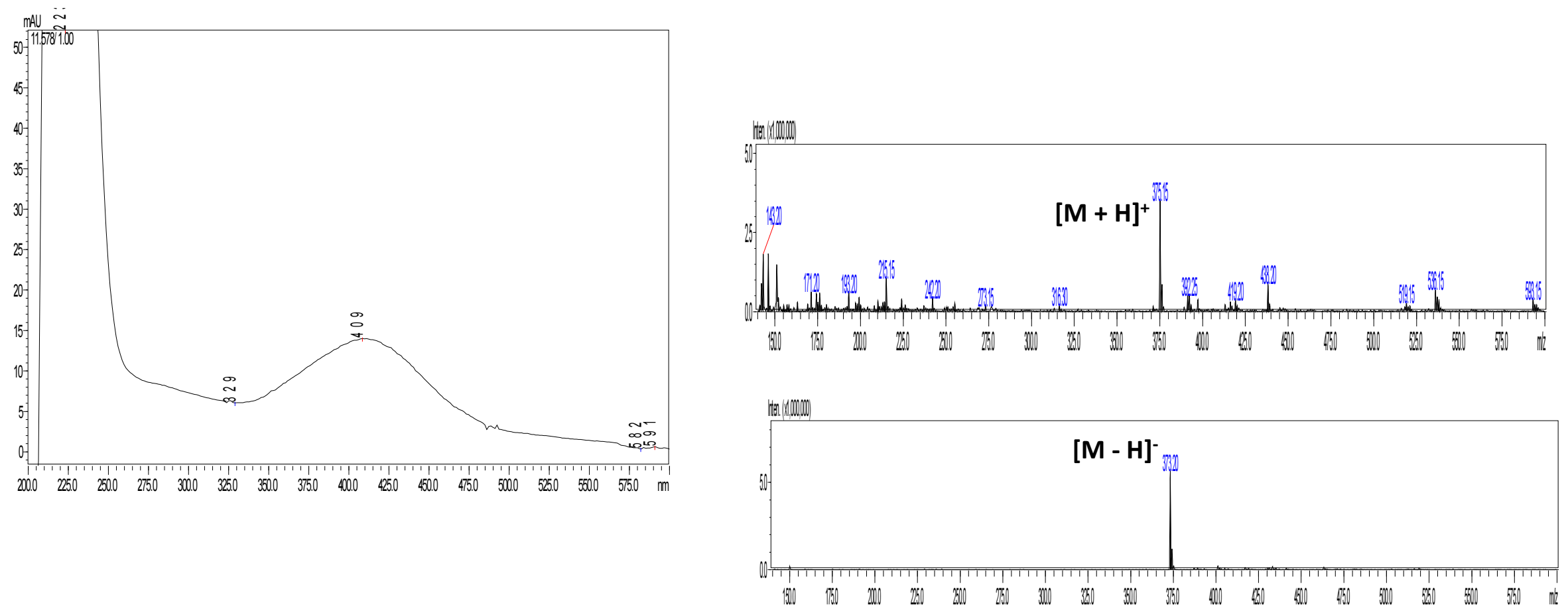
PDA Data and ESI (+) and (-) MS Data for Compound N. 7
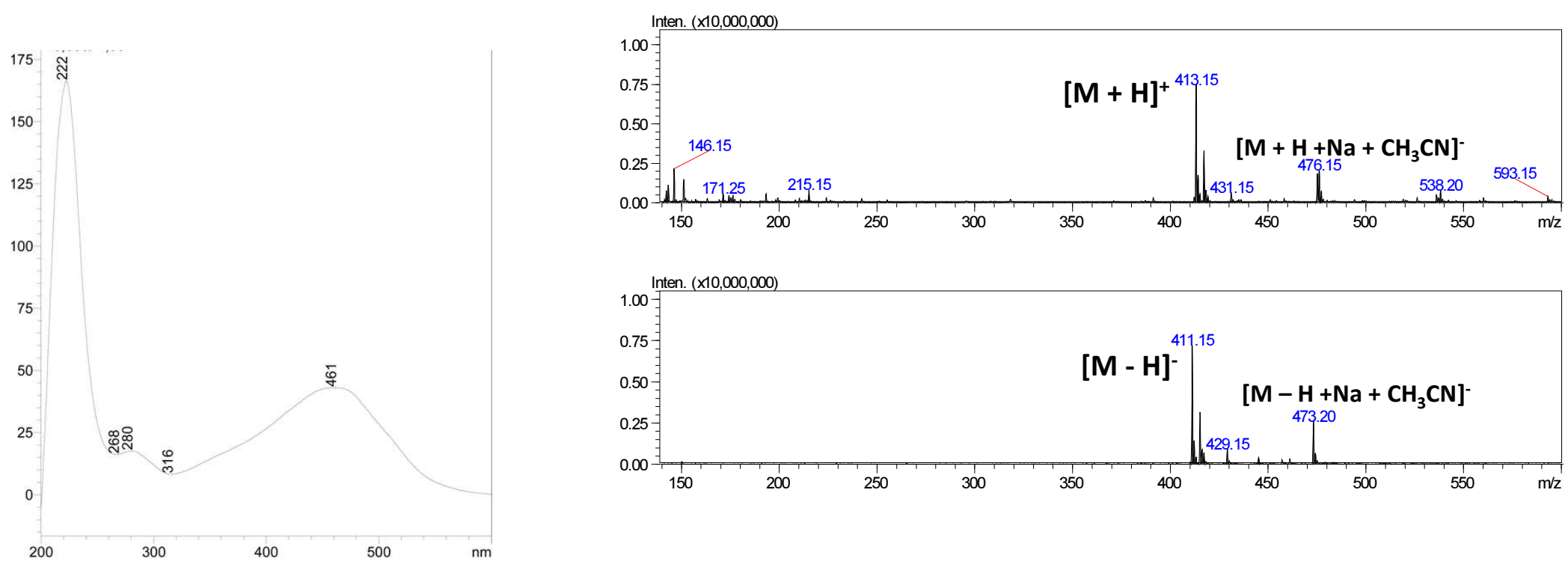
PDA Data and ESI (+) and (-) MS Data for Compound N. 8
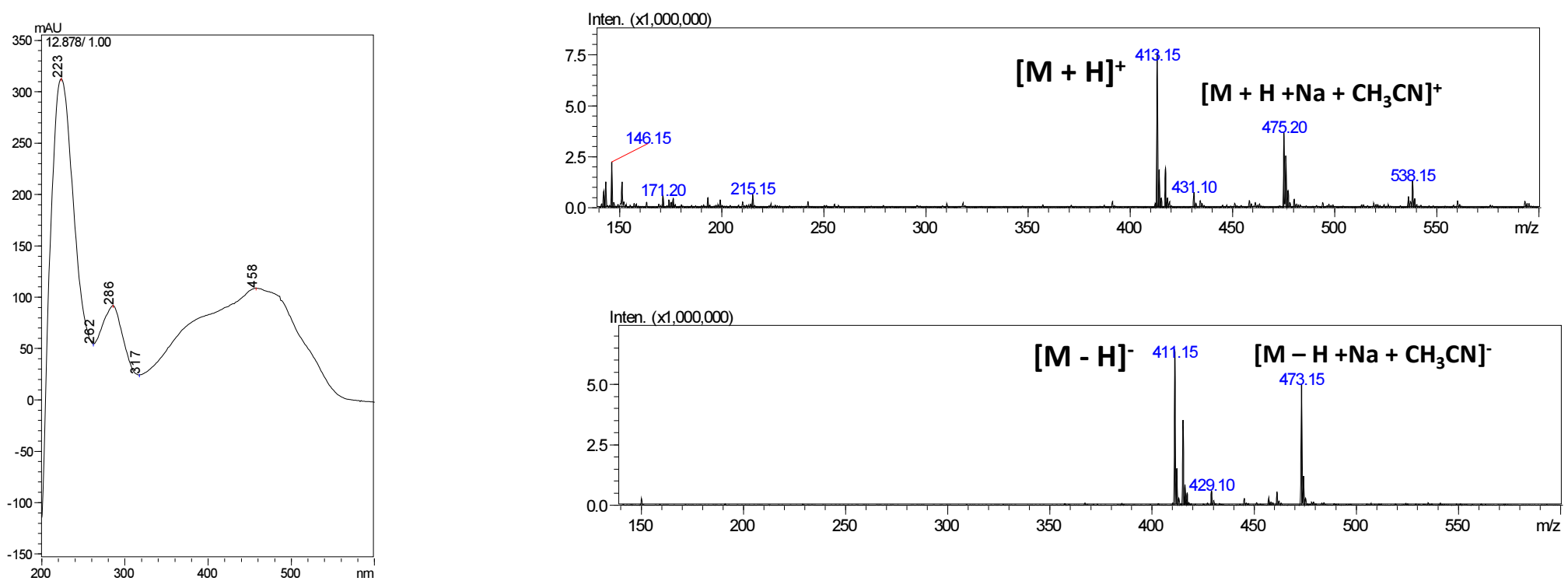
PDA Data and ESI (+) and (-) MS Data for Compound N. 9
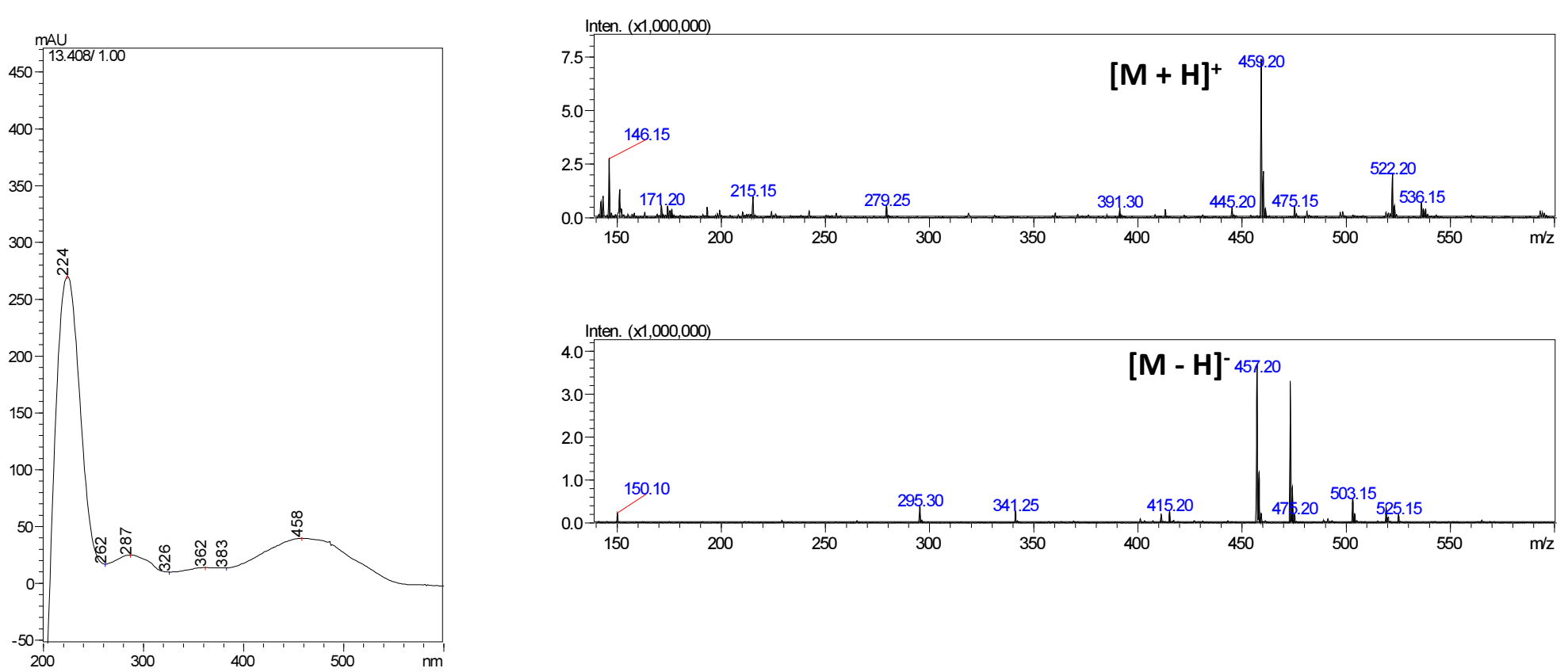
PDA Data and ESI (+) and (-) MS Data for Compound N. 10
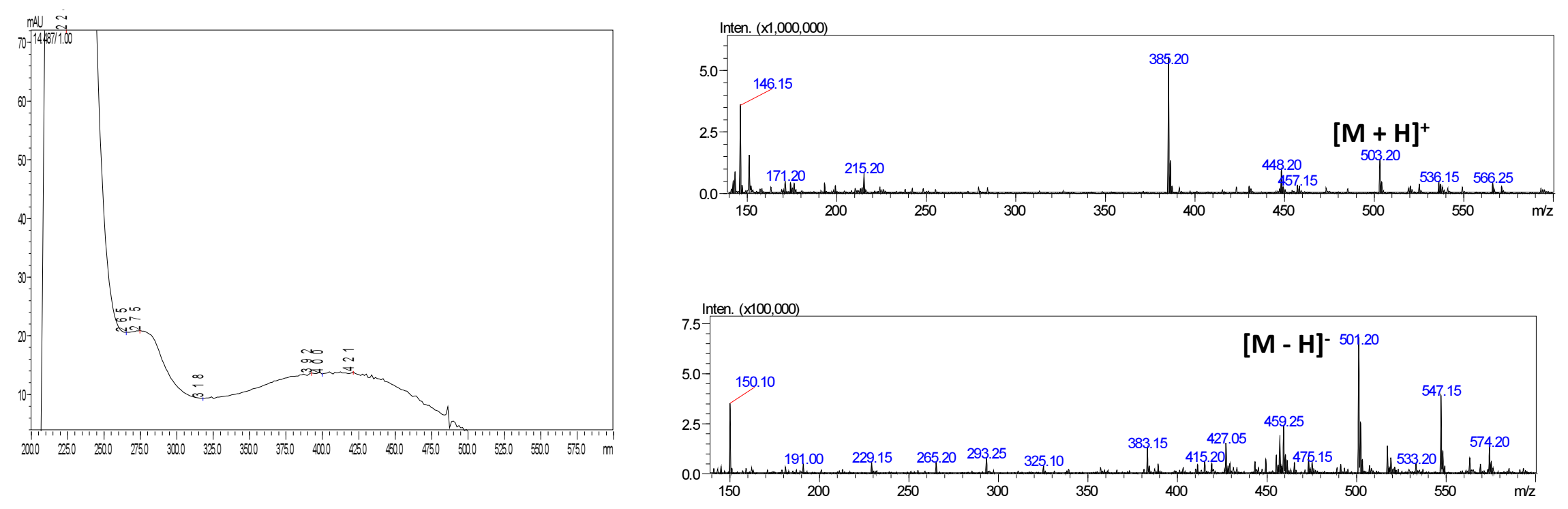
PDA Data and ESI (+) and (-) MS Data for Compound N. 11
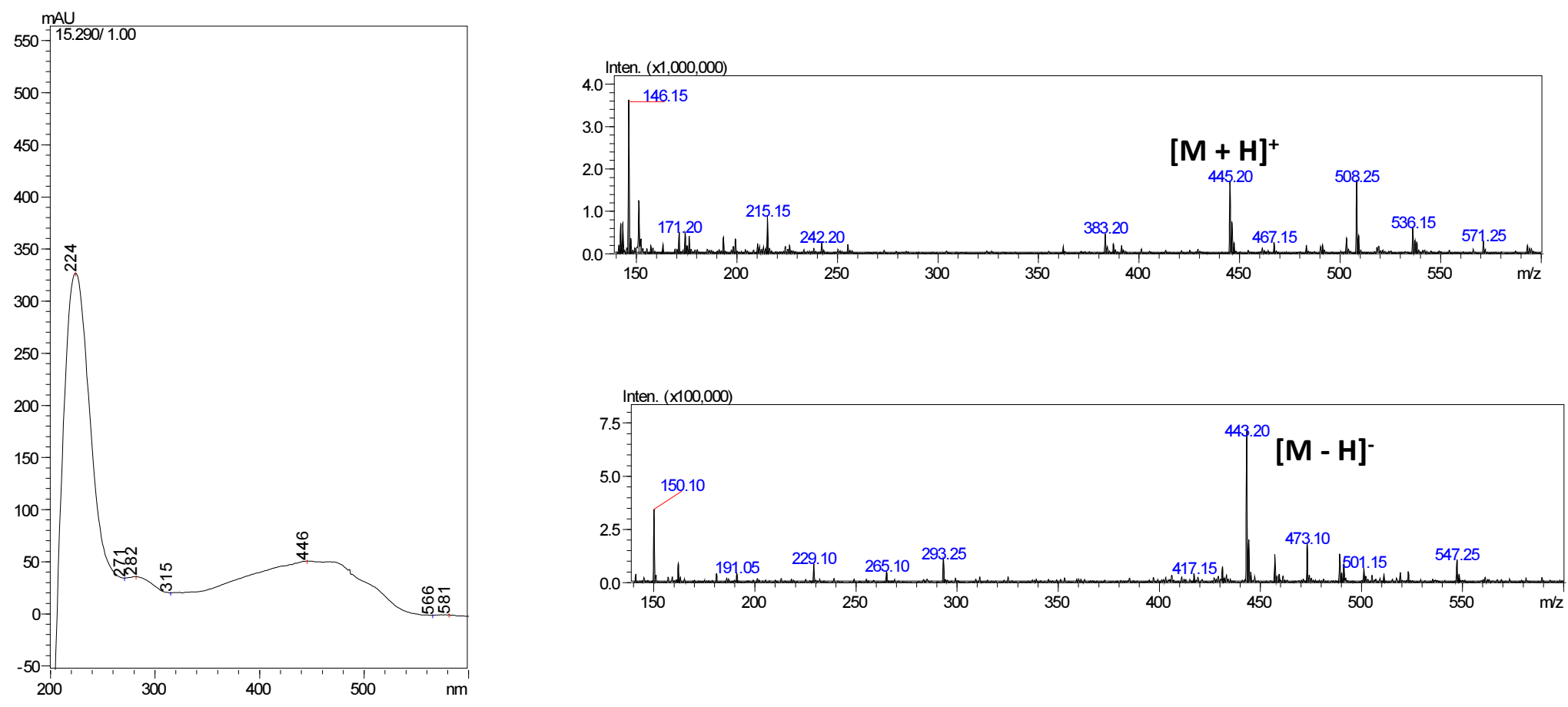


\section{PDA Data and ESI (+) for compound 12}
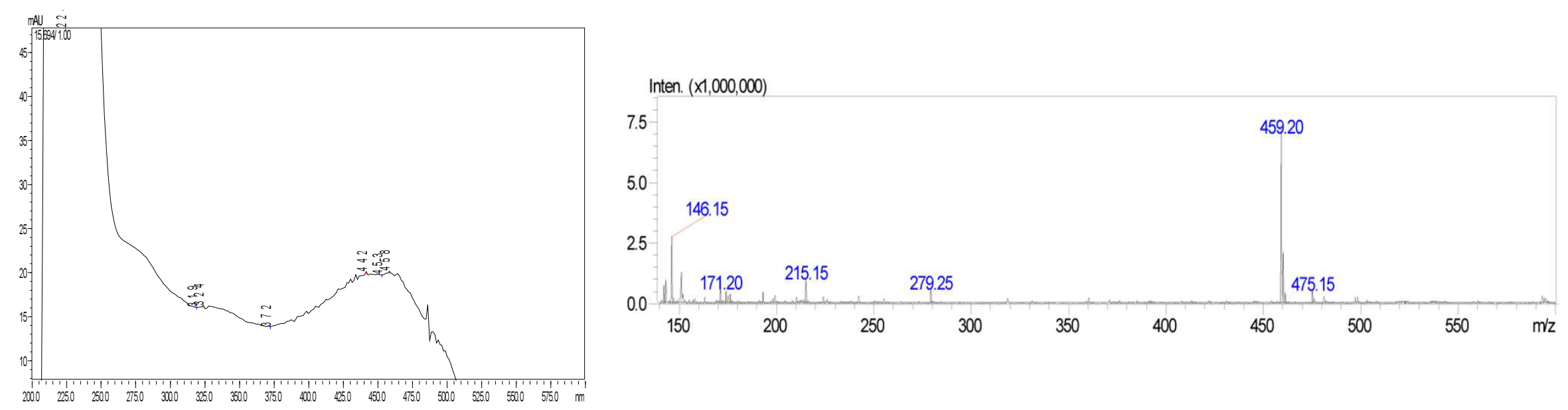
Figure S2. NMR data for compound 4 


\section{Proposed Name: N-GABA-PP-V}

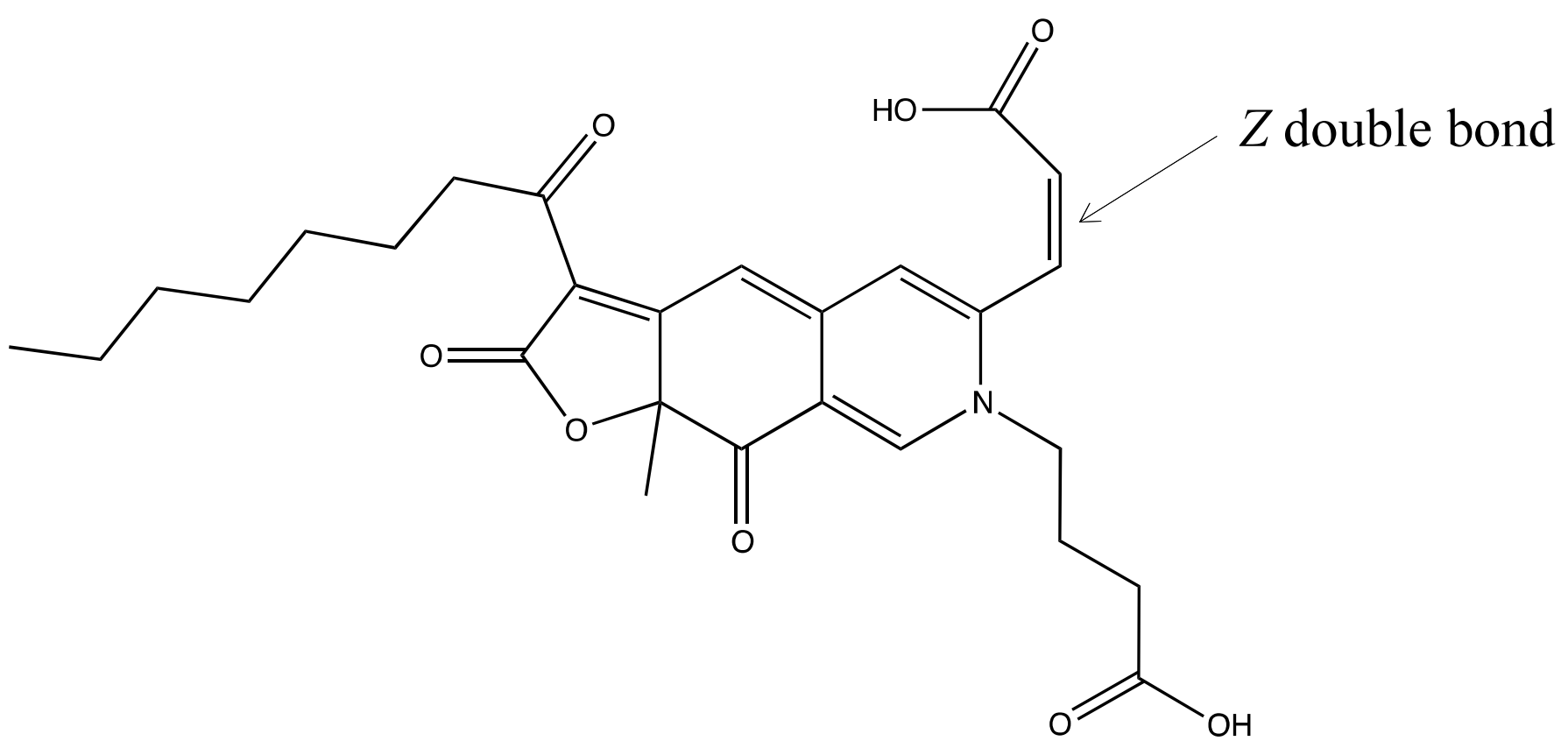

New proposed structure for compound n. 4 of chromatogram shown in Figure 3 
Already reported structure in Chem Spider database with $E$ double bond, although not reported in Talaromyces species and no source or reference provided.

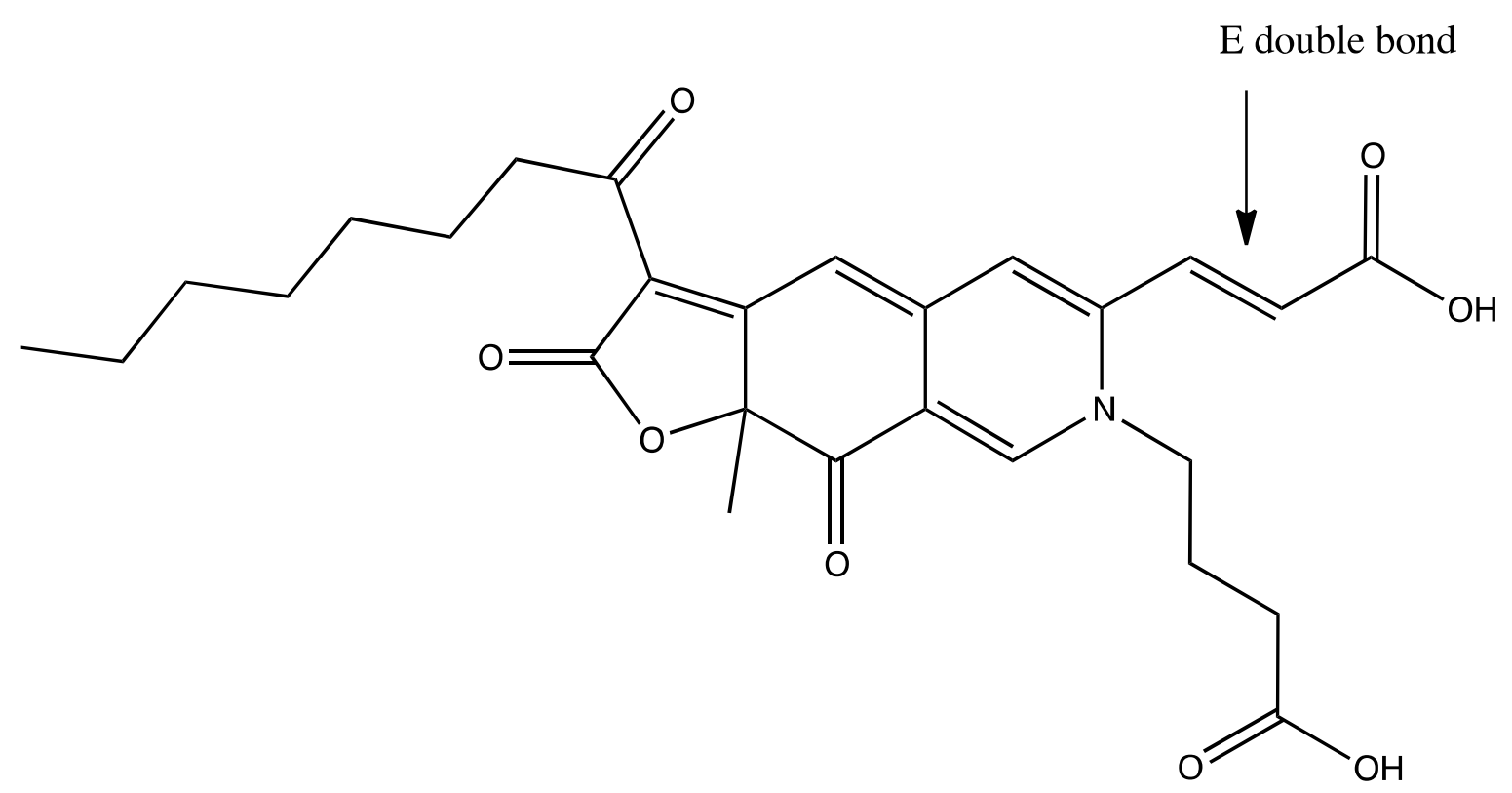

4-\{6-[(E)-2-Carboxyvinyl]-9a-methyl-3-octanoyl-2,9-dioxo-9,9a-dihydrofuro[3,2g]isoquinolin-7(2H)-yl $\}$ butanoic acid

(PubChem CID:44715338). No information available on source and literature. 


\section{Supplementary NMR data}

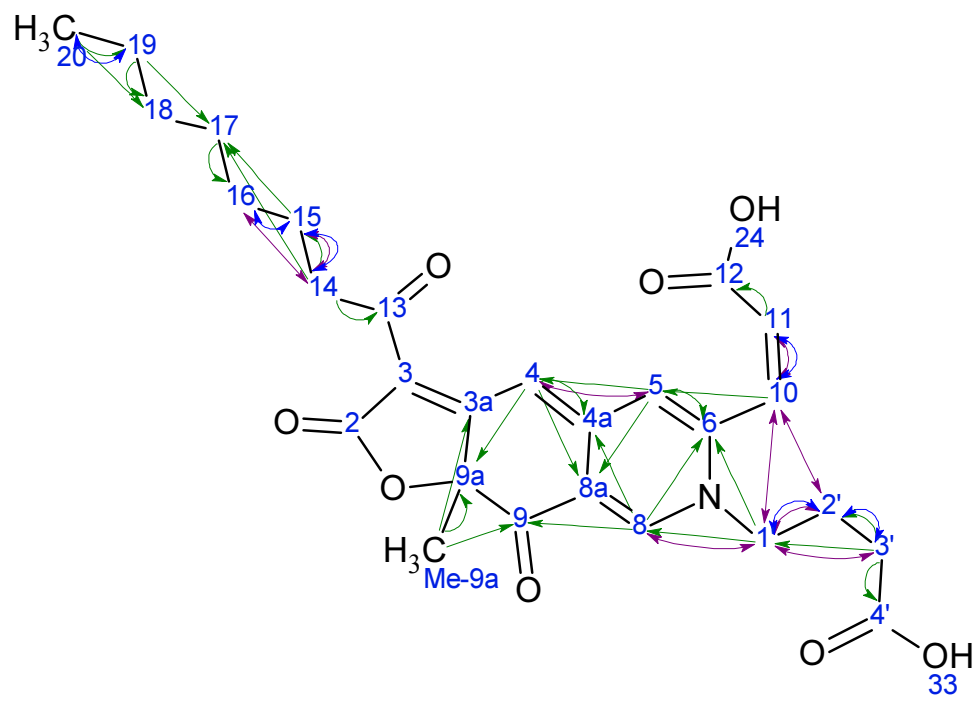

Figure 1S. Molecular scheme of 4 with connections indicated by different colours, specifically green, magenta and blue for HMBC, NOESY and COSY respectively

Table 1S. Total board of the ${ }^{1} \mathrm{H}$ and ${ }^{13} \mathrm{C}$ resonances for compound 4 in methanol.

\begin{tabular}{|c|c|c|c|c|c|c|c|c|c|c|c|c|c|}
\hline \# & Atom\# & C Label & C Shift & $\mathrm{XHn}$ & H Label & H Shift & C Calc Shift & H Calc Shift & H Multiplicity & $\cos Y$ & NOESY & H HMBC & C HMBC \\
\hline 1 & 20 & $\mathrm{C} 20$ & 14.479 & $\mathrm{CH} 3$ & $\mathrm{H} 2 \mathrm{O}$ & 0.887 & 14.428 & 0.903 & $\operatorname{brt}(7.08,7.08)$ & 19 & & & 19,18 \\
\hline 2 & 19 & C19 & 23.755 & $\mathrm{CH} 2$ & $\mathrm{H} 19$ & 1.297 & 22.763 & 1.275 & $\mathrm{~m}$ & 20 & & 20 & 17,18 \\
\hline 3 & 15 & C15 & 26.444 & $\mathrm{CH} 2$ & H15 & 1.584 & 24.354 & 1.444 & br quin (6.07) & $17,16,14$ & 14 & 14 & 17 \\
\hline 4 & $2^{\prime}$ & $\mathrm{C} 2^{\prime}$ & 26.513 & $\mathrm{CH} 2$ & $\mathrm{H}^{\prime}$ & 2.081 & 24.980 & 2.060 & quin & $3^{\prime}, 1^{\prime}$ & 1', 10 & $3^{\prime}$ & \\
\hline 5 & 17,16 & C16 & 30.348 & $\mathrm{CH} 2$ & H16 & 1.324 & 28.319 & $1.243,1.204$ & brs & 15 & 14 & & \\
\hline 6 & $\mathrm{Me}-9 \mathrm{a}$ & Me-9a & 30.542 & $\mathrm{CH} 3$ & $\mathrm{H}-9 \mathrm{a}$ & 1.656 & 21.820 & 1.695 & $\mathrm{~s}$ & & & & $9 a, 3 a, 9$ \\
\hline 7 & 16,17 & C17 & 30.655 & $\mathrm{CH} 2$ & $\mathrm{H} 17$ & 1.285 & 28.875 & $1.204,1.243$ & $\mathrm{~m}$ & & & $19,15,14$ & 19 \\
\hline 8 & $3^{\prime}$ & C3' & 31.456 & $\mathrm{CH} 2$ & $\mathrm{H}^{\prime}{ }^{\prime}$ & 2.400 & 31.969 & 2.390 & brt $(6.65,6.65)$ & $2^{\prime}$ & $1^{\prime}$ & & $22^{\prime}, 1^{\prime}, 4^{\prime}$ \\
\hline 9 & 18 & C18 & 33.000 & $\mathrm{CH} 2$ & $\mathrm{H} 18$ & 1.283 & 31.803 & 1.235 & $\mathrm{~m}$ & & & 20,19 & \\
\hline 10 & 14 & C14 & 41.339 & $\mathrm{CH} 2$ & H 14 & 2.798 & 39.708 & 2.984 & $t$ & 15 & $17,16,15$ & & $15,17,13$ \\
\hline 11 & $1^{\prime}$ & C1' & 56.020 & $\mathrm{CH} 2$ & H 1' & 4.139 & 52.054 & 4.394 & $\mathrm{~m}$ & $2^{\prime}$ & $23^{\prime}, 3^{\prime}, 10,8$ & 3', 8 & 8,6 \\
\hline 12 & $9 a$ & C9a & 87.125 & C & & & 84.863 & & & & & Me-9a, 4 & \\
\hline 13 & 4 & C4 & 99.015 & $\mathrm{CH}$ & $\mathrm{H} 4$ & 6.663 & 111.376 & 8.155 & $\mathrm{~s}$ & & 5 & 5 & $9 a, 8 a, 4 a$ \\
\hline 14 & 3 & $\mathrm{C} 3$ & 102.748 & C & & & 112.334 & & & & & & \\
\hline 15 & $8 a$ & C8a & 120.047 & C & & & 109.433 & & & & & 4,5 & \\
\hline 16 & 5 & C5 & 121.402 & $\mathrm{CH}$ & $\mathrm{H} 5$ & 6.939 & 115.535 & 6.330 & $\mathrm{~s}$ & & 4 & 10 & $4,8 \mathrm{a}, 10,6$ \\
\hline 17 & 10 & C10 & 126.671 & $\mathrm{CH}$ & $\mathrm{H} 10$ & 6.712 & 136.095 & 6.266 & d (11.85) & 11 & $2^{\prime}, 1^{\prime}, 11$ & 5 & 5 \\
\hline 18 & 11 & C11 & 137.320 & $\mathrm{CH}$ & H 11 & 6.475 & 121.932 & 6.178 & br d (12.43) & 10 & 10 & & 12 \\
\hline 19 & 8 & $\mathrm{C} 8$ & 143.504 & $\mathrm{CH}$ & $\mathrm{H} 8$ & 8.324 & 140.335 & 8.958 & $\mathrm{~s}$ & & $1^{\prime}$ & 1' & $1^{\prime}, 6,4 a, 9$ \\
\hline 20 & 6 & C6 & 151.179 & C & & & 140.584 & & & & & $1^{\prime}, 5,8$ & \\
\hline
\end{tabular}

\begin{tabular}{|c|c|c|c|c|c|c|c|c|c|c|c|c|c|}
\hline$\#$ & Atom\# & C Label & C Shift & $\mathrm{XHn}$ & H Label & H Shift & C Calc Shift & H Calc Shift & H Multiplicity & $\cos Y$ & NOESY & H HMBC & C HMBC \\
\hline 1 & 20 & $\mathrm{C} 20$ & 14.479 & $\mathrm{CH} 3$ & $\mathrm{H} 2 \mathrm{O}$ & 0.887 & 14.428 & 0.903 & $\operatorname{brt}(7.08,7.08)$ & 19 & & & 19,18 \\
\hline 2 & 19 & C19 & 23.755 & $\mathrm{CH} 2$ & H19 & 1.297 & 22.763 & 1.275 & $\mathrm{~m}$ & 20 & & 20 & 17,18 \\
\hline 3 & 15 & C15 & 26.444 & $\mathrm{CH} 2$ & $\mathrm{H} 15$ & 1.584 & 24.354 & 1.444 & br quin (6.07) & $17,16,14$ & 14 & 14 & 17 \\
\hline 4 & $2^{\prime}$ & C2' & 26.513 & $\mathrm{CH} 2$ & $\mathrm{H} 2^{\prime}$ & 2.081 & 24.980 & 2.060 & quin & $3^{\prime}, 1^{\prime}$ & 1', 10 & $3^{\prime}$ & \\
\hline 5 & 17,16 & C16 & 30.348 & $\mathrm{CH} 2$ & H16 & 1.324 & 28.319 & $1.243,1.204$ & brs & 15 & 14 & & \\
\hline 6 & Me-9a & Me-9a & 30.542 & $\mathrm{CH} 3$ & $\mathrm{H}-9 \mathrm{a}$ & 1.656 & 21.820 & 1.695 & $s$ & & & & $9 a, 3 a, 9$ \\
\hline 7 & 16,17 & C17 & 30.655 & $\mathrm{CH} 2$ & H17 & 1.285 & 28.875 & $1.204,1.243$ & $\mathrm{~m}$ & & & $19,15,14$ & 19 \\
\hline
\end{tabular}

${ }^{1} \mathrm{H}$ NMR $\left(500 \mathrm{MHz}, \mathrm{METHANOL}-d_{4}\right) \delta$ ppm $0.89(\mathrm{br} \mathrm{t}, J=7.08 \mathrm{~Hz}, 4 \mathrm{H}) 1.26-1.30(\mathrm{~m}, 3 \mathrm{H}) 1.28$ $1.29(\mathrm{~m}, 2 \mathrm{H}) 1.28-1.32(\mathrm{~m}, 4 \mathrm{H}) 1.32$ (br s, $6 \mathrm{H}) 1.58$ (br d, $J=6.07 \mathrm{~Hz}, 3 \mathrm{H}) 1.66(\mathrm{~s}, 3 \mathrm{H}) 2.05-$ $2.13(\mathrm{~m}, 2 \mathrm{H}) 2.40$ (br t, $J=6.65 \mathrm{~Hz}, 2 \mathrm{H}) 2.78-2.82(\mathrm{~m}, 2 \mathrm{H}) 4.11-4.16$ (m, $2 \mathrm{H}) 6.47$ (br d, $J=12.43 \mathrm{~Hz}, 1 \mathrm{H}) 6.66(\mathrm{~s}, 1 \mathrm{H}) 6.71(\mathrm{~d}, J=11.85 \mathrm{~Hz}, 1 \mathrm{H}) 6.94(\mathrm{~s}, 1 \mathrm{H}) 8.32(\mathrm{~s}, 1 \mathrm{H})$ 

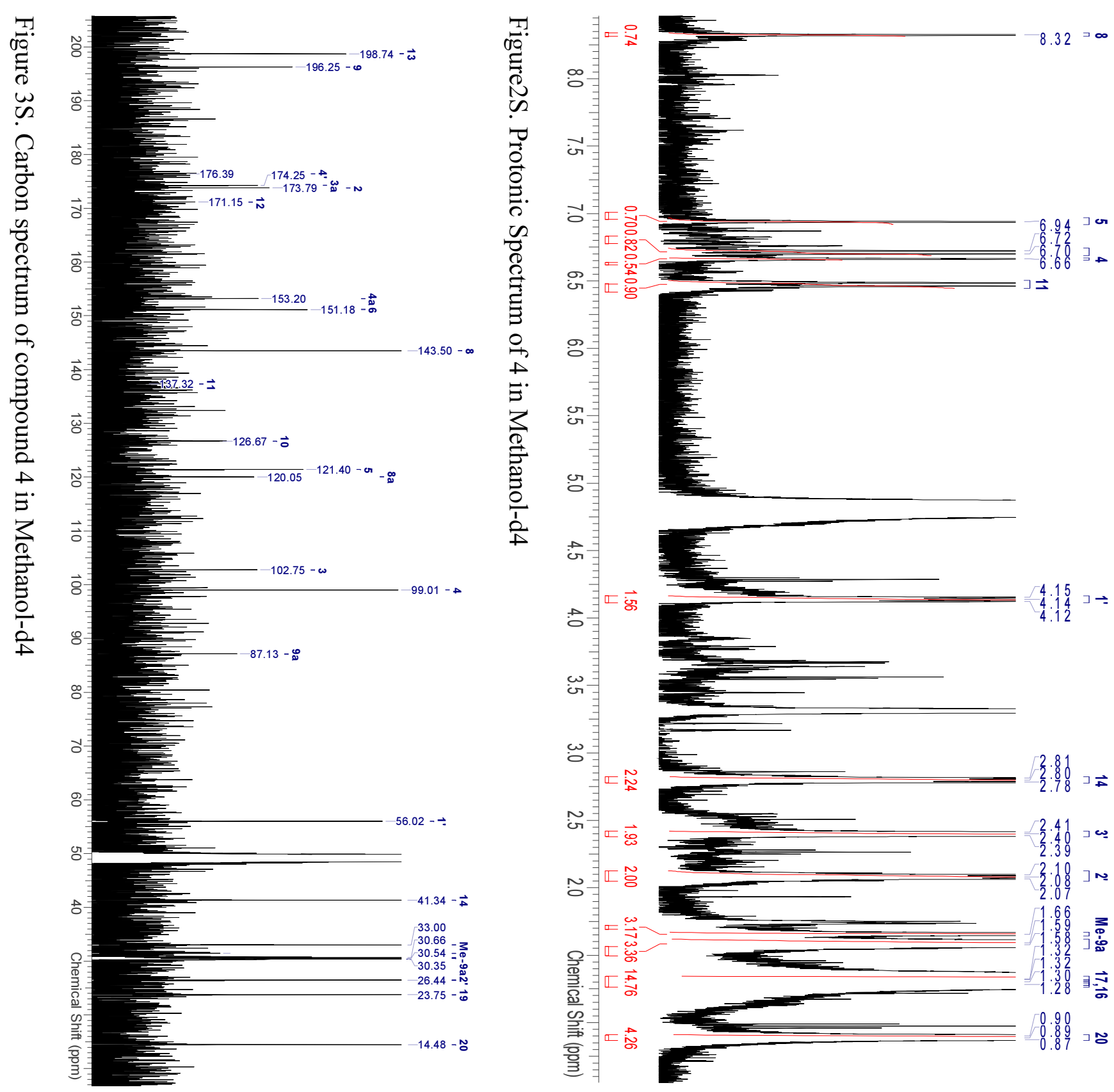


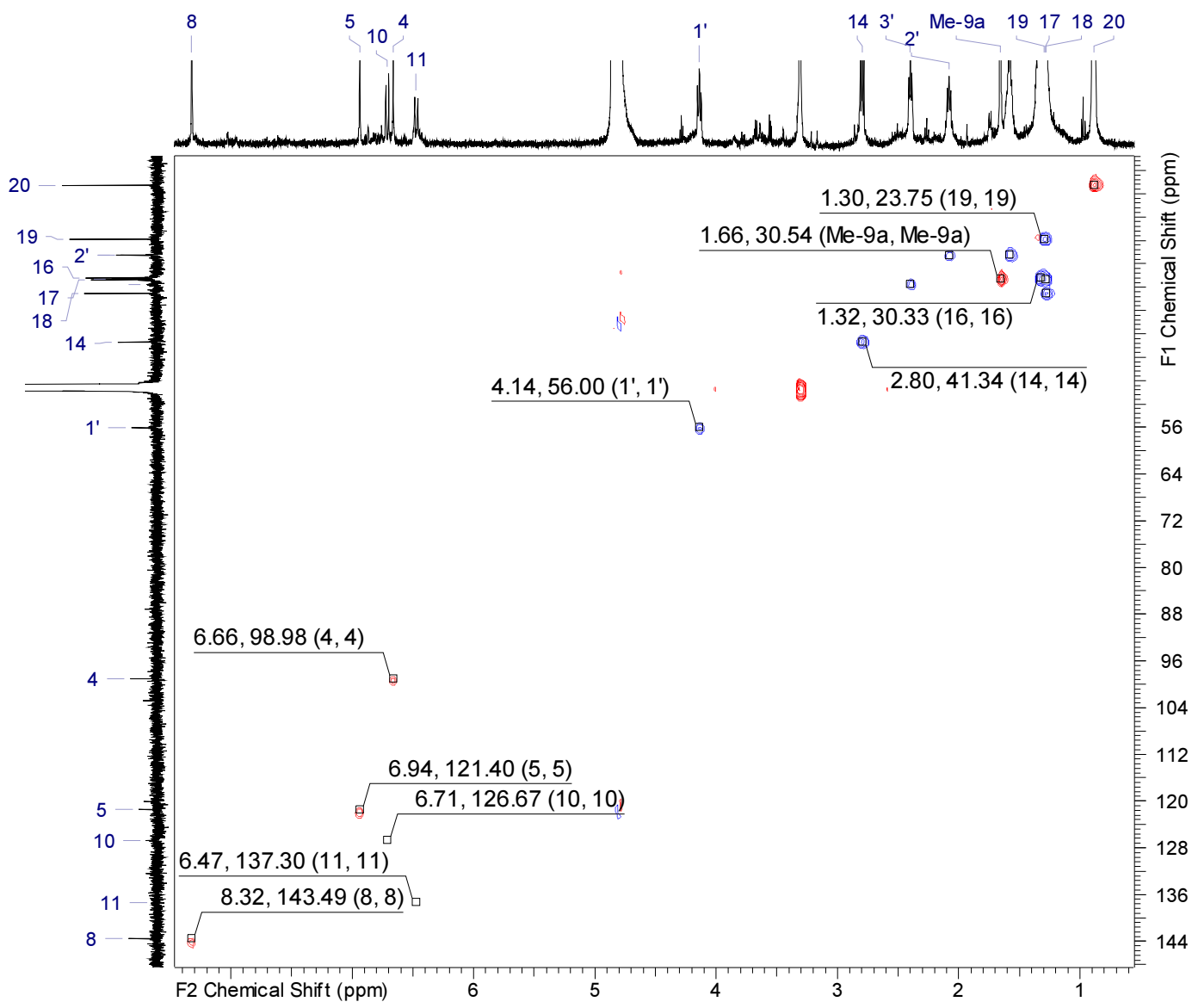

Figure 4S. ${ }^{1} \mathrm{H}_{-}{ }^{13} \mathrm{C}-\mathrm{HSQC}$ plot for the molecule 4 in methanol-d4

Table 2S. Scheme of the HSQC connections.

\begin{tabular}{|c|c|c|c|c|}
\hline No. & F2 Atom & F1 Atom & $\begin{array}{c}\text { F2 } \\
(\mathrm{ppm})\end{array}$ & $\begin{array}{c}\mathrm{F} 1 \\
(\mathrm{ppm})\end{array}$ \\
\hline 1 & Me-9a & Me-9a & 1.66 & 30.54 \\
\hline 2 & $1^{\prime}$ & $1^{\prime}$ & 4.14 & 56.00 \\
\hline 3 & $2^{\prime}$ & $2^{\prime}$ & 2.08 & 26.51 \\
\hline 4 & $3^{\prime}$ & $3^{\prime}$ & 2.40 & 31.48 \\
\hline 5 & 4 & 4 & 6.66 & 98.98 \\
\hline 6 & 5 & 5 & 6.94 & 121.40 \\
\hline 7 & 8 & 8 & 8.32 & 143.49 \\
\hline 8 & 10 & 10 & 6.71 & 126.67 \\
\hline 9 & 11 & 11 & 6.47 & 137.30 \\
\hline 10 & 14 & 14 & 2.80 & 41.34 \\
\hline 11 & 15 & 15 & 1.58 & 26.44 \\
\hline 12 & 16 & 16 & 1.32 & 30.33 \\
\hline 13 & 17 & 17 & 1.29 & 30.65 \\
\hline 14 & 18 & 18 & 1.28 & 32.99 \\
\hline 15 & 19 & 19 & 1.30 & 23.75 \\
\hline 16 & 20 & 20 & 0.89 & 14.47 \\
\hline
\end{tabular}




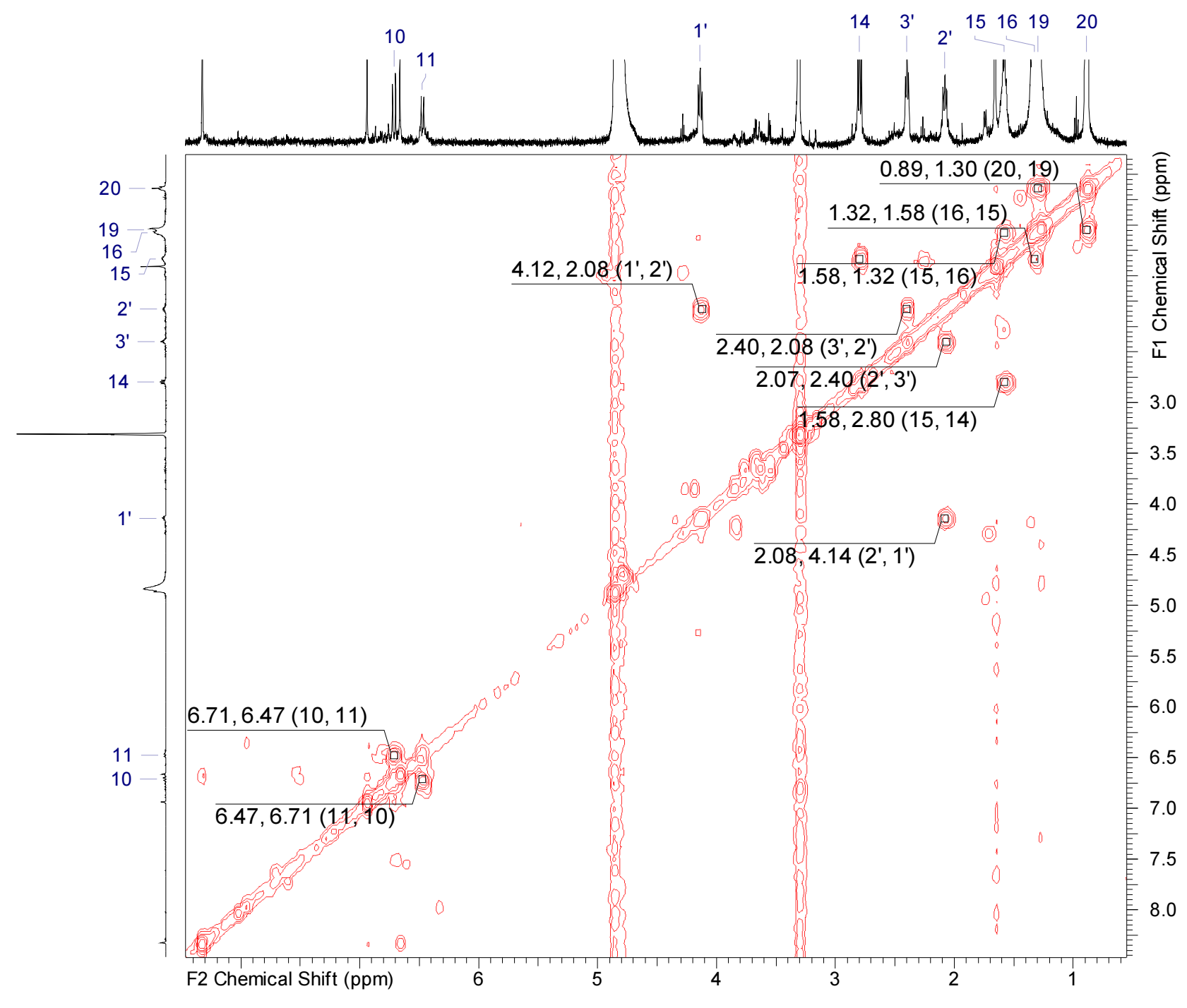

Figure $5 \mathrm{~S} .{ }^{1} \mathrm{H}-{ }^{1} \mathrm{H}-\mathrm{COSY}$ plot for the molecule 4 in methanol-d4

Table 3S. Scheme of the COSY connections.

\begin{tabular}{|c|c|c|c|c|}
\hline No. & F2 Atom & F1 Atom $^{\prime}$ & $\begin{array}{c}\text { F2 } \\
\text { (ppm) }\end{array}$ & $\begin{array}{c}\text { F1 } \\
\text { (ppm) }\end{array}$ \\
\hline 1 & $2^{\prime}$ & $1^{\prime}$ & 2.08 & 4.14 \\
\hline 2 & $1^{\prime}$ & $2^{\prime}$ & 4.12 & 2.08 \\
\hline 3 & $3^{\prime}$ & $2^{\prime}$ & 2.40 & 2.08 \\
\hline 4 & $2^{\prime}$ & $3^{\prime}$ & 2.07 & 2.40 \\
\hline 5 & 11 & 10 & 6.47 & 6.71 \\
\hline 6 & 10 & 11 & 6.71 & 6.47 \\
\hline 7 & 15 & 14 & 1.58 & 2.80 \\
\hline 8 & 14 & 15 & 2.80 & 1.58 \\
\hline 9 & 16 & 15 & 1.32 & 1.58 \\
\hline 10 & 15 & 16 & 1.58 & 1.32 \\
\hline 11 & 20 & 19 & 0.89 & 1.30 \\
\hline 12 & 19 & 20 & 1.30 & 0.89 \\
\hline
\end{tabular}




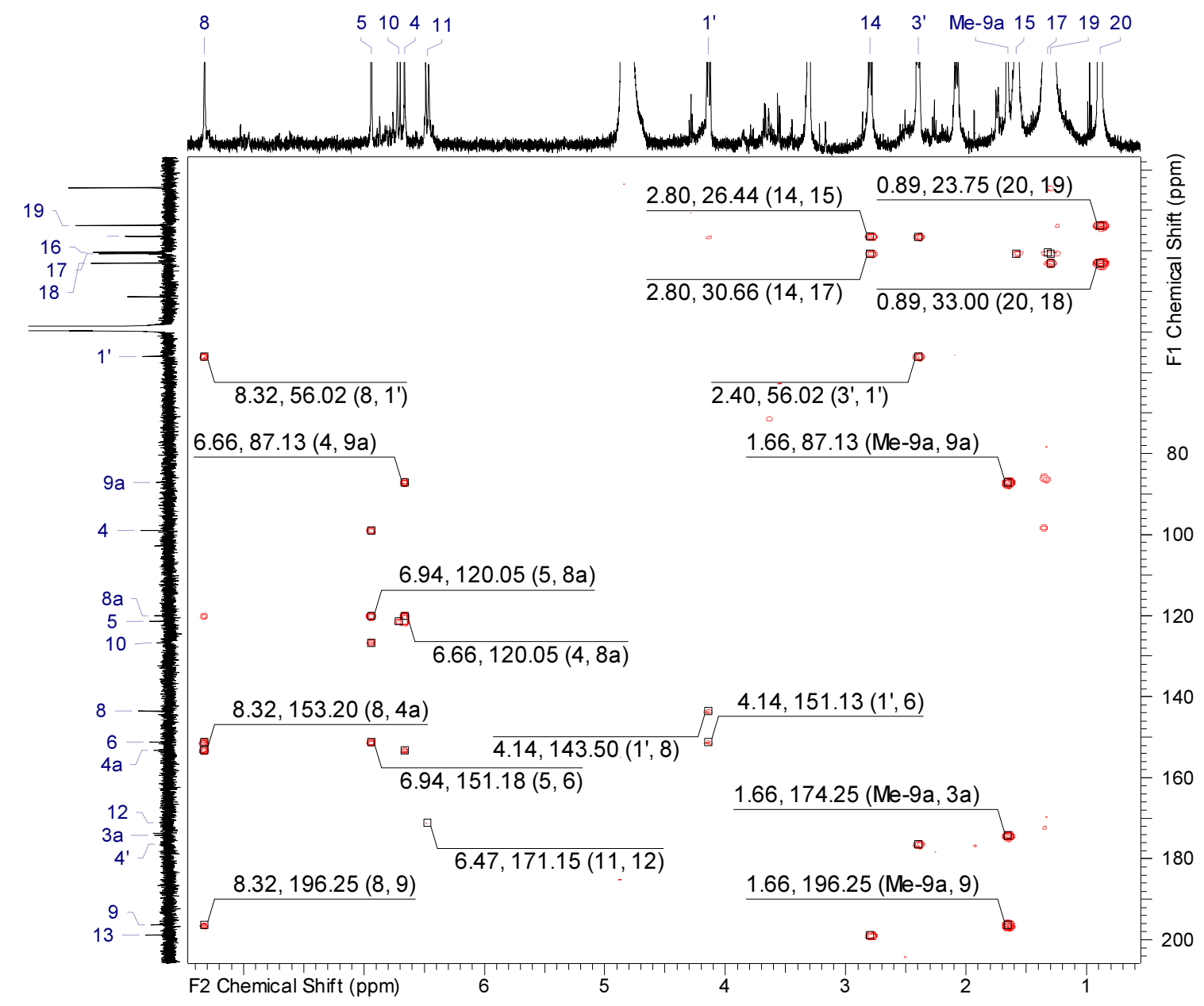

Figure 6S. ${ }^{1} \mathrm{H}-{ }^{13} \mathrm{C}-\mathrm{HMBC}$ plot for the molecule 4 in methanol-d4

Table 4S. Scheme of the HMBC connections.

\begin{tabular}{|c|c|c|c|c|}
\hline No. & F2 Atom & F1 Atom & $\begin{array}{c}\text { F2 } \\
\text { (ppm) }\end{array}$ & $\begin{array}{c}\text { F1 } \\
\text { (ppm) }\end{array}$ \\
\hline 1 & $3^{\prime}$ & $1^{\prime}$ & 2.40 & 56.02 \\
\hline 2 & 8 & $1^{\prime}$ & 8.32 & 56.02 \\
\hline 3 & $3^{\prime}$ & $2^{\prime}$ & 2.40 & 26.51 \\
\hline 4 & Me-9a & $3 a$ & 1.66 & 174.25 \\
\hline 5 & 5 & 4 & 6.94 & 99.01 \\
\hline 6 & $3^{\prime}$ & $4^{\prime}$ & 2.40 & 176.39 \\
\hline 7 & 4 & $4 a$ & 6.66 & 153.20 \\
\hline 8 & 8 & $4 a$ & 8.32 & 153.20 \\
\hline 9 & 10 & 5 & 6.71 & 121.40 \\
\hline 10 & $1^{\prime}$ & 6 & 4.14 & 151.13 \\
\hline 11 & 5 & 6 & 6.94 & 151.18 \\
\hline 12 & 8 & 6 & 8.32 & 151.18 \\
\hline 13 & $1^{\prime}$ & 8 & 4.14 & 143.50 \\
\hline 14 & 4 & $8 a$ & 6.66 & 120.05 \\
\hline 15 & 5 & $8 a$ & 6.94 & 120.05 \\
\hline 16 & Me-9a & 9 & 1.66 & 196.25 \\
\hline 17 & 8 & 9 & 8.32 & 196.25 \\
\hline 18 & Me-9a & $9 a$ & 1.66 & 87.13 \\
\hline 19 & 4 & $9 a$ & 6.66 & 87.13 \\
\hline 20 & 5 & 10 & 6.94 & 126.67 \\
\hline 21 & 11 & 12 & 6.47 & 171.15 \\
\hline 22 & 14 & 13 & 2.80 & 198.74 \\
\hline 23 & 14 & 15 & 2.80 & 26.44 \\
\hline 24 & 17 & 16 & 1.32 & 30.35 \\
\hline 25 & 14 & 17 & 2.80 & 30.66 \\
\hline 26 & 15 & 17 & 1.58 & 30.66 \\
\hline 27 & 19 & 17 & 1.30 & 30.66 \\
\hline 28 & 19 & 18 & 1.30 & 33.00 \\
\hline 29 & 20 & 18 & 0.89 & 33.00 \\
\hline 30 & 20 & 19 & 0.89 & 23.75 \\
\hline
\end{tabular}




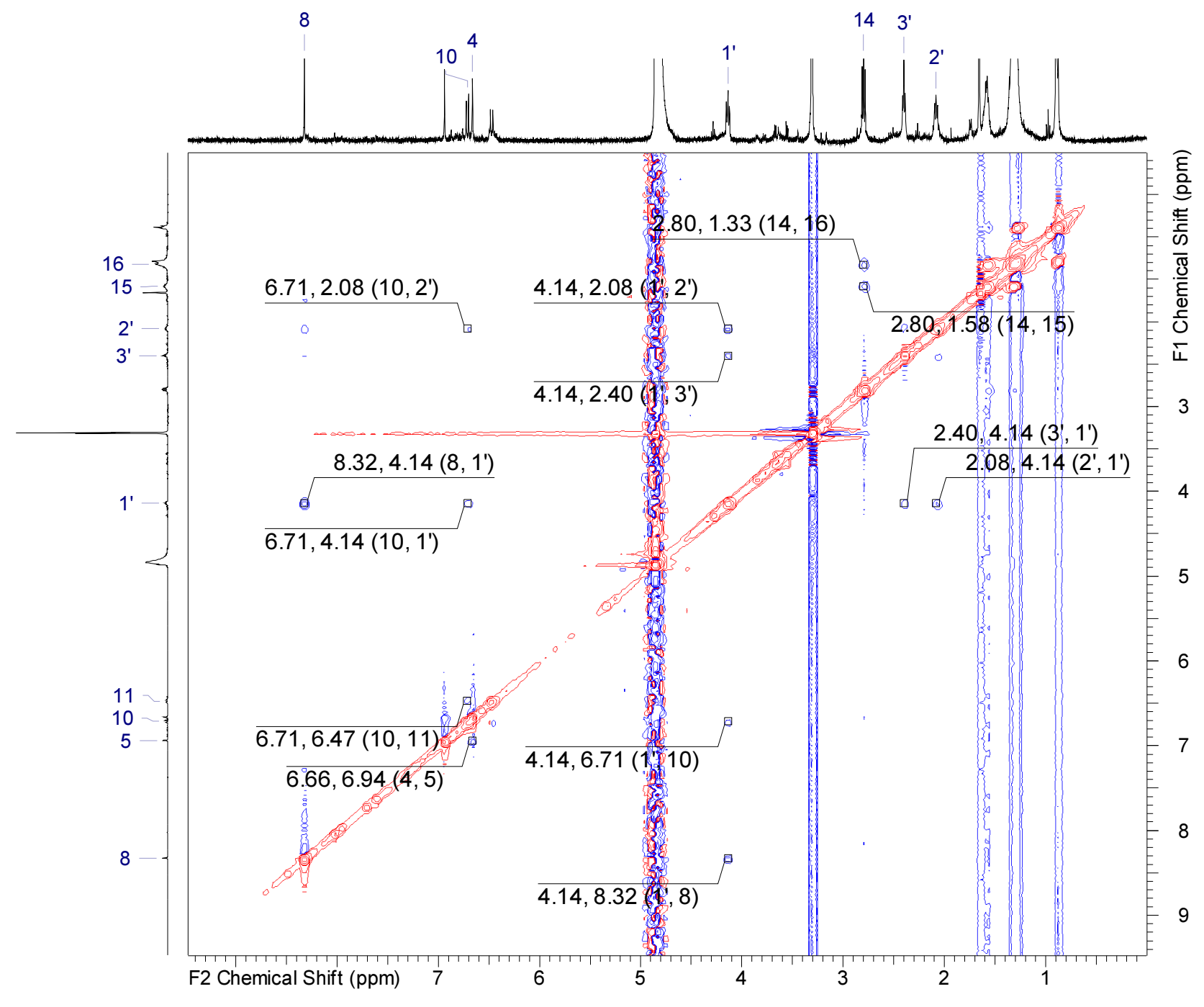

Figure 7S. Noesy spectrum in methanol-d4

Table 5S. Scheme of the NOESY connections.

\begin{tabular}{|c|c|c|c|c|}
\hline No. & F2 Atom & F1 Atom $^{\prime}$ & $\begin{array}{c}\text { F2 } \\
\text { (ppm) }\end{array}$ & $\begin{array}{c}\text { F1 } \\
\text { (ppm) }\end{array}$ \\
\hline 1 & $2^{\prime}$ & $1^{\prime}$ & 2.08 & 4.14 \\
\hline 2 & $3^{\prime}$ & $1^{\prime}$ & 2.40 & 4.14 \\
\hline 3 & 8 & $1^{\prime}$ & 8.32 & 4.14 \\
\hline 4 & 10 & $1^{\prime}$ & 6.71 & 4.14 \\
\hline 5 & $1^{\prime}$ & $2^{\prime}$ & 4.14 & 2.08 \\
\hline 6 & 10 & $2^{\prime}$ & 6.71 & 2.08 \\
\hline 7 & $1^{\prime}$ & $3^{\prime}$ & 4.14 & 2.40 \\
\hline 8 & 4 & 5 & 6.66 & 6.94 \\
\hline 9 & $1^{\prime}$ & 8 & 4.14 & 8.32 \\
\hline 10 & $1^{\prime}$ & 10 & 4.14 & 6.71 \\
\hline 11 & 10 & 11 & 6.71 & 6.47 \\
\hline 12 & 14 & 15 & 2.80 & 1.58 \\
\hline 13 & 14 & 16 & 2.80 & 1.33 \\
\hline
\end{tabular}



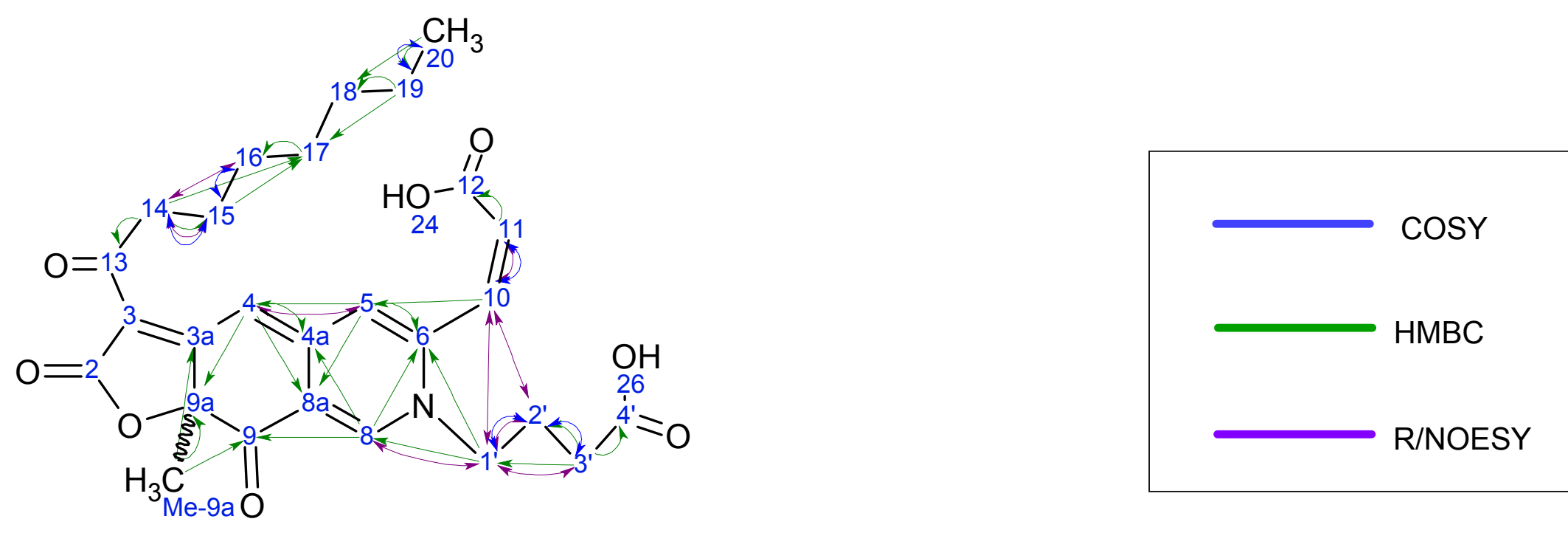

\begin{tabular}{|c|c|c|c|c|c|c|c|c|c|c|c|c|c|}
\hline$\#$ & Atom\# & C Label & C Shift & $\mathrm{XHn}$ & H Label & H Shift & C Calc Shift & H Calc Shift & H Multiplicity & COSY & NOESY & $\mathrm{H}$ HMBC & C HMBC \\
\hline 1 & 20 & $\mathrm{C} 20$ & 14.479 & $\mathrm{CH} 3$ & $\mathrm{H} 20$ & 0.887 & 14.428 & 0.903 & brt $(7.08,7.08)$ & 19 & & & 19,18 \\
\hline 2 & 19 & C19 & 23.755 & $\mathrm{CH} 2$ & H19 & 1.297 & 22.763 & 1.275 & $\mathrm{~m}$ & 20 & & 20 & 17,18 \\
\hline 3 & 15 & C15 & 26.444 & $\mathrm{CH} 2$ & $\mathrm{H} 15$ & 1.584 & 24.354 & 1.444 & br quin (6.07) & $17,16,14$ & 14 & 14 & 17 \\
\hline 5 & 17,16 & C16 & 30.348 & $\mathrm{CH} 2$ & $\mathrm{H} 16$ & 1.324 & 28.319 & $1.243,1.204$ & br s & 15 & 14 & & \\
\hline 6 & Me-9a & Me-9a & 30.542 & $\mathrm{CH} 3$ & $\mathrm{H}-9 \mathrm{a}$ & 1.656 & 21.820 & 1.695 & $\mathrm{~s}$ & & & & $9 a, 3 a, 9$ \\
\hline 7 & 16,17 & C17 & 30.655 & $\mathrm{CH} 2$ & $\mathrm{H} 17$ & 1.285 & 28.875 & $1.204,1.243$ & m & & & $19,15,14$ & 19 \\
\hline 9 & 18 & $\mathrm{C} 18$ & 33.000 & $\mathrm{CH} 2$ & $\mathrm{H} 18$ & 1.283 & 31.803 & 1.235 & $\mathrm{~m}$ & & & 20,19 & \\
\hline 10 & 14 & C14 & 41.339 & $\mathrm{CH} 2$ & H 14 & 2.798 & 39.708 & 2.984 & $\mathrm{t}$ & 15 & $17,16,15$ & & $15,17,13$ \\
\hline 11 & $1^{\prime}$ & C1' & 56.020 & $\mathrm{CH} 2$ & H 1' & 4.139 & 52.054 & 4.394 & $\mathrm{~m}$ & $2^{\prime}$ & 2', 3', 10, 8 & $3 \prime, 8$ & 8,6 \\
\hline 12 & $9 a$ & $\mathrm{C9a}$ & 87.125 & $C$ & & & 84.863 & & & & & Me-9a, 4 & \\
\hline 13 & 4 & $\mathrm{C} 4$ & 99.015 & $\mathrm{CH}$ & $\mathrm{H} 4$ & 6.663 & 111.376 & 8.155 & $\mathrm{~s}$ & & 5 & 5 & $9 a, 8 a, 4 a$ \\
\hline 14 & 3 & $\mathrm{C} 3$ & 102.748 & $C$ & & & 112.334 & & & & & & \\
\hline 15 & $8 a$ & $\mathrm{C} 8 \mathrm{a}$ & 120.047 & $\mathrm{C}$ & & & 109.433 & & & & & 4,5 & \\
\hline 16 & 5 & $\mathrm{C} 5$ & 121.402 & $\mathrm{CH}$ & H 5 & 6.939 & 115.535 & 6.330 & $\mathrm{~s}$ & & 4 & 10 & $4,8 a, 10,6$ \\
\hline 18 & 11 & C11 & 137.320 & $\mathrm{CH}$ & H 11 & 6.475 & 121.932 & 6.178 & br d (12.43) & 10 & 10 & & 12 \\
\hline 19 & 8 & $\mathrm{C} 8$ & 143.504 & $\mathrm{CH}$ & $\mathrm{H} 8$ & 8.324 & 140.335 & 8.958 & $\mathrm{~s}$ & & $1^{\prime}$ & $1^{\prime}$ & $1^{\prime}, 6,4 a, 9$ \\
\hline 20 & 6 & $\mathrm{C} 6$ & 151.179 & $C$ & & & 140.584 & & & & & $1^{\prime}, 5,8$ & \\
\hline
\end{tabular}

\section{C:IDATINlavorilALIMIDanieleGiuffridalJFCA2016\AP3_fordrawings.gnr}




\begin{tabular}{|c|c|c|c|c|c|c|c|c|c|c|c|c|c|}
\hline$\#$ & Atom\# & C Label & C Shift & $\mathrm{XHn}$ & H Label & H Shift & C Calc Shift & H Calc Shift & H Multiplicity & COSY & NOESY & $\mathrm{H}$ HMBC & C HMBC \\
\hline 21 & $4 a$ & $\mathrm{C} 4 \mathrm{a}$ & 153.201 & C & & & 143.636 & & & & & 4,8 & \\
\hline 22 & 12 & $\mathrm{C} 12$ & 171.145 & C & & & 169.827 & & & & & 11 & \\
\hline 23 & 2 & C2 & 173.790 & C & & & 169.147 & & & & & & \\
\hline 25 & $4^{\prime}$ & C4' & 176.392 & C & & & 177.759 & & & & & $3^{\prime}$ & \\
\hline 26 & 9 & C9 & 196.252 & C & & & 189.149 & & & & & Me-9a, 8 & \\
\hline 27 & 13 & C12 & 198.745 & C & & & 199.835 & & & & & 14 & \\
\hline
\end{tabular}




\begin{tabular}{|c|c|c|c|}
\hline Acquisition Time (sec) & 2.8001 & & \\
\hline Comment & Calibration fo & MR on 08Jun2016 Samp & e : F19 S/N test sample \\
\hline Date & Jun 122016 & Date Stamp & Jun 122016 \\
\hline File Name & C:IDATINlavor & DanieleGiuffridalazaphil3 & lazaphilone3CD3OHnew_1Hnew.fidlfid \\
\hline Frequency $(\mathrm{MHz})$ & 499.8096 & Nucleus & $1 \mathrm{H}$ \\
\hline Number of Transients & 8 & Original Points Count & 13258 \\
\hline Points Count & 16384 & Pulse Sequence & PRESAT \\
\hline SW(cyclical) $(\mathrm{Hz})$ & 4734.85 & Solvent & METHANOL-d4 \\
\hline Spectrum Offset $(\mathrm{Hz})$ & 2369.4717 & Spectrum Type & standard \\
\hline Sweep Width $(\mathrm{Hz})$ & 4734.56 & Temperature (degree $C$ & 25.000 \\
\hline
\end{tabular}

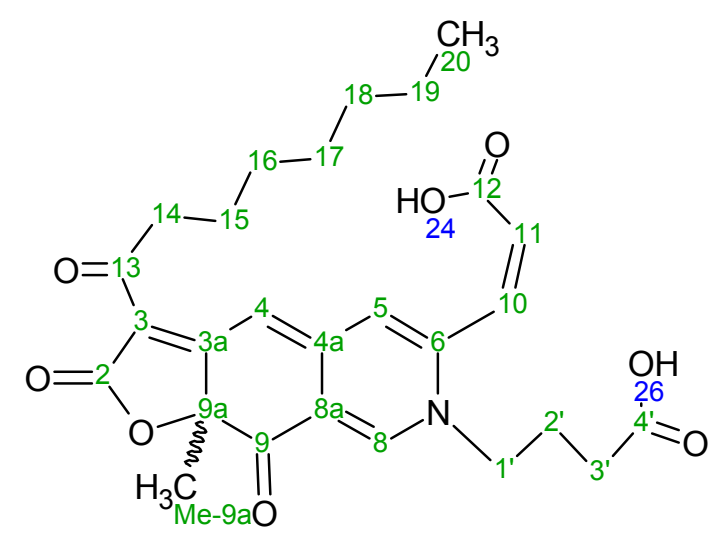

${ }^{1} \mathrm{H}$ NMR $\left(500 \mathrm{MHz}\right.$, METHANOL- $d_{4}$ ) d ppm 0.89 (br t, $\left.J=7.08 \mathrm{~Hz}, 4 \mathrm{H}\right) 1.26-1.30$ (m, $\left.3 \mathrm{H}\right) 1.28-1.29$ (m, $\left.2 \mathrm{H}\right) 1.28-1.32$ (m, $\left.4 \mathrm{H}\right) 1.32$ (br s, $\left.6 \mathrm{H}\right) 1.58$ (br d, $J=6.07 \mathrm{~Hz}, 3 \mathrm{H}) 1.66$ (s, $3 \mathrm{H}) 2.05-2.13$ (m, 2 H) 2.40 (br t, $J=6.65 \mathrm{~Hz}, 2 \mathrm{H}) 2.78-2.82$ (m, $2 \mathrm{H}) 4.11-4.16$ (m, 2 H) 6.47 (br d, $J=12.43 \mathrm{~Hz}, 1 \mathrm{H}$ ) $6.66(\mathrm{~s}, 1 \mathrm{H}) 6.71(\mathrm{~d}, J=11.85 \mathrm{~Hz}, 1 \mathrm{H}) 6.94(\mathrm{~s}, 1 \mathrm{H}) 8.32(\mathrm{~s}, 1 \mathrm{H})$

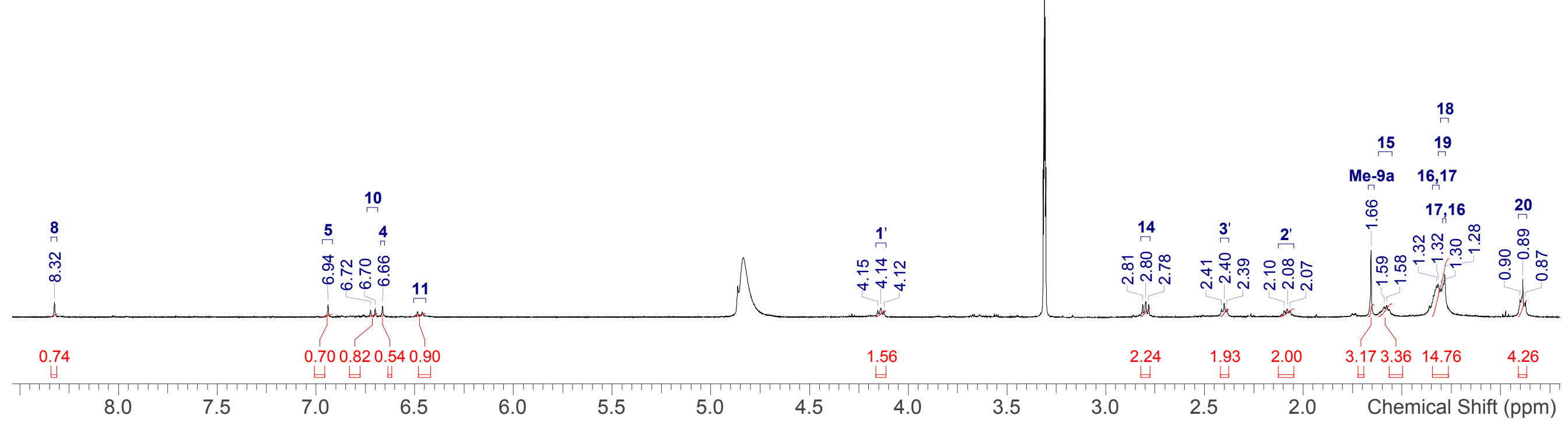




\begin{tabular}{|c|c|c|c|}
\hline Acquisition Time (sec) & 1.5000 & & \\
\hline Comment & \multicolumn{3}{|c|}{ Calibration for OneNMR on 08Jun2016 Sample : F19 S/N test sample } \\
\hline Date & Jun 122016 & Date Stamp & Jun 122016 \\
\hline File Name & \multicolumn{3}{|c|}{ C:IDATIIlavorilALIMIDanieleGiuffridalazaphil3_ACDlazaphil3CD3OH_13Clong.fidlfic } \\
\hline Frequency $(\mathrm{MHz})$ & 125.6904 & Nucleus & $13 \mathrm{C}$ \\
\hline Number of Transients & 6752 & Original Points Count & 46875 \\
\hline Points Count & 65536 & Pulse Sequence & s2pul \\
\hline Receiver Gain & 30.00 & SW(cyclical) $(\mathrm{Hz})$ & 31250.00 \\
\hline Solvent & METHANOL-d4 & Spectrum Offset $(\mathrm{Hz})$ & 14011.8770 \\
\hline Spectrum Type & standard & Sweep Width $(\mathrm{Hz})$ & 31249.52 \\
\hline
\end{tabular}

Temperature (degree C) 25.000

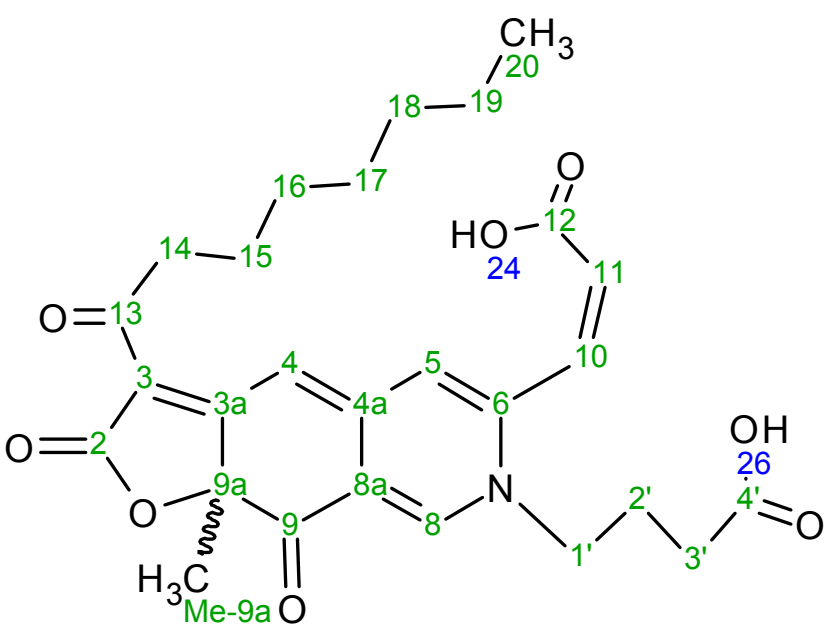

3'

Me-9a

1615

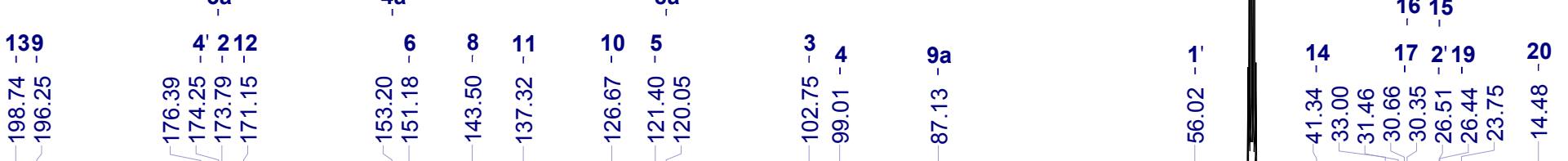




\begin{tabular}{|c|c|c|c|}
\hline Acquisition Time (sec & $(0.4000,0.0092)$ & & \\
\hline Comment & Calibration for OneNM & 08Jun2016 Sampl & $\mathrm{S} / \mathrm{N}$ test sample \\
\hline Date & 16 Jun 2016 00:08:02 & Date Stamp & Jun 152016 \\
\hline File Name & C:IDATIIlavorilALIMID & Giuffridalazaphil3 & azaphil3CD3OH_HSQCbig.fidlfid \\
\hline Frequency $(\mathrm{MHz})$ & $(499.8072,125.6766)$ & Nucleus & $(1 \mathrm{H}, 13 \mathrm{C})$ \\
\hline Number of Transients & 64 & Original Points & $(1894,160)$ \\
\hline Points Count & $(2048,1024)$ & Pulse Sequence & gHSQCAD \\
\hline Solvent & METHANOL-d4 & Spectrum Type & HSQC \\
\hline
\end{tabular}

Sweep Width $(\mathrm{Hz}) \quad(4732.54,17450.19)$

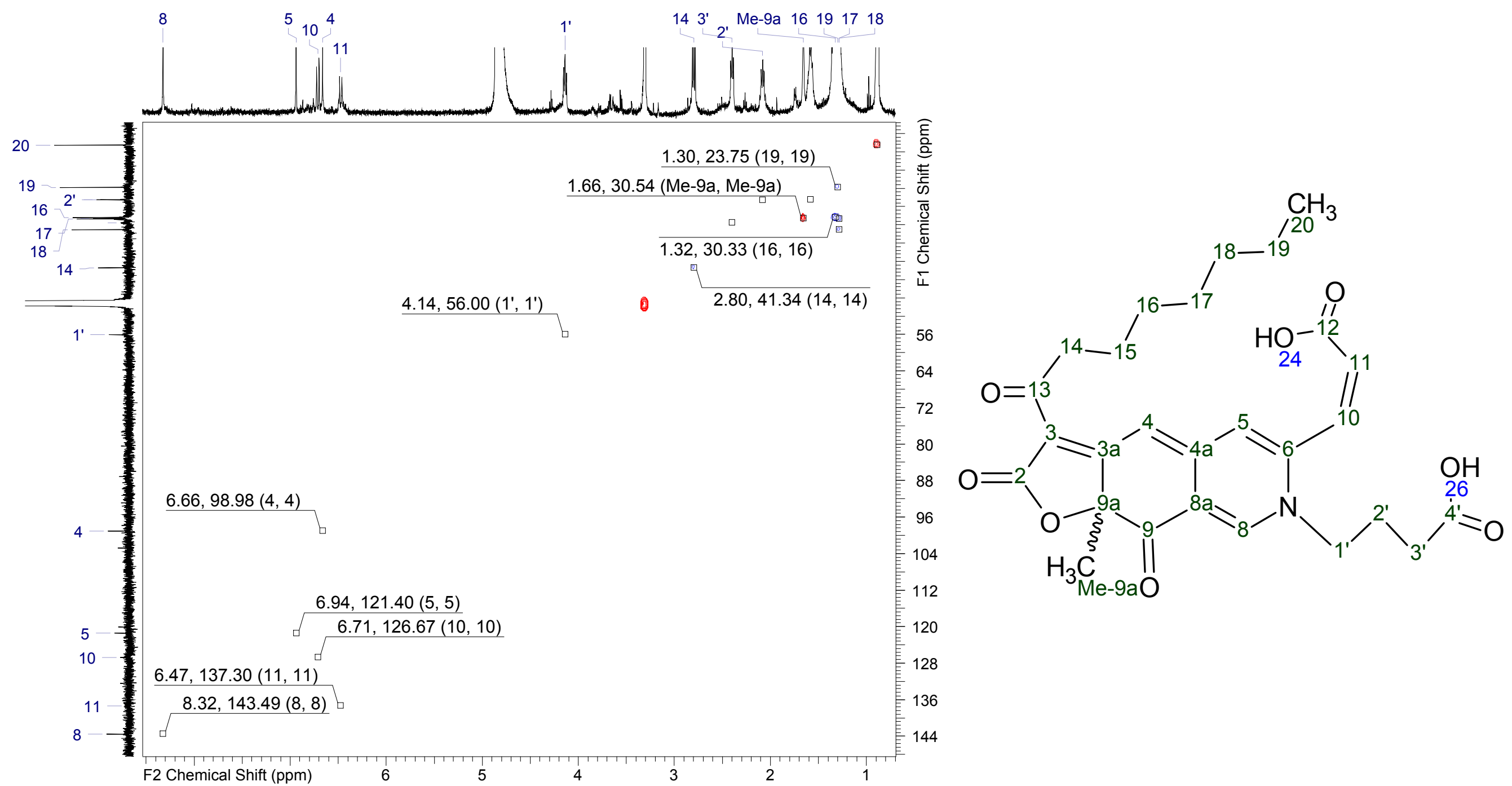




\begin{tabular}{|c|c|c|c|c|}
\hline No. & F2 Atom & F1 Atom & $\begin{array}{c}\text { F2 } \\
\text { (ppm) }\end{array}$ & $\begin{array}{c}\text { F1 } \\
\text { (ppm) }\end{array}$ \\
\hline 1 & Me-9a & Me-9a & 1.66 & 30.54 \\
\hline 2 & $1^{\prime}$ & $1^{\prime}$ & 4.14 & 56.00 \\
\hline 3 & $2^{\prime}$ & $2^{\prime}$ & 2.08 & 26.51 \\
\hline 4 & $3^{\prime}$ & $3^{\prime}$ & 2.40 & 31.48 \\
\hline 5 & 4 & 4 & 6.66 & 98.98 \\
\hline 6 & 5 & 5 & 6.94 & 121.40 \\
\hline 7 & 8 & 8 & 8.32 & 143.49 \\
\hline 8 & 10 & 10 & 6.71 & 126.67 \\
\hline 9 & 11 & 11 & 6.47 & 137.30 \\
\hline 10 & 14 & 14 & 2.80 & 41.34 \\
\hline 11 & 15 & 15 & 1.58 & 26.44 \\
\hline 12 & 16 & 16 & 1.32 & 30.33 \\
\hline 13 & 17 & 17 & 1.29 & 30.65 \\
\hline 14 & 18 & 18 & 1.28 & 32.99 \\
\hline 15 & 19 & 19 & 1.30 & 23.75 \\
\hline 16 & 20 & 20 & 0.89 & 14.47 \\
\hline
\end{tabular}

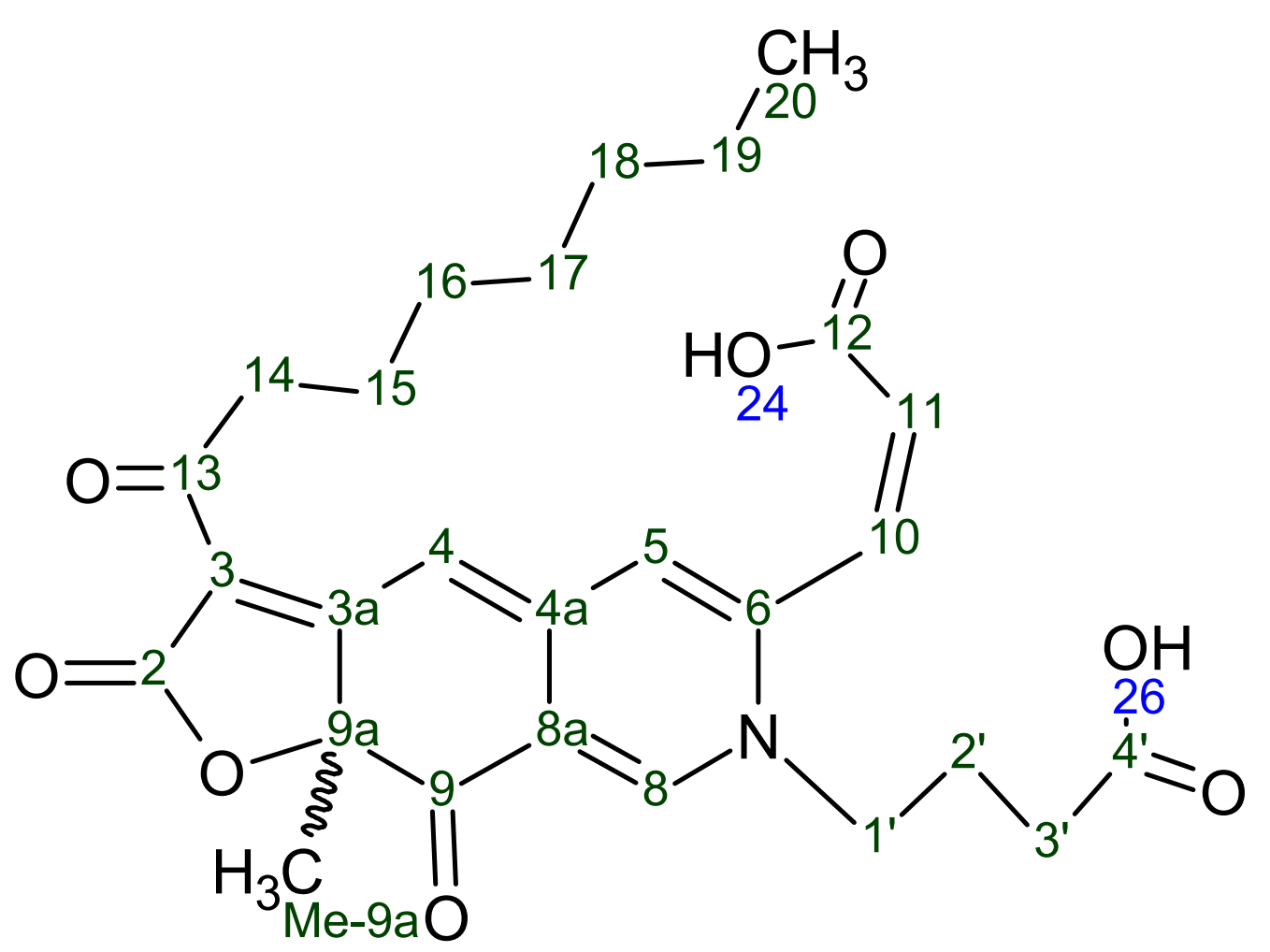




\begin{tabular}{|c|c|c|c|}
\hline \multicolumn{4}{|c|}{ Acquisition Time (sec) $(0.2999,0.0338)$} \\
\hline Comment & \multicolumn{3}{|c|}{ Calibration for OneNMR on 08Jun2016 Sample : F19 S/N test sample } \\
\hline Date & 09 Jun 2016 18:44:12 & Date Stamp & Jun 92016 \\
\hline File Name & \multicolumn{3}{|c|}{ C:IDATINlavorilALIMIDanieleGiuffridalazaphil3_ACDlazaphilone3CD3OHnew_1Hcosy_8scanll.fidlfid } \\
\hline Frequency $(\mathrm{MHz})$ & $(499.8072,499.8072)$ & Nucleus & $(1 \mathrm{H}, 1 \mathrm{H})$ \\
\hline Number of Transients & 8 & Original Points $\mathrm{C}$ & $(1420,160)$ \\
\hline Points Count & $(2048,1024)$ & Pulse Sequence & gCOSY \\
\hline Solvent & METHANOL-d4 & Spectrum Type & COSY \\
\hline
\end{tabular}

Sweep Width $(\mathrm{Hz})$ (4732.54, 4730.22)

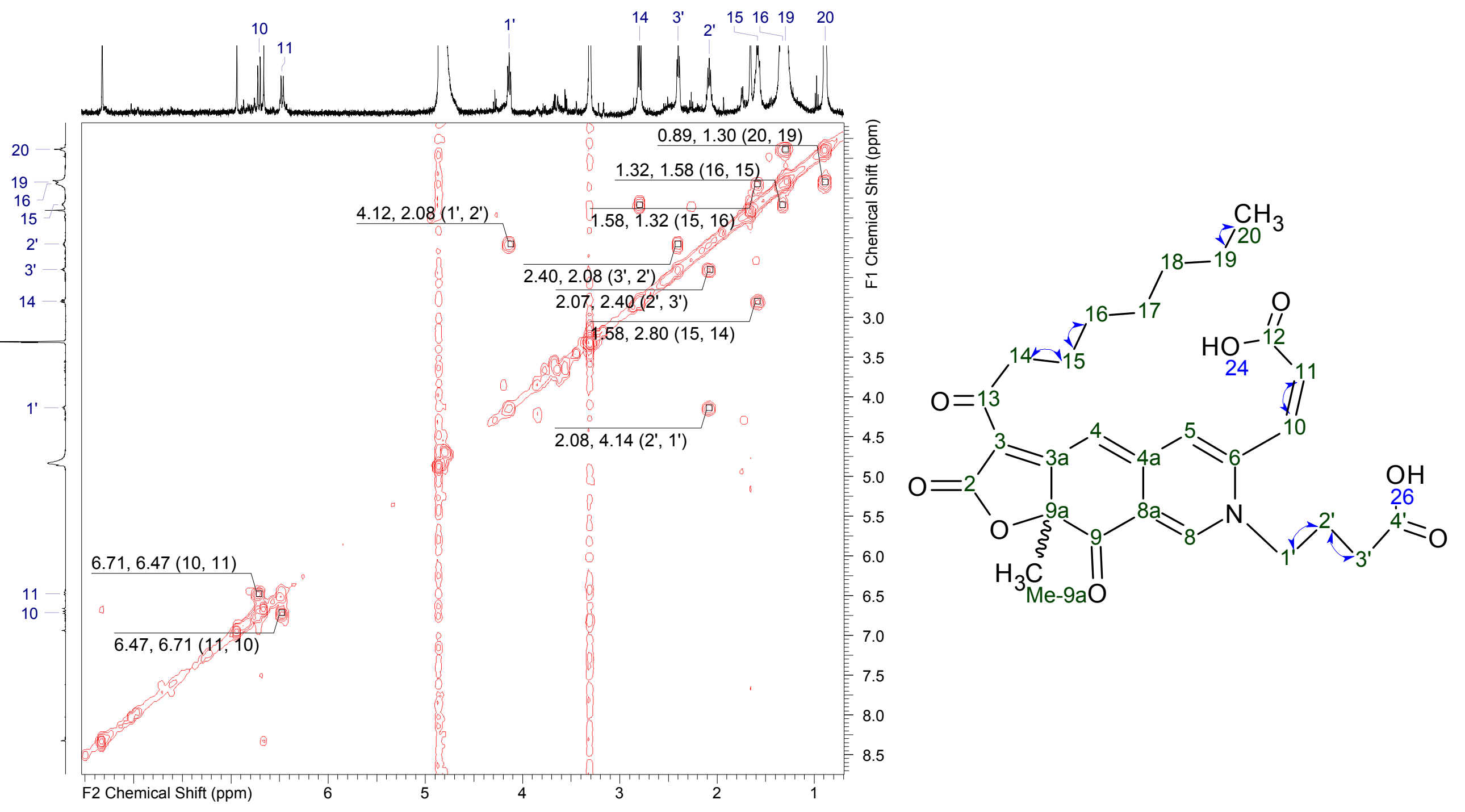




\begin{tabular}{|c|c|c|c|c|}
\hline No. & F2 Atom & F1 Atom & $\begin{array}{c}\text { F2 } \\
\text { (ppm) }\end{array}$ & $\begin{array}{c}\text { F1 } \\
\text { (ppm) }\end{array}$ \\
\hline 1 & $2^{\prime}$ & $1^{\prime}$ & 2.08 & 4.14 \\
\hline 2 & $1^{\prime}$ & $2^{\prime}$ & 4.12 & 2.08 \\
\hline 3 & $3^{\prime}$ & $2^{\prime}$ & 2.40 & 2.08 \\
\hline 4 & $2^{\prime}$ & $3^{\prime}$ & 2.07 & 2.40 \\
\hline 5 & 11 & 10 & 6.47 & 6.71 \\
\hline 6 & 10 & 11 & 6.71 & 6.47 \\
\hline 7 & 15 & 14 & 1.58 & 2.80 \\
\hline 8 & 14 & 15 & 2.80 & 1.58 \\
\hline 9 & 16 & 15 & 1.32 & 1.58 \\
\hline 10 & 15 & 16 & 1.58 & 1.32 \\
\hline 11 & 20 & 19 & 0.89 & 1.30 \\
\hline 12 & 19 & 20 & 1.30 & 0.89 \\
\hline
\end{tabular}

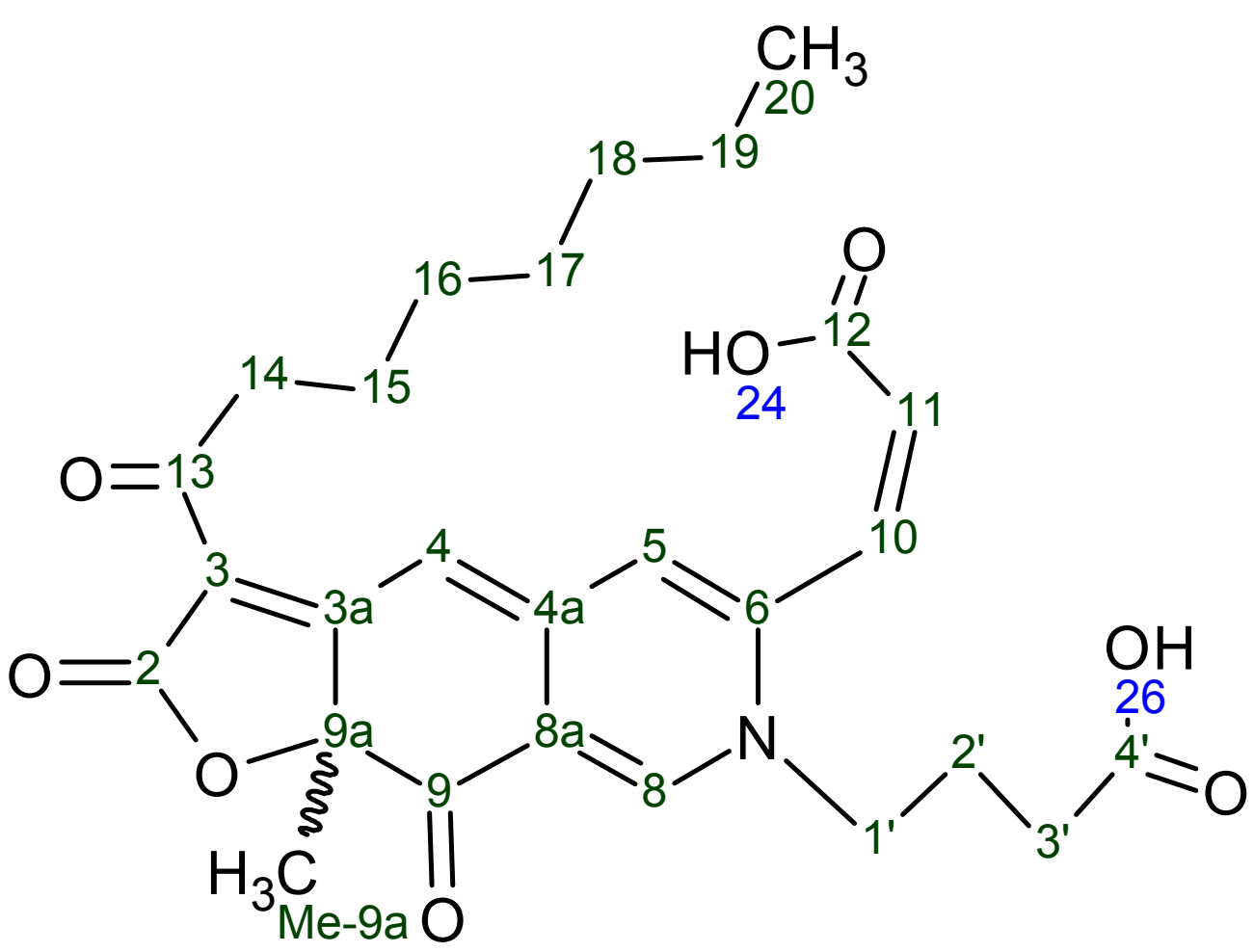




\section{Acquisition Time (sec) $(0.2999,0.0085)$}

Comment Calibration for OneNMR on 08Jun2016 Sample : F19 S/N test sample

\begin{tabular}{|c|c|c|}
\hline Constant $(\mathrm{Hz})$ & 6.0 & 19 Jun 2016 21:18:16 \\
\hline Date Stamp & Jun 182016 & \\
\hline File Name & \multicolumn{2}{|c|}{ C:IDATIIlavorilALIMIDanieleGiuffridalazaphil3_ACDlazaphil3CD3OH_HMBC_super.fidlfid } \\
\hline Frequency $(\mathrm{MHz})$ & $(499.8072,125.6766)$ & Nucleus $\quad(1 \mathrm{H}, 13 \mathrm{C})$ \\
\hline Number of Transients & 80 & Original Points Count $(1420,256)$ \\
\hline Points Count & $(2048,1024)$ & Pulse Sequence $\quad$ gHMBCAD \\
\hline Solvent & METHANOL-d4 & Spectrum Type \\
\hline
\end{tabular}

Solvent METHANOL-d4

Spectrum Type $\mathrm{HMBC}$

Sweep Width $(\mathrm{Hz}) \quad(4732.54,30136.45)$

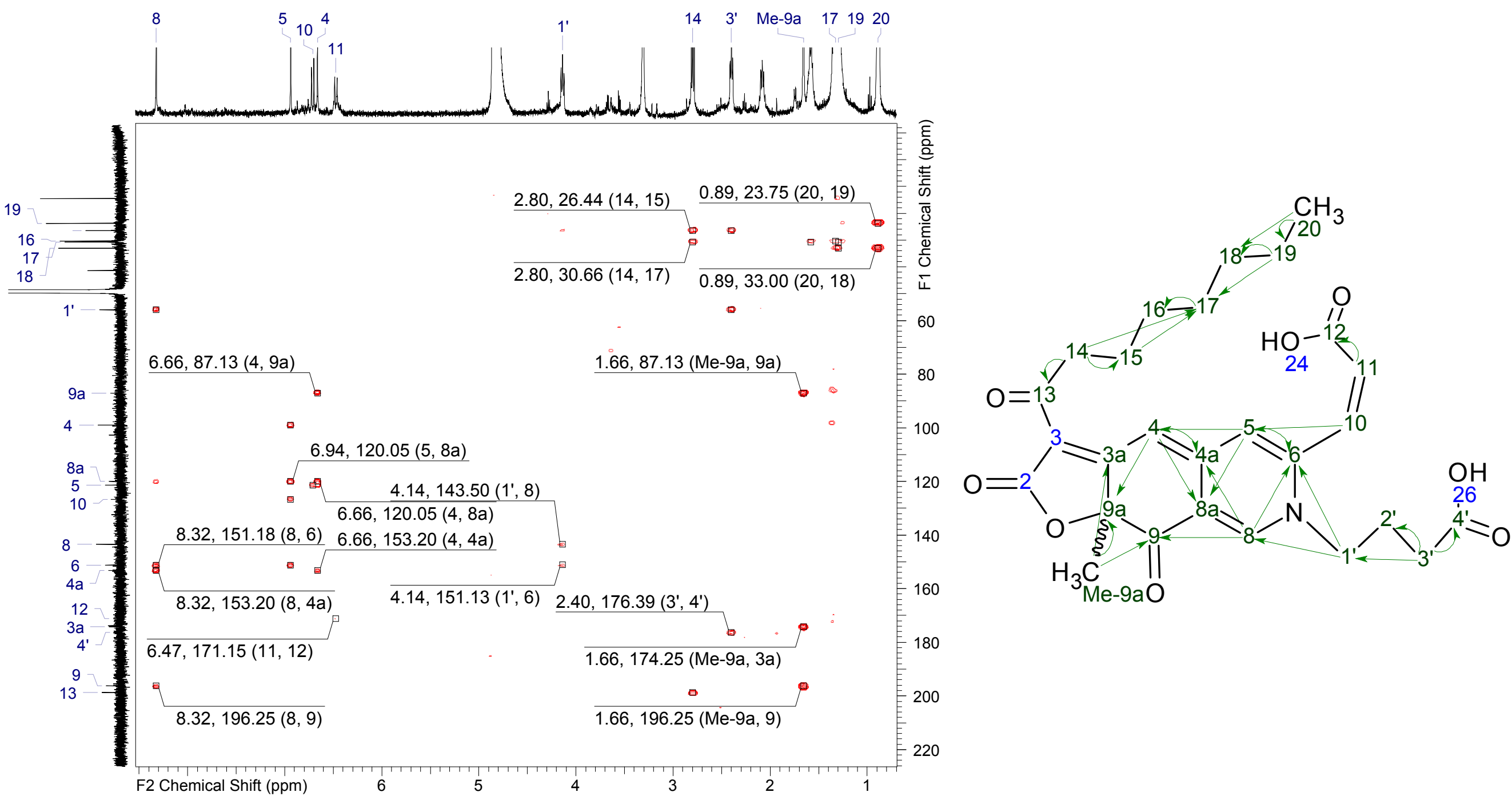




\begin{tabular}{|c|c|c|c|c|}
\hline No. & F2 Atom $^{\prime}$ & F1 Atom $^{\text {F2 }}$ & $\begin{array}{c}\text { F1 } \\
\text { (ppm) }\end{array}$ \\
\hline 1 & $3^{\prime}$ & $1^{\prime}$ & 2.40 & 56.02 \\
\hline 2 & 8 & $1^{\prime}$ & 8.32 & 56.02 \\
\hline 3 & $3^{\prime}$ & $2^{\prime}$ & 2.40 & 26.51 \\
\hline 4 & Me-9a & $3 a$ & 1.66 & 174.25 \\
\hline 5 & 5 & 4 & 6.94 & 99.01 \\
\hline 6 & $3^{\prime}$ & $4{ }^{\prime}$ & 2.40 & 176.39 \\
\hline 7 & 4 & $4 a$ & 6.66 & 153.20 \\
\hline 8 & 8 & $4 a$ & 8.32 & 153.20 \\
\hline 9 & 10 & 5 & 6.71 & 121.40 \\
\hline 10 & 1 & 6 & 4.14 & 151.13 \\
\hline 11 & 5 & 6 & 6.94 & 151.18 \\
\hline 12 & 8 & 6 & 8.32 & 151.18 \\
\hline 13 & $1^{\prime}$ & 8 & 4.14 & 143.50 \\
\hline 14 & 4 & $8 a$ & 6.66 & 120.05 \\
\hline 15 & 5 & $8 a$ & 6.94 & 120.05 \\
\hline 16 & Me-9a & 9 & 1.66 & 196.25 \\
\hline 17 & 8 & 9 & 8.32 & 196.25 \\
\hline 18 & Me-9a & $9 a$ & 1.66 & 87.13 \\
\hline 19 & 4 & $9 a$ & 6.66 & 87.13 \\
\hline 20 & 5 & 10 & 6.94 & 126.67 \\
\hline 21 & 11 & 12 & 6.47 & 171.15 \\
\hline 22 & 14 & 13 & 2.80 & 198.74 \\
\hline 23 & 14 & 15 & 2.80 & 26.44 \\
\hline 24 & 17 & 16 & 1.32 & 30.35 \\
\hline 25 & 14 & 17 & 2.80 & 30.66 \\
\hline 26 & 15 & 17 & 1.58 & 30.66 \\
\hline 27 & 19 & 17 & 1.30 & 30.66 \\
\hline 28 & 19 & 18 & 1.30 & 33.00 \\
\hline 29 & 20 & 18 & 0.89 & 33.00 \\
\hline 30 & 20 & 19 & 0.89 & 23.75 \\
\hline
\end{tabular}

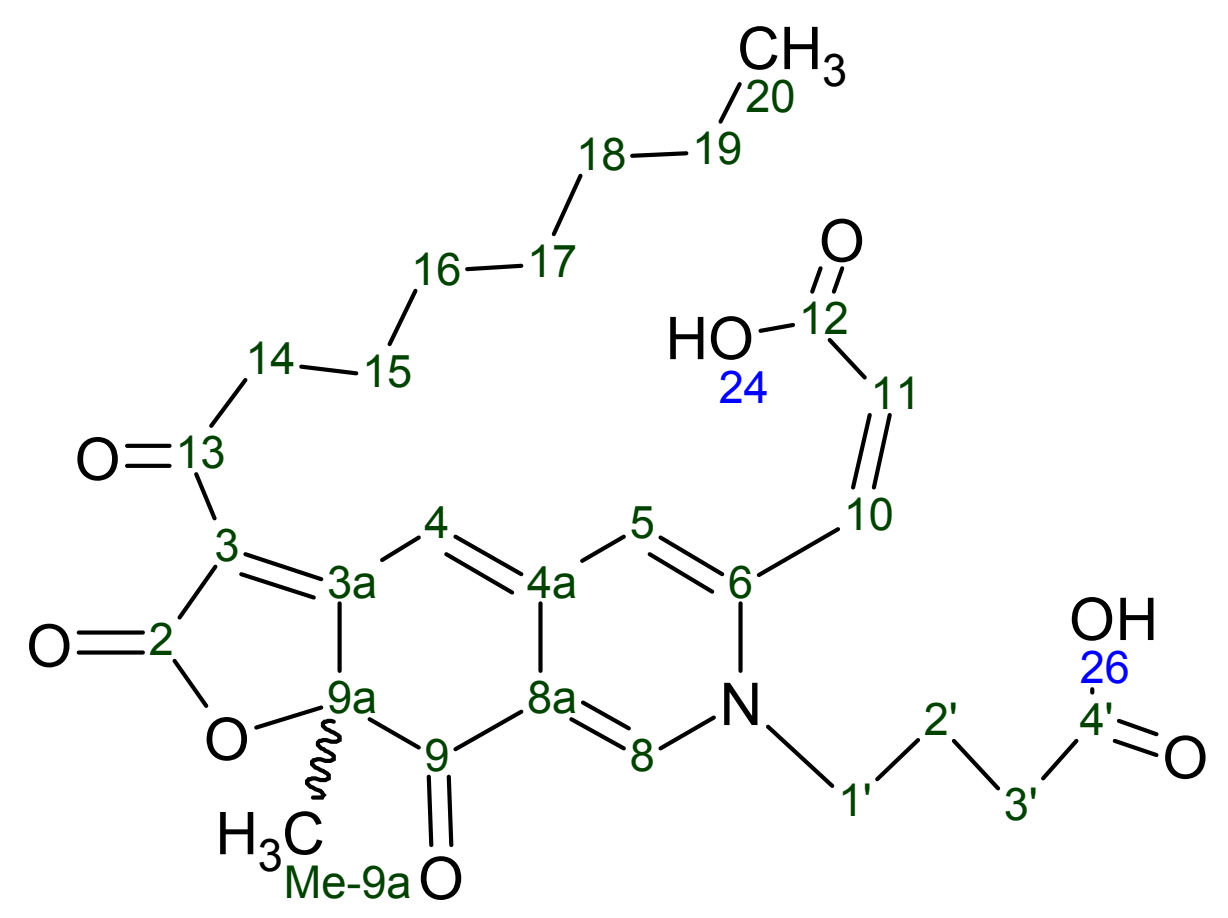




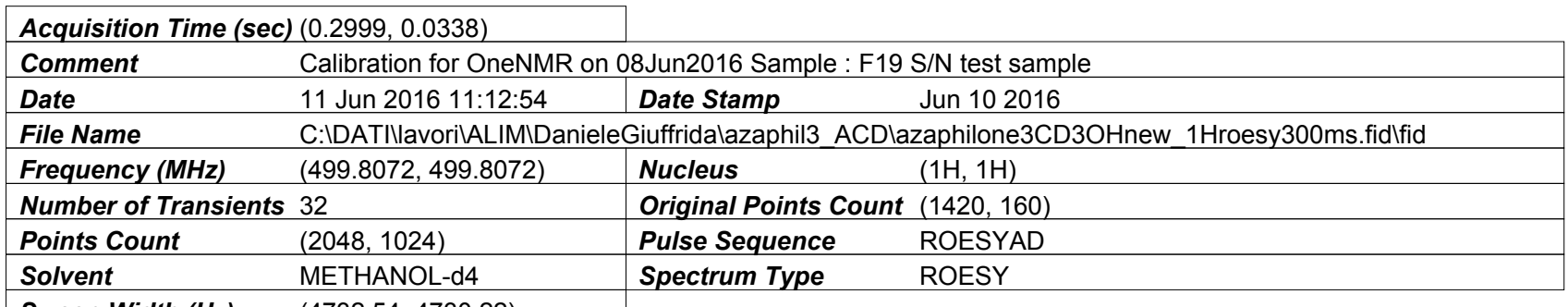

Solvent $\quad$ METHANOL-d4

Sweep Width $(\mathrm{Hz}) \quad(4732.54,4730.22)$

Pulse Sequence ROESYAD

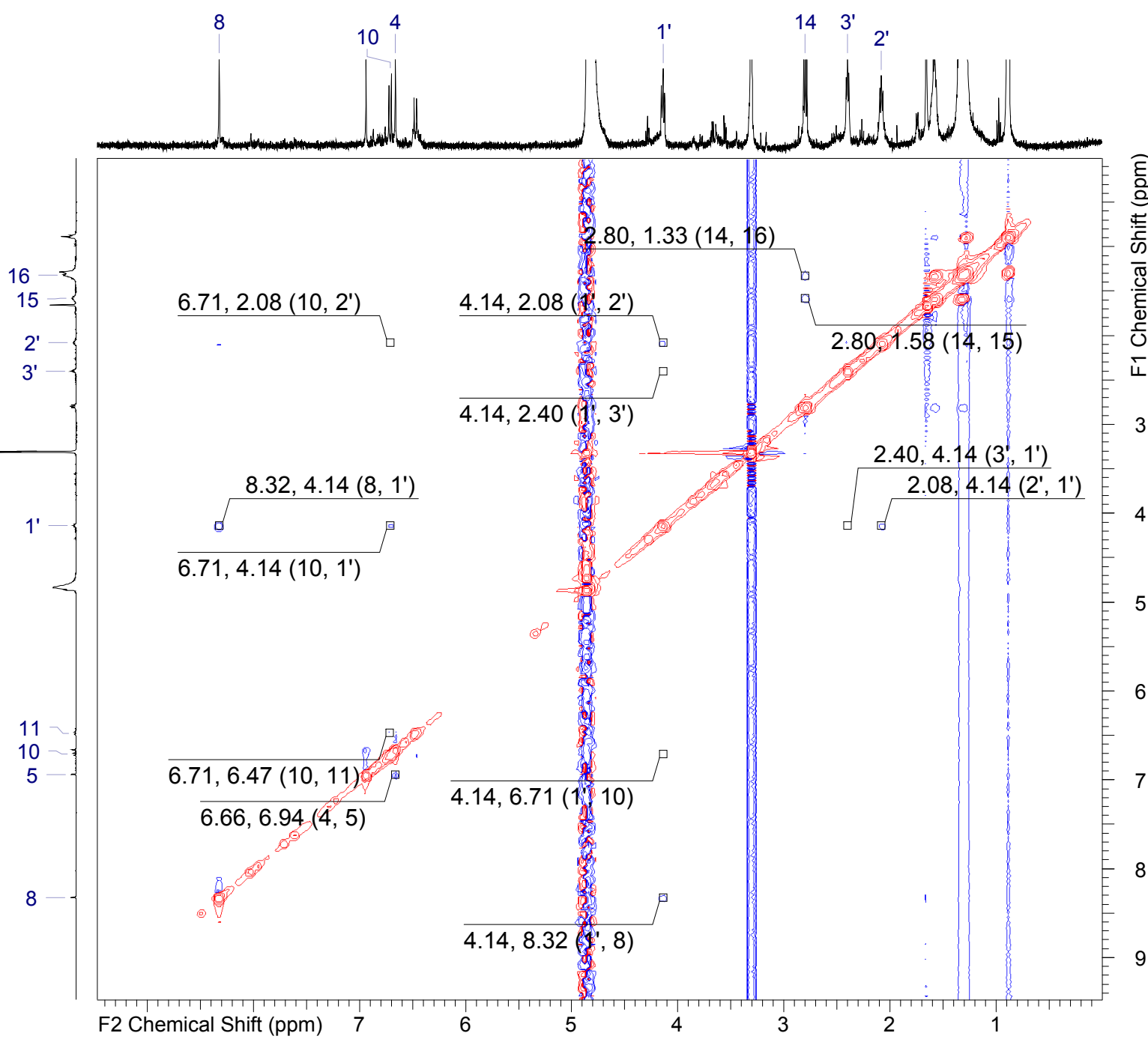

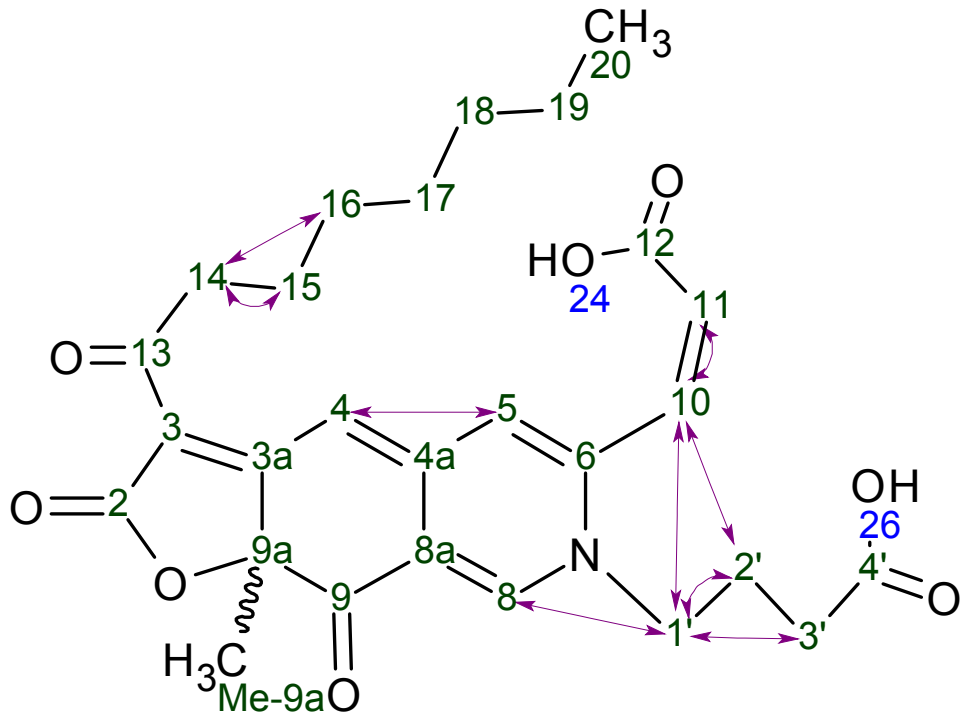




\begin{tabular}{|c|c|c|c|c|}
\hline No. & F2 Atom & F1 Atom & $\begin{array}{c}\text { F2 } \\
\text { (ppm) }\end{array}$ & $\begin{array}{c}\text { F1 } \\
\text { (ppm) }\end{array}$ \\
\hline 1 & $2^{\prime}$ & $1^{\prime}$ & 2.08 & 4.14 \\
\hline 2 & $3^{\prime}$ & $1^{\prime}$ & 2.40 & 4.14 \\
\hline 3 & 8 & $1^{\prime}$ & 8.32 & 4.14 \\
\hline 4 & 10 & $1^{\prime}$ & 6.71 & 4.14 \\
\hline 5 & $1^{\prime}$ & $2^{\prime}$ & 4.14 & 2.08 \\
\hline 6 & 10 & $2^{\prime}$ & 6.71 & 2.08 \\
\hline 7 & $1^{\prime}$ & $3^{\prime}$ & 4.14 & 2.40 \\
\hline 8 & 4 & 5 & 6.66 & 6.94 \\
\hline 9 & $1^{\prime}$ & 8 & 4.14 & 8.32 \\
\hline 10 & $1^{\prime}$ & 10 & 4.14 & 6.71 \\
\hline 11 & 10 & 11 & 6.71 & 6.47 \\
\hline 12 & 14 & 15 & 2.80 & 1.58 \\
\hline 13 & 14 & 16 & 2.80 & 1.33 \\
\hline
\end{tabular}

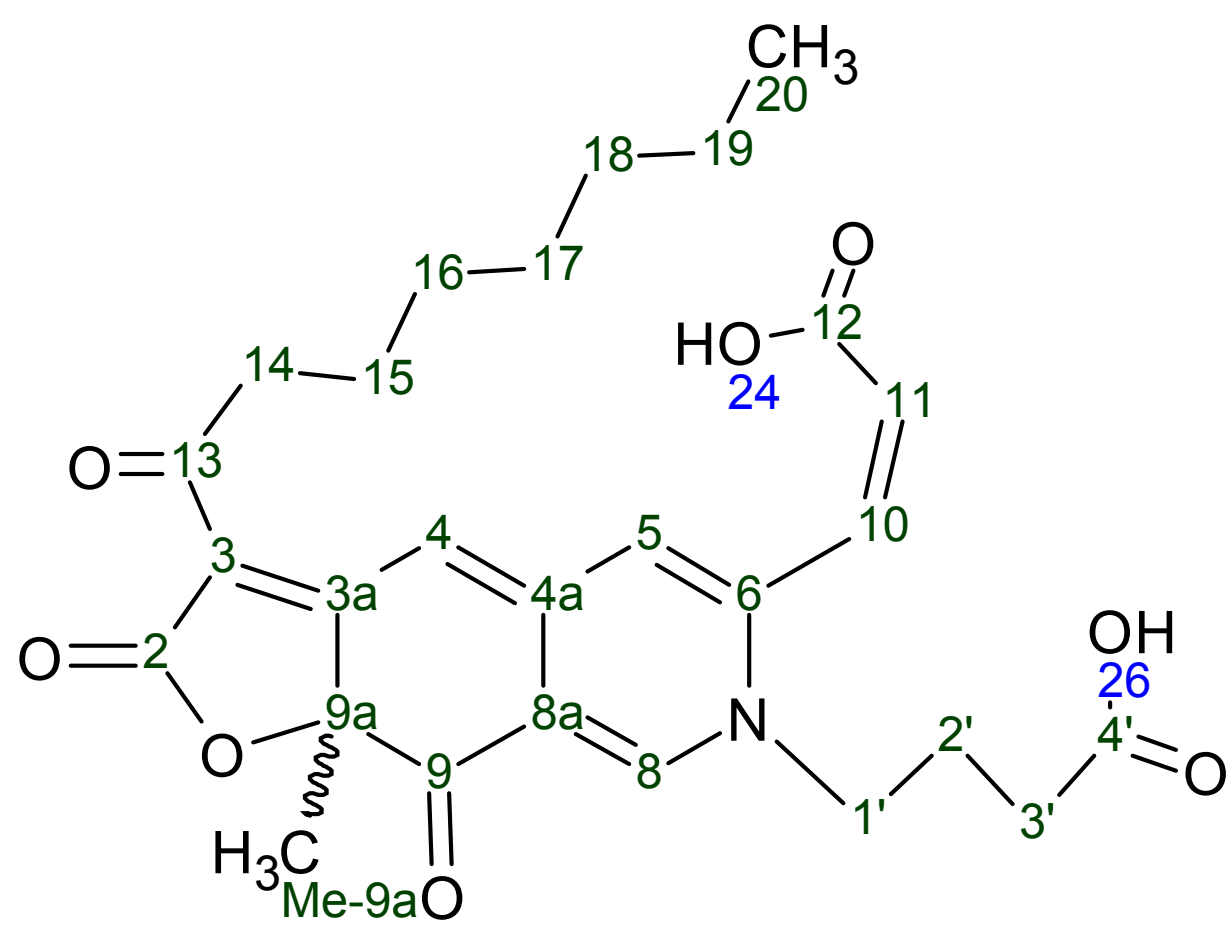

